UNIVERSIDADE DE SÃO PAULO

FACULDADE DE ODONTOLOGIA DE RIBEIRÃO PRETO

Daniele Manfrim

Influência da inclinação do garfo de mordida do arco

facial na montagem do modelo superior em articulador semi-ajustável do tipo arcon e não-arcon 


\section{Influência da inclinação do garfo de mordida do arco facial na montagem do modelo superior em articulador semi-ajustável do tipo arcon e não-arcon}

Tese apresentada à Faculdade de Odontologia de Ribeirão Preto - Universidade de São Paulo para obtenção do título de Doutora em Odontologia, Área de Concentração em Reabilitação Oral, do Departamento de Materiais Dentários e Prótese.

Orientadora: Profa. Dra. Mariane Gonçalves 
AUTORIZO A REPRODUÇÃO E DIVULGAÇÃO TOTAL OU PARCIAL DESTE TRABALHO, POR QUALQUER MEIO CONVENCIONAL OU ELETRÔNICO, PARA FINS DE ESTUDO E PESQUISA, DESDE QUE CITADA A FONTE.

Catalogação na Publicação Serviço de Documentação Odontológica

Faculdade de Odontologia da Universidade de São Paulo

\section{Manfrim, Daniele}

Influência da inclinação do garfo de mordida do arco facial na montagem do modelo superior em articulador semi-ajustável do tipo arcon e não-arcon. Ribeirão Preto, 2008.

108 p. : il. ; $30 \mathrm{~cm}$

Orientadora: Profa. Dra. Mariane Gonçalves.

Tese de Doutorado, apresentada à Faculdade de Odontologia de Ribeirão Preto/USP. Área de Concentração: Reabilitação Oral.

1. articulador semi-ajustável. 2. arco facial. 3. garfo de mordida. 


\section{Daniele Manfrim}

Influência da inclinação do garfo de mordida do arco facial na montagem do modelo superior em articulador semi-ajustável do tipo arcon e não-arcon

Tese apresentada à Faculdade de Odontologia de Ribeirão Preto - Universidade de São Paulo, para obtenção do título de Doutora em Odontologia, Área de Concentração em Reabilitação Oral, do Departamento de Materiais Dentários e Prótese.

Orientadora: Profa. Dra. Mariane Gonçalves

\section{Aprovada em:}

\section{Banca Examinadora}

Prof. Dr.

Instituição:

Assinatura:

Prof. Dr.

Instituição:

Assinatura:

Prof. Dr.

Instituição:

Assinatura:

Prof. Dr.

Instituição:

Assinatura:

Prof. Dr.

Instituição:

Assinatura: 
Dedico este trabalho às pessoas mais importantes da minha vida:

Minha filhinha Manoela, pela alegria de sua existência;

Meu marido Luciano, por seu amor e companheirismo;

Meu irmão Danilo, pelo incentivo dado a minha carreira, e,

Meu pai Luiz e à minha mãe Lúcia, por terem possibilitado a minha formação, me provendo suporte e orientação. 


\section{AGRADECIMENTOS ESPECIAIS}

À Profa. Dra. Mariane Gonçalves, por sua orientação atenta, pela presença e dedicação na gestão deste curso, pela oportunidade do aprendizado num convívio tão agradável, que transformou-se numa verdadeira e grande relação de amizade. Meus eternos agradecimentos. 
Ao Diretor Prof. Dr. Osvaldo Luiz Bezzon, por sua atenção, pela oportunidade e ajuda em todos os momentos. Muito Obrigada por me receber gentilmente em seu ambiente de trabalho.

À Profa. Dra. Iara Augusta Orsi, pela ajuda na realização da estatística deste trabalho, pela disponibilidade em me atender e por tornar-se uma grande amiga. 


\section{AGRADECIMENTOS}

À Faculdade de Odontologia de Ribeirão Preto - Universidade de São Paulo, em especial ao Departamento de Materiais Dentários e Prótese, que me recebeu e permitiu minha formação no curso de Pós-Graduação, nível Doutorado, Área de Concentração Reabilitação Oral.

À Profa. Dra. Helena de Freitas Oliveira Paranhos, chefe do Departamento de Materiais Dentários e Prótese.

À Profa. Dra. Léa Assed Bezerra da Silva, presidente da comissão de PósGraduação.

Às secretárias da pós-graduação Izabel Cristina Galino Sola e Regiane Cristina Moi Sacilotto, pela assessoria e suporte sediado durante a minha jornada.

À Rejiane de Cássia Tirado Damasceno, secretária do Departamento de Materiais Dentários e Prótese, pela responsabilidade em seu trabalho, estando sempre disposta em ajudar a qualquer momento.

À Ana Paula Xavier, secretária administrativa do Departamento de Materiais Dentários e Prótese, pela atenção e amizade dedicadas a mim.

Ao Luiz Sérgio Soares, funcionário da oficina de precisão do Departamento de Materiais Dentários e Prótese, pela confecção do suporte utilizado como material deste trabalho. 
Aos meus sócios Stella Máris Gatto Spadotto e Rodrigo José Luduvério Pizauro, pela forte amizade, tornando-se pessoas muito especiais.

Aos meus amigos do Doutorado Camila Tirapelli, Fernando Kurita Varoli, Hamilton Pedrazzi, Leandro Dorigan Macedo, Mônica Barbosa Leal e Rodrigo Galo, os quais estiveram comigo desde o Mestrado.

Aos meus amigos, Carolina Maito Villela Rosa, Danilo Ennes Morgato, Juliana Ferreira Natal, Luciano Messana Natal, Mariana Rodrigues Miotto, Marina Garcia, Paola Kirsten Miani e Taisa Lucia Berlingieri, que se prontificaram a me ajudar.

A todos os professores e funcionários do Departamento de Materiais Dentários e Prótese que me receberam de braços abertos.

A todos aqueles que de modo direto ou indireto contribuíram e proporcionaram viabilidade para a realização deste trabalho.

Muito obrigada a todos. 


\section{RESUMO}

MANFRIM, D. Influência da inclinação do garfo de mordida do arco facial na montagem do modelo superior em articulador semi-ajustável do tipo arcon e não-arcon. 2008. 108p. Tese (Doutorado) - Faculdade de Odontologia de Ribeirão Preto, Universidade de São Paulo, Ribeirão Preto, 2008.

Durante o processo ensino/aprendizagem em Odontologia, é comum a ocorrência de inclinações do garfo de mordida em relação ao plano oclusal maxilar dos pacientes durante a tomada do arco facial realizada por alunos. Este trabalho avaliou a influência das inclinações do garfo de mordida para anterior e para posterior em relação ao plano oclusal na montagem do modelo maxilar em articuladores semi-ajustáveis do tipo arcon e não-arcon. Foram obtidos vinte modelos do arco maxilar de vinte pacientes, nos quais dois pontos foram marcados: um na aresta vestibular do canino direito e outro na aresta vestibular da cúspide mésio-vestibular do primeiro molar direito. Os registros no garfo de mordida foram realizados em três posições: garfo de mordida paralelo ao plano oclusal dos modelos, inclinado para anterior e para posterior (ambas $5^{\circ}$ ). Cada posição foi repetida cinco vezes, sendo o conjunto articulador/arco facial fixado em suporte especial para registro fotográfico. Cada fotografia foi levada ao programa Auto CAD, obtendo-se linhas de referências para a coleta de cinco medidas (uma angular e quatro lineares). Os dados obtidos foram submetidos à análise estatística paramétrica (Análise de Variância). Os resultados indicaram não haver diferença estatisticamente significante para inclinações do garfo de mordida tanto para anterior como para posterior em relação ao plano oclusal do modelo tanto para o articulador semi-ajustável do tipo arcon como para o não-arcon. O trabalho sugere que pequenas inclinações do garfo de mordida não comprometem a tomada do arco facial e sua transferência para articuladores semi-ajustáveis.

Palavras-chave: Articulador semi-ajustável, arco facial, garfo de mordida. 


\begin{abstract}
MANFRIM, D. Influence of the inclination of the face-bow's bite fork on mounting of maxillary cast in arcon and nonarcon semiadjustable articulators. 2008. 108p. Thesis (Doctoral) - School of Dentistry of Ribeirão Preto, São Paulo University, Ribeirão Preto, 2008.
\end{abstract}

During the process teaching/learning in Dentistry, the occurrence of adverse inclinations of the bite fork concerned to maxillary occlusal plane of patients are current during the face-bow taking performed by students. This study evaluated the influence of the inclinations of bite fork to anterior and posterior related to oclusal plane on mounting of the maxillary cast in arcon and nonarcon semiadjustable articulators. Twenty casts of the maxillary arch from twenty patients were obtained, on which two points were marked: one on the vestibular edge of the right canine and another on the vestibular edge of mesiovestibular cusp of the right first molar. The records in the bite fork were made in three positions: the bite fork parallel to the casts's plane occlusal, inclined to anterior and to posterior (both $5^{\circ}$ ). Each position was repeated five times, being the articulator/face-bow set fixed in special support for photographic register. Each photograph was introduced in Auto CAD program, resulting in lines of references for the collection of five measures (one angular and four linear). The data were subjected to statistical analysis parametric (Analysis of Variance). The results showed no significant statistical difference for inclinations of the bite fork to both anterior and to posterior related to the casts's occlusal plane for the arcon and nonarcon semiadjustable articulators. The work suggests that small inclinations of bite fork do not compromise the face-bow taking and its transfer for the semiadjustable articulators.

Key words: Semiadjustable articulator, face-bow, bite fork. 


\section{SUMÁRIO}

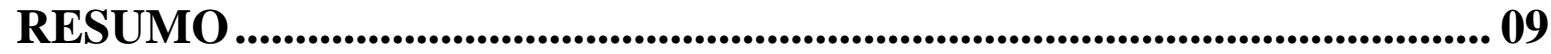

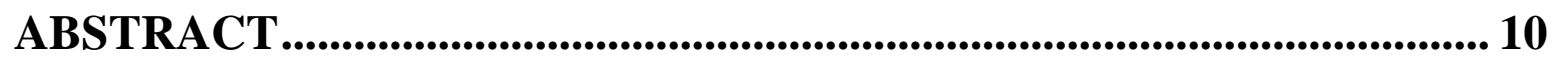

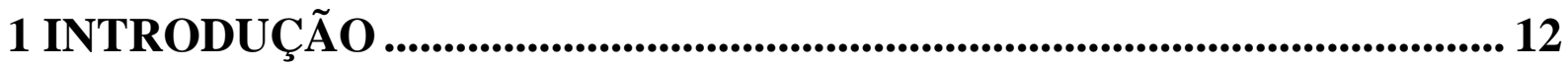

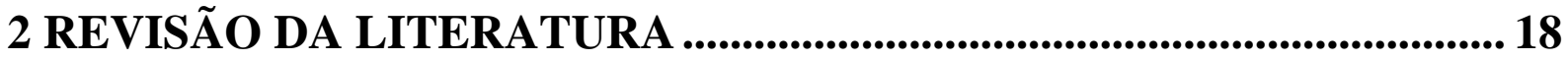

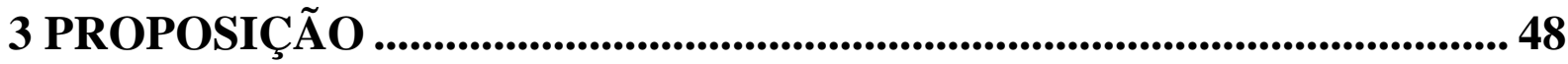

4 MATERIAL E MÉTODO ..........................................................................50

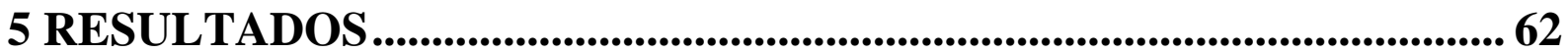

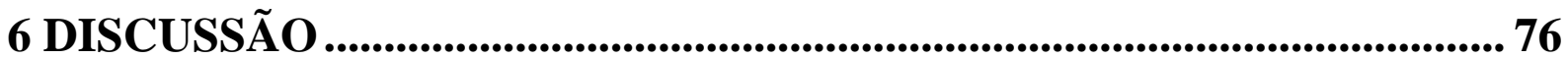

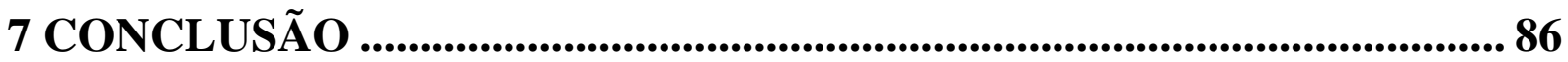

REFERÊNCIAS BIBLIOGRÁFICAS ..........................................................8 88

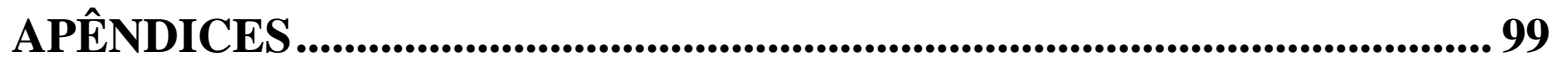


1 INTRODUÇÃO 
A reabilitação oral envolve uma seqüência de etapas clínicas e laboratoriais que precisam ser realizadas de maneira altamente criteriosa. O sucesso do tratamento, de modo geral, depende de vários aspectos, dentre eles a fidelidade da montagem dos modelos no articulador.

Os modelos montados adequadamente em articulador são essenciais para o planejamento e tratamento dos problemas oclusais, pois viabilizam a correta determinação do plano oclusal, tão importante para estética, fonética e função mastigatória (ASH; RAMFJORD, 1995; OKESON, 2000; PIEHSLINGER; BAUER; SCHMIEDMAYER, 1995; SHILLINGBURG et al., 1998).

O articulador dental é um instrumento que representa a junção temporomandibular, a maxila e a mandíbula e no qual os modelos da maxila e mandíbula são fixados. Descrito originalmente, há muito tempo, em 1756, seu uso foi, por muitos anos, exclusivo das áreas de dentística restauradora e prótese. Os articuladores fornecem a reprodução do relacionamento oclusal fora da boca, e são de indispensável ajuda para a fabricação de próteses; diferem quanto ao tipo e/ou modelo, que variam em sua complexidade. Articuladores mais simples incorporam valores médios do paciente para representar a inclinação da fossa glenóide e o relacionamento fossa/côndilo, e não reproduzem precisamente os movimentos excursivos mandibulares do indivíduo. Articuladores semi-ajustáveis podem ser modificados pelo ajuste da porção fossa/côndilo do instrumento usando registros de cera nas excursões laterais e protrusiva do paciente. Articuladores totalmente ajustáveis apresentam grande variedade de ajustes em três dimensões, e são os mais complexos e caros dos instrumentos (CLARK; HUTCHINSON; SANDY, 2001). Dependendo da complexidade do instrumento, os movimentos da mandíbula serão registrados com maior ou menor grau de precisão (MEZZOMO, 1997). 
Os articuladores podem ser classificados também em função da localização das esferas condilares em dois tipos: arcon e não-arcon, cuja etmiologia provém da contração das palavras inglesas “articulator” e “condyle”. Nos articuladores do tipo arcon, as esferas condilares, as quais representam os côndilos, estão situadas no ramo inferior do aparelho e as caixas articulares são fixadas ao ramo maxilar. Os articuladores do tipo não-arcon possuem um projeto mecânico diferente, no qual as esferas condilares estão situadas no ramo superior e os componentes que simulam as cavidades glenóideas estão ligados ao ramo inferior do articulador (MEZZOMO et al., 2006; OLIVEIRA, 2002).

O articulador é utilizado no estabelecimento do diagnóstico, no desenvolvimento do plano de tratamento e na confecção do trabalho laboratorial da restauração protética. Essas três fases do tratamento reabilitador estão extremamente ligadas e interdependentes, sendo o resultado final do trabalho um espelho dos cuidados do profissional (MEZZOMO, 1997).

A finalidade de um articulador em prótese é transferir os movimentos mandibulares eficazes de um paciente ao laboratório. A exatidão da simulação dos movimentos mandibulares controla a precisão na fabricação da prótese. Por sua vez, a precisão maior das próteses permite um planejamento mais exato da reprodução dos relacionamentos oclusais, diminuindo desse modo o número das alterações da superfície oclusal da restauração confeccionada (BELLANTI, 1973). O objetivo é fazer uma restauração com uma morfologia oclusal compatível com o movimento da mandíbula (CARVALHO, 1998).

Um articulador deve, conseqüentemente, ser capaz de simular o movimento mandibular de um indivíduo de modo que os modelos montados nele possam ser observados no articulador da mesma maneira como os dentes são na boca. (CLARK; HUTCHINSON; SANDY, 2001). 
De acordo com Weinberg (1963a), o objetivo de todos os articuladores é auxiliar as fases laboratoriais do trabalho protético, substituindo partes anatômicas por partes mecânicas equivalentes, imitando deste modo, os movimentos fisiológicos apresentados pelos pacientes.

O desenho, a construção e o uso prático dos articuladores são ditados por fatores tais como o conhecimento dos movimentos mandibulares e da anatomia funcional da junção temporomandibular, a especificação das posições e movimentos a serem reproduzidos pelo articulador e a solução prática para a transferência das posições e movimentos do articulador, assim como suas possibilidades e limitações (CARVALHO, 1998).

A reprodução dos movimentos mandibulares representa o desafio a que se propõe este dispositivo, pois de acordo com Clark, Hutchinson e Sandy (2001), os mesmos são influenciados por muitos fatores, tais como os ligamentos das junções temporomandibular e dos músculos mastigatórios, entre outros.

Para a execução de seu propósito, os articuladores recebem a montagem dos modelos dos arcos superior e inferior de um paciente. Esta montagem deve representar de forma exata a oclusão do paciente. O processo de montagem de modelos inclui transferência com o arco facial e vários registros interoclusais, os quais tentam reproduzir a oclusão do paciente. Entretanto, todos os procedimentos de montagem possuem erros inerentes que podem negativamente influenciar o resultado final (BOYARSKY; LOOS; LEKNIUS, 1999).

Os modelos obtidos das arcadas dentárias necessitam de uma determinada orientação no articulador para que se reproduza uma situação similar às relações intermaxilares do paciente. Para que esse objetivo seja atendido, utiliza-se o arco facial e registros da relação cêntrica e dos movimentos protrusivos e laterais (MEZZOMO, 1997).

O arco facial foi desenvolvido conjuntamente com articuladores para relacionar o arco maxilar ao eixo condilar em três planos do espaço. Trata-se de um dispositivo mecânico que usa a localização tripoidal, por duas referências posteriores, cada uma das junções 
temporomandibular, e um ponto de referência anterior para relacionar o modelo maxilar verticalmente ao plano de referência horizontal selecionado (O’MALLEY; MILOSEVIC, 2000). Durante a tomada, um arco facial registra em três planos (anteroposterior, lateral e vertical) a posição da maxila em relação a dois pontos no crânio, isto é, as duas fossas glenóides. Mais especificamente, ele relaciona a maxila à linha intercondilar, ou eixo horizontal sobre o qual os movimentos de abertura da mandíbula ocorrem (CRADDOCK; SYMMONS, 1952).

O registro convencional do arco-facial relaciona o modelo maxilar ao conjunto condilar de um articulador e ao plano horizontal de Frankfort. Isto é suposto para reproduzir a maneira na qual a maxila do paciente se relaciona ao eixo terminal de rotação dos côndilos mandibulares (BAMBER et al., 1996).

O uso do arco facial para a montagem do modelo superior prende-se à necessidade de se relacionar os dentes superiores ao eixo terminal de rotação condilar, para possibilitar um arco de fechamento correto do articulador e assim, contatos oclusais precisos. Além disso, o arco facial também registra a distância intercondilar do paciente, que é um dos determinantes da morfologia oclusal (MEZZOMO, 1997).

Muitas falhas na transferência do arco facial podem produzir montagens incorretas dos modelos no articulador (PALIK; NELSON; WHITE, 1985).

Quando a transferência do arco facial é realizada, o objetivo maior é reproduzir o relacionamento do modelo superior com o plano de orientação no articulador de forma a coincidir com a relação da maxila com as articulações temporomandibulares. Portanto, o arco facial tem por função registrar espacialmente a posição do arco maxilar em relação ao crânio. Se o posicionamento do garfo de mordida do arco facial for incorretamente registrado e transferido para o articulador, tal fato poderá influenciar adversamente no resultado dos 
trabalhos em execução, sejam eles relativos à fase de diagnóstico ou, principalmente, na reconstrução protética em casos clínicos mais complexos.

O sucesso do trabalho, há que se considerar, está na dependência direta da aprendizagem de conceitos e princípios relativos ao tema, assim como na prática continuada e persistente para o melhor treinamento possível do profissional.

Durante a fase acadêmica, grandes são as dificuldades dos estudantes para o aprendizado do procedimento de montagem de modelos em articuladores semi-ajustáveis, e freqüentemente são observadas introduções de erros ou pequenas inclinações, no registro do garfo de mordida do arco facial durante sua tomada. Estes erros nos procedimentos de tomada do arco facial e transferência para o articulador, podem conduzir a tratamentos restauradores insatisfatórios. 
2 REVISÃO DA LITERATURA 
O primeiro articulador foi desenvolvido por Gariot em 1805; seu instrumento era constituído por dois ramos nos quais os modelos eram adaptados. Um parafuso na porção posterior do instrumento mantinha a dimensão vertical. Apresentava uma única direção de movimento, abertura e fechamento e os modelos montados proporcionavam uma reprodução aproximada do relacionamento entre os arcos superior e inferior (HALL, 1930).

Segundo o registro oficial de patentes, foi Cameron (Philadelphia) quem desenvolveu o segundo articulador, em abril de 1840, o qual apresentava a seguinte descrição: novo e importante instrumento para ajuste de dentes artificiais e superfícies guias. O articulador de Cameron era provido de ajustes horizontais e verticais permitindo mais de um movimento da mandíbula dentro do espaço tridimensional do articulador. Em agosto daquele mesmo ano, Evans obteve a patente de seu articulador o qual foi construído para imitar os movimentos mandibulares e exibir a relação dos dentes e rebordos gengivais. O articulador de Evans apresentava dois tipos de arcos góticos dimensionais, copiava os princípios do articulador de Gariot e acrescentava os movimentos protusivo, retrusivo e laterais da mandíbula (HALL, 1930).

Mais tarde, em 1858, Bonwill descreveu o movimento do côndilo mandibular, no sentido póstero-anterior e a inclinação para baixo, durante o movimento de abertura bucal. Naquele mesmo ano, sentindo a necessidade de que estes movimentos fossem reproduzidos nos articuladores, o estudioso desenvolveu o primeiro articulador anatômico, o articulador de Bonwill, que além de reproduzir os movimentos de lateralidade, apresentava um dispositivo condilar horizontal (TAMAKI, 1983).

Bonwill ainda estabeleceu normas que deveriam ser empregadas como referências nas montagens dos modelos no articulador: mensurações da linha média, chapa de prova e as inclinações condilares. Segundo Bonwill, a distância entre os côndilos é de $10 \mathrm{~cm}$ qualquer que seja a mandíbula do adulto e juntamente com as bordas dos incisivos inferiores, determina 
um triângulo eqüilátero. Deste modo os modelos superiores são posicionados no articulador de maneira que o plano oclusal situa-se horizontalmente a uma mesma distância entre os ramos superior e inferior, e distante 2 cm do plano condilar (HARRIS, 1892).

Em 1866, um novo dispositivo é apresentado por Balkwill, cuja finalidade era medir a angulação entre o plano oclusal e o plano condilar, para em seguida os modelos serem montados no articulador. O autor ainda descreveu as características dos movimentos mandibulares no plano horizontal (BRANDRUP-WOGNSEN, 1953).

As montagens arbitrárias dos modelos prosseguiram até que Hayes, em 1880, desenvolveu um aparelho denominado Caliper. Neste, uma ponteira anterior era posicionada na borda incisal dos incisivos centrais e os dispositivos laterais posteriores localizavam e determinavam a distância dos dois côndilos; estas referências orientavam o modelo superior no articulador (DRISCOLL, 1884).

Em 1882, Gilmore sugeriu medidas para a colocação dos modelos no articulador, procurando reproduzir a posição natural. Os modelos superiores preservariam as mesmas relações que os dentes possuem em relação ao crânio, quando estivessem montados no articulador (SOUZA, 1917).

Há indicações de que em 1889 Snow já havia desenvolvido o arco facial. Nessa época o autor já estava consciente de que o relacionamento da maxila ao crânio deveria ser transportado para o articulador, mas o seu uso só foi difundido mais tarde (HALL, 1930).

Walker, em 1890, desenvolveu o arco facial denominado Clinometer. Este dispositivo permitia registrar o relacionamento dos arcos dentais com as articulações, bem como a inclinação da cavidade articular (BRANDRUP-WOGNSEN, 1953).

Seis anos após o desenvolvimento do Clinometer, Walker e Christian (1896), vendo as dificuldades de seu uso, começaram a utilizá-lo como medidor da cavidade articular. Os autores também descreveram a teoria do movimento translatório durante a abertura bucal 
onde, durante o movimento, o côndilo se desloca para frente e para baixo, acompanhando a inclinação da parede anterior da cavidade articular.

O movimento condilar foi registrado em 1896 por Ulrich e Walker com um arco facial que apresentava duas placas, uma fixada à mandíbula e outra ao crânio (ULRICH, 1959).

Broomell (1897) preconizava que a orientação do modelo superior deveria ser paralela ao plano que ia do centro da fossa glenóide à espinha nasal anterior, o que proporcionaria uma melhor estabilidade do plano oclusal.

Segundo Posselt (1962), Snow em 1899 desenvolveu um dispositivo que tinha a finalidade de transportar os modelos ou planos de orientação da boca ao articulador respeitando a distância côndilo-incisivo. Este dispositivo era acoplado ao articulador anatômico e foi a base para a construção dos arcos faciais.

Campion (1902) determinou a posição dos côndilos mandibulares por palpação e marcou sua trajetória durante o movimento de abertura bucal na pele do paciente, demonstrando assim o percurso que o mesmo faz durante este movimento.

O plano oclusal apresenta uma relação tridimensional individual e esta deve ser transportada para o articulador. Baseado neste pensamento, Snow apresentou em 1906 um arco facial que possuía dois planos de orientação. Aplicando os princípios de anatomia dos tecidos relacionados aos planos craniométricos de orientação preconizados por Broomell, o arco facial seguia a orientação do plano B, representado pela linha que vai do tragus à porção mais inferior do rebordo orbital e do plano oclusal que seria paralelo ao plano B. No arco facial, o plano B era produzido pela haste lateral que apresentava dois dispositivos posicionados sobre o eixo de rotação (localização arbitrária) e uma ponteira anterior que era colocada na porção mais inferior do rebordo orbital (localização por palpação) e do guia de mordida que reproduzia o plano oclusal (CAMPION, 1902). 
Segundo Piehslinger et al. (1991), Eltner já descrevia em 1909 o eixo de rotação como sendo o local que ocorre o movimento de rotação puro e ele ainda acrescentava que este era individual para cada paciente.

Passado algum tempo, Gysi (1910) construiu um aparelho para registrar o curso do côndilo mandibular. Este dispositivo acabou sendo usado no transporte da relação dos dentes ao plano protético Ébene, que se estende da porção superior do tragus à porção mais inferior do rebordo orbital, para o articulador Gysi Simples.

Em 1910, Luce desenvolveu um articulador que possuía no ramo inferior duas caixas, uma direita e outra esquerda, destinadas a receber material moldável que a partir da montagem em cêntrica pudesse, com os movimentos dos modelos, gravar de forma estereográfica, a forma equivalente da cavidade articular e de todos os componentes anatômicos que permitem os registros em cera (POSSELT, 1962).

A introdução da localização cinemática do eixo de rotação foi feita por Andresen em 1912 quando usou um arco facial ajustável preso à mandíbula. Este arco apresentava, adaptada à sua porção posterior, uma ponteira que era direcionada ao côndilo. Ele solicitava ao paciente para abrir e fechar a boca em pequenos movimentos e quando a ponteira não descrevia nenhum arco, ele concluiu que ali se localizava o eixo de rotação (PIEHSLINGER et al., 1991).

Hanau em 1920 desenvolveu um articulador semi-ajustável que foi amplamente difundido e utilizado (HALL, 1930).

Hanau (1930) descreveu a função do arco facial como sendo um aparelho para registrar as relações posicionais corretas do rebordo maxilar e transferi-las para o articulador, com o qual se obtém uma relação posicional que permite uma melhor interpretação das condições dos arcos dentais. A não utilização do arco facial traz complicações no que concerne à construção de aparelhos protéticos, considerou o autor. 
Nichols (1930) cita que Wadsworth adiciona ao arco facial de Snow um dispositivo em forma de T fixado com uma chave do mesmo tipo que é usada com o garfo de mordida, sendo uma haste horizontal e a outra perpendicular. O plano oclusal tinha início na área condilar e seria orientado em ângulo reto com a linha que une os pontos mais proeminentes do mento e da fronte.

McCollum (1938) introduziu a Gnatografia (os traçados dos movimentos do côndilo) na programação de articuladores.

A articulação mecânica dos articuladores deve simular o relacionamento da mandíbula com a cavidade articular e a natureza dos movimentos cêntricos e excêntricos da mandíbula, obtidos com o auxílio do arco facial e dos registros interoclusais (JORDAN, 1952).

Craddock e Symmons (1952) consideraram que falhas do uso do arco facial resultam em graves problemas para a oclusão, decorrentes de uma não exata transferência do modelo superior ao articulador e o seu uso requer o despendimento de pouco tempo, o que é recompensado pela exatidão da montagem obtida.

Brandrup-Wognsen (1953) apresentou um arco facial que possuía a inovação de ser fixado aos meatos acústicos externos por meio de pinos auriculares de madeira, sendo as suas hastes laterais ajustáveis e na sua porção anterior tinha um ponteiro posicionado no ponto infra-orbital; desse modo montava-se o modelo de acordo com o plano eixo orbital.

Augsburger (1953) descreveu como é importante transportar, por meio do arco facial, a relação do plano oclusal com o plano de referência eixo infra-orbital, sendo usado um ponto de referência, no caso o infra-orbital. O autor comentou que, do ponto de vista biológico, as linhas de força devem ser diferentes conforme o tipo craniométrico e, mecanicamente, essas forças devem ser perpendiculares ao plano oclusal, o que demonstra a necessidade de respeitarmos a individualidade do paciente. 
O consenso de opinião é que o plano oclusal está relacionado à linha de Camper. Visto que esta linha foi aceita pelos protesistas como um ponto de referência, pareceria desejável delinear exatamente e propagar seu uso. Em 1780, Petrus Camper, um anatomista holandês, situou em cima da lateral dos crânios, uma linha que se extende da borda mais baixa da ala do nariz ao centro do meato auditivo externo. O Plano Oclusal é a linha que representa um plano de oclusão tangente às cúspides dos primeiros e segundos molares maxilares. O plano oclusal em dentições naturais pode desviar-se na altura vertical na região do segundo molar em 4 mm (AUGSBURGER, 1953).

Schuyler (1953) considerou que o uso meticuloso do arco facial, proporciona uma montagem adequada dos modelos nos articuladores, permitindo análise detalhada da oclusão dental e levando à confecção de melhores trabalhos.

Sloane e Cook (1953) mencionaram a existência de uma relação entre os pontos craniométricos fixos comuns do crânio, os modelos maxilares desdentados e o plano oclusal. Sugeriram que um instrumento calibrado deveria ser usado para localizar o plano oclusal.

Para Lucia (1953), a importância do uso do eixo de rotação está no fato de que pela sua determinação e transferência para o articulador é possível ter os modelos nas suas exatas relações dinâmicas e estáticas, da mesma forma que se encontram na cabeça do paciente.

Collett (1955) analisando que os modelos superiores devem seguir uma orientação no sentido anteroposterior e sagital mediano, verificou que, quando o modelo superior é afastado do eixo de rotação no sentido linear e estando os modelos em oclusão, haveria contato prematuro na região posterior e quando muito próximo, a prematuridade ocorreria na região dos dentes anteriores.

Lazzari (1955) apresentou as seguintes vantagens do emprego do arco facial: a. permite uso mais acurado do ponto de rotação lateral para o engrenamento dos dentes; b. ajuda a assegurar a posição anteroposterior do modelo em relação aos côndilos da cabeça da 
mandíbula; c. o registro da relação horizontal do modelo superior fica preciso e assim ajuda na localização correta do modelo no articulador; e, d. ajuda no posicionamento vertical do modelo superior no articulador.

De acordo com Jamieson (1956), o uso do arco facial auxilia a orientação dos modelos no articulador em uma posição aproximada dos maxilares e mandíbula, em relação à articulação temporomandibular.

Stuart (1959) desenvolveu o articulador totalmente ajustável que denominou de Stuart, capaz de simular as relações anatômicas crânio-dentais e maxilo-mandibulares, permitindo assim estudar o sistema mastigatório em todos os ângulos. Para o autor, o articulador não é uma máquina mastigatória e nem tão pouco a boca do paciente, é em primeiro lugar um instrumento que reproduz as relações crânio-dentais e maxilo-mandibulares, os eixos de rotação e as trajetórias condilianas. À primeira vista este instrumento pode parecer complicado, mas torna-se um jogo fascinante à medida que se domina a técnica.

Schlosser e Gehl (1959) destacaram que durante a montagem arbitrária do modelo superior podem ocorrer erros na localização e inclinação dos modelos segundo os planos frontal, mediano sagital e horizontal.

Christiansen (1959) partindo do objetivo do arco facial que é orientar o modelo maxilar em relação aos côndilos do articulador, realizou um estudo onde comparou os procedimentos envolvidos na montagem de modelos totalmente desdentados com arco facial arbitrário e cinemático. O autor concluiu que é vantajoso simular no articulador as relações anatômicas dos rebordos residuais e do côndilo para se obter harmonia oclusal nas próteses totais. O método arbitrário de localização do centro de rotação é aceitável, a técnica é boa, mas necessita de cuidado, enquanto o método cinemático é mais preciso. O autor ainda ressalta que o plano eixo infra-orbital se aproxima muito ao plano de Frankfort e deve orientar o plano oclusal. 
O modelo superior com relação ao eixo de rotação condilar tem que ser o mesmo no articulador e no paciente, e todos os registros subseqüentes serão em função deste plano estabelecido (TYLMANN; TYLMANN, 1960).

Segundo McCracken (1960), o uso do arco facial dotado de ponteira infra-orbital não registra somente o raio dos côndilos, mas também a relação angular do plano oclusal com o plano eixo infra-orbital.

Weinberg (1961) alega que a montagem arbitrária dos modelos pode causar sérios deslocamentos anteroposteriores da mandíbula quando feita sem os devidos cuidados, e que a localização do eixo de rotação com o arco facial arbitrário possibilita um erro num raio de 5 mm do eixo real de rotação, que resulta num insignificante deslocamento anteroposterior da mandíbula em 0,2 mm. Para o autor tais arcos faciais, quando bem utilizados, resultam em pequenas correções intra-orais dos trabalhos.

McCollum, De Pietro, Stuart e Lucia apud Lucia (1961) utilizavam arcos faciais cinemáticos que apresentavam também o ponteiro infra-orbital, que relacionava o modelo superior de modo que o plano eixo infra-orbital ou orbital estivessem em paralelismo com o ramo superior do articulador.

O modelo básico ou original de Stuart é a base dos vários modelos da Whip-Mix e de outros fabricantes que produzem articuladores semi-ajustáveis (WEINBERG, 1963b).

Compreendemos com Swenson (1964) o grande valor dos articuladores, seja para análise oclusal seja para outros procedimentos que devem ser executados dentro dos princípios fisiológicos do conceito de uma oclusão próxima da ideal, tudo isto tomando também como alicerce as pesquisas desenvolvidas por Posselt, McCollum e os adeptos da Escola Gnatológica da Califórnia.

De acordo com Swenson (1964), falhas no uso do arco facial podem incorrer em erros de oclusão. Os erros podem ser pequenos quando o desvio na orientação dos modelos for 
pequeno. O registro com arco facial, portanto, é indispensável e o tempo despendido em seu uso é compensado ao final do tratamento, porque os ajustes necessários serão mínimos.

Teteruck e Lundeen (1966) desenvolveram um novo método arbitrário de montagem de modelos maxilares utilizando um arco facial auricular e o compararam ao método arbitrário convencional, de $13 \mathrm{~mm}$ adiante do tragus e ao verdadeiro eixo de rotação. Este novo arco facial auricular era posicionado posteriormente na porção externa do meato auditivo por meio de uma oliva auricular e anteriormente no ponto násio (terceiro ponto de referência). No estudo foram avaliados três métodos de montagem em 47 pacientes. Os resultados mostraram que esta simples modificação melhorou o nível de acerto na localização do eixo de rotação em 75 \% e assim, os autores verificaram vantagens em se usar o arco facial auricular e o recomendaram para vários procedimentos restauradores.

De acordo com Kornfeld (1967), o plano eixo orbital fornece uma posição constante do maxilar em relação ao crânio. Este plano se estende do eixo condilar a um ponto situado a $54 \mathrm{~mm}$ no lado direito do nariz, a partir da borda incisal do incisivo central superior direito ou tomado em relação à borda inferior da órbita do lado direito do nariz. Estes pontos guiam a transferência com o arco facial de modo a orientarmos o modelo no articulador, obedecendo a mesma relação que o maxilar guarda com o eixo de rotação.

Segundo Hickey, Lundeen e Bohannan (1967) o arco facial nos fornece a orientação espacial que os modelos dos arcos dentais devem ter no sentido anteroposterior e médiolateral, em relação ao eixo terminal de rotação do articulador. Isso faz com que possamos avaliar corretamente a relação da articulação temporomandibular com os dentes dos modelos.

Nunes (1968) estudou a validade do ponto infra-orbital como terceiro ponto de referência dos arcos faciais e concluiu que os modelos transferidos para o articulador semiajustável por meio de arco facial que utiliza o ponto infra-orbital como referência anterior 
apresenta grandes vantagens, pois transporta para o articulador a relação dos dentes com o plano craniométrico eixo infra-orbital.

Por outro ângulo de observação, Wirth (1971) destacou o tipo de articulador e suas características. O articulador tipo arcon, tais como o Whip-Mix, permite o movimento dos modelos da relação cêntrica para a posição intercuspídea sem ajuste condilar, desde que a inclinação protrusiva seja a mesma ou menos do que a inclinação do paciente. Os articuladores não-arcon com as cavidades condilares inseparáveis requerem afrouxamento das inclinações condilares para permitir o movimento dos modelos na posição intercuspídea. Nos articuladores tipo arcon com a guia condilar reta, a esfera condilar pode estar fora da cavidade quando os modelos são movidos para a posição intercuspídea. Isto pode ocorrer porque o instrumento tem uma guia reta e no paciente esta guia é curvilínea.

Os estudiosos Azamehr e Yarmand (1973), por sua vez, relataram que na montagem de modelos em articuladores semi-ajustáveis o uso dos registros interoclusais laterais não é muito freqüente.

Nunes (1973) estudou a identidade de posicionamento entre o modelo superior no articulador e o maxilar no crânio pelo método clínico, radiográfico e geométrico. O autor concluiu que o ponto infra-orbital é uma característica individual e não arbitrária, apresentando posição própria no espaço geométrico em relação ao eixo de rotação, o qual deve ser transportado ao articulador através do ponteiro orbital, que dará o melhor relacionamento do modelo no espaço geométrico do articulador.

Balshi et al. (1976) destacaram a mesa guia incisal, que é um componente do articulador usado para: registrar e/ou reestabilizar uma guia anterior fisiologicamente aceitável, produzir uma restauração oclusal em harmonia com a oclusão fisiológica do paciente, ajudar o técnico do laboratório dental no desenvolvimento da oclusão e diminuir o tempo do dentista na cadeira para ajustes. A técnica para o uso da mesa guia incisal pode ser 
dividida em duas categorias principais. Primeiramente, a restauração será fabricada na oclusão cêntrica habitual ou adquirida do paciente. A segunda aplicação da técnica ocorre quando uma oclusão inteiramente nova deve ser estabelecida usando a relação cêntrica.

Hobo, Shillingburg e Whitsett (1976) relataram que os articuladores semi-ajustáveis permitem uma aproximação da distância anatômica entre o eixo de rotação condilar e os dentes. A distância intercondilar pode ser ajustada em três posições: pequena, média e grande. Na maioria destes aparelhos o ângulo de Bennett e a inclinação da cavidade articular são reproduzidos de maneira gradual.

Winstanley (1977) descreveu o uso do traçado do eixo de rotação feito com o auxílio do pantógrafo na programação do articulador e concluiu que a experiência clínica do operador no uso deste instrumento permite reproduzir os traçados dos movimentos mandibulares no articulador.

Henderson e Steffel (1979) relataram que o arco facial é um instrumento relativamente simples, usado para obter o registro de transferência com a finalidade de orientar o modelo maxilar no instrumento de articulação. Afirmaram ainda, que o dispositivo intra-oral do arco facial deve ser ligeiramente pressionado contra o modelo de estudo, com a linha mediana do dispositivo intra-oral do arco facial correspondendo à linha mediana dos incisivos centrais.

Para Okane et al. (1979), a orientação do plano oclusal é um procedimento clínico importante no tratamento protético e quando não é reproduzido no articulador, altera a atividade muscular e a efetividade mastigatória. Os autores mediram a atividade eletromiográfica de 4 pacientes desdentados totais que receberam 3 pares de próteses, sendo que o plano oclusal destas próteses eram: A) plano oclusal posicionado paralelo à linha asatragus; B) plano oclusal com $5^{\circ}$ de inclinação anterior; e, C) plano oclusal com $5^{\circ}$ de inclinação posterior. Verificou-se que a atividade eletromiográfica foi diferente nas três situações. 
Preston (1979) reavaliando a teoria do eixo horizontal mandibular transversal relatou que as variações na orientação do modelo maxilar no articulador comparado com a orientação do eixo horizontal transversal do paciente podem resultar em discrepâncias oclusais por causa dos desvios nos arcos do fechamento.

Walker (1980) pesquisando as discrepâncias entre eixos de rotação arbitrários e verdadeiros determinou a localização anatômica do eixo terminal de rotação de 222 estudantes, totalizando 444 pontos, com o localizador de eixo da Denar e comparou-os com o eixo de rotação arbitrário e verificou que o eixo de rotação arbitrário difere do eixo terminal de rotação anatômico e este erro é de no mínimo 5 mm.

Zuckerman (1982), analisando a geometria do eixo terminal de rotação arbitrário em relação à oclusão, relatou que quando ocorrem erros na localização e transferência do eixo terminal de rotação, os modelos superiores ficam montados em posição diferente da anatômica e este fato pode incorrer em erros durante a avaliação dos modelos montados e dos trabalhos executados sobre estes modelos.

A orientação incorreta do modelo superior no articulador leva a erros, por isso Stade, Hanson e Baker (1982) avaliaram a possibilidade de erros utilizando um arco facial convencional de Hanau (Hanau Mode 132-2SM, Teledyne Hanau, Buffalo, N.Y.) comparado a outro arco facial de Hanau que tinha como modificação em cada haste lateral uma bolha de nível. Neste estudo os autores verificaram que o uso dos planos de referência horizontal ditado pelas bolhas de nível mostrou melhores resultados estéticos e o plano oclusal bem orientado, enquanto as orientações feitas com o eixo arbitrário de rotação e o ponto orbital podem trazer erros de orientação do plano oclusal.

Morita, Miyagawa e Lang (1982) em seu estudo sobre a determinação do percurso do movimento protrusivo em articuladores arcon e não-arcon por equações matemáticas, relataram que os dois tipos de articuladores arcon e não-arcon representam os tipos de 
instrumentos que são usados geralmente pela profissão hoje. Os estudos mostraram que o mecanismo condilar do arcon ou do não-arcon tem uma influência na inclinação da guia protrusiva e no desenvolvimento dos ângulos das cúspides da superfície oclusal.

Santos Júnior (1982) considerou que durante a montagem de modelos em articulador, a fase mais importante é a fase clínica de registro das relações anatômicas com o arco facial e a obtenção dos registros intra-orais. O cuidado na montagem dos modelos é facilmente controlado pela experiência do cirurgião-dentista na utilização do aparelho. O ajuste propriamente dito dos articuladores está na dependência do desempenho mecânico do aparelho, podendo cada um deles, de acordo com as próprias possibilidades estruturais de construção, fornecer uma calibração mais precisa ou não. Na maioria das vezes, os articuladores de que dispomos no mercado utilizam valores médios para obtenção do eixo terminal de rotação, ponto de referência para cada lado da face do indivíduo. O ponto craniométrico anterior é escolhido de acordo com o plano de referência a ser usado. Os mais comuns são: o infra-orbital e o násio.

Gold e Setchell (1983) investigaram a reprodutibilidade da posição do modelo maxilar em articuladores semi-ajustáveis e a transferência do arco facial foi repetida dez vezes no mesmo indivíduo. Os resultados obtidos com os arcos faciais Dentatus AEB, Whipmix Quickmount e Almore, foram comparados. As variações na posição do modelo raramente ultrapassaram 1,0 mm em qualquer um dos três planos e com base nos resultados observados, a transferência do arco facial foi um procedimento clínico confiável.

Yanus, Finger e Weinberg (1983) revisaram a literatura e concluíram que a utilização do arco facial é um procedimento preciso e que os registros de transferência do arco facial são reprodutíveis no mesmo indivíduo.

Segundo Miranda (1984), quando os modelos de estudo são montados em articuladores semi-ajustáveis, as condições de planejamento de uma prótese parcial fixa e 
conseqüentemente de uma reabilitação oral protética são mais concretas, uma vez que poderão ser analisadas as possíveis interferências oclusais que são facilmente detectadas por este procedimento, como também teremos subsídios concretos para concluir se os trabalhos pretendidos apresentam possibilidades reais para a sua execução.

Bailey e Nowlin (1984) avaliando o terceiro ponto de referência para a montagem do modelo maxilar no articulador Hanau, verificaram que a relação entre o plano de Frankfort e o plano oclusal superior não é transferida para o articulador Hanau quando se utiliza o ponto orbital como terceiro ponto de referência craniométrico.

Callison (1985) investigou uma modificação no garfo de mordida para ajudar a orientação do plano oclusal. O autor criou um dispositivo útil para transferência do arco facial; trata-se do uso de uma bolha de nível, unida ao braço de extensão do garfo de mordida, com o objetivo do plano oclusal permanecer horizontal. A bolha de nível serve como uma guia segura quando da fixação do arco facial no paciente e durante a transferência deste relacionamento ao articulador, têm-se uma maneira do plano oclusal estar horizontal. Depois que é unido ao articulador, o arco facial pode ser ajustado para cima ou para baixo até que o nível da extensão do braço do garfo de mordida esteja horizontal.

Zuckerman (1985) destacou que uma grande variedade de articuladores dentais está à disposição dos protesistas, onde o relacionamento entre as estruturas cranianas, a postura e o articulador ocorre quando se transferem as medidas obtidas com o arco facial. Nota-se que as partes horizontais e verticais do articulador são paralelas ao eixo horizontal e vertical da face. A linha mediana da face deve coincidir com o centro do articulador.

Gross e Gazit (1985) fizeram um estudo no qual enviaram um questionário a 59 escolas de Odontologia norte-americanas em 1984. Os itens do questionário pediam informações a respeito de quais instrumentos eram empregados nas escolas. Os autores evidenciaram que, para o ensino dos estudantes nas disciplinas de próteses e oclusão, o 
articulador semi-ajustável era usado na maioria das escolas de Odontologia. Os quatro tipos de articuladores mais usados são o Whip Mix, Hanau H 158, Denar Mark II e Hanau H2 96, todos eles articuladores semi-ajustáveis. Os articuladores totalmente ajustáveis foram julgados serem instrumentes complexos desnecessários para o ensino dos estudantes na maioria das escolas.

Palik, Nelson e White (1985) em seu estudo sobre a precisão de um arco facial com dispositivo auricular, avaliaram a localização do eixo de rotação mandibular utilizando o arco facial auricular e o arco facial cinemático Hanau. Foram analisados 18 pacientes e observouse diferença estatística na localização do eixo mandibular entre o arco facial auricular e o eixo terminal de rotação. Os autores descreveram a necessidade de se fazer modificações nos arcos faciais arbitrários para que eles apresentem um melhor desempenho clínico. Concluíram que o arco facial arbitrário relacionou a maxila ao eixo terminal dentro da escala aceitável de 5 milímetros. O arco facial registrou o eixo arbitrário anteriormente ao eixo terminal em $92 \%$.

Ash e Ramfjord (1985) comentaram que o articulador é um instrumento onde os modelos das arcadas dentárias dos pacientes são conectados de forma que se possam analisar, diagnosticar e executar procedimentos restauradores sem a presença do paciente.

Chow, Clark e Cooke (1985) investigaram erros na montagem do modelo maxilar usando registros do arco facial como resultado de uma variação anatômica e observaram que quando articuladores semi-ajustáveis são usados, a orientação dos modelos no articulador com referência ao eixo intercondilar e o plano horizontal tem que ser a mesma orientação da maxila do paciente. No caso da referência horizontal isto é comumente conseguido pelo uso de um arco facial com um ponteiro orbital, o qual transfere a relação do plano de Frankfort. O plano de Frankfort ou sua proximidade, o plano eixo-orbital, é usado na montagem dos modelos em articulador. O plano de Frankfort é o plano formado pelos dois pórios e o orbital 
esquerdo. Este plano é largamente aceito como um plano de referência horizontal da cabeça e é a base do desenho de muitos articuladores.

Dykema, Goodacre e Phillips (1986) relataram que o articulador é um instrumento mecânico capaz de manter os modelos, superior e inferior em seu correto relacionamento interoclusal, enquanto certos movimentos mandibulares podem ser duplicados. O número de movimentos mandibulares conseguidos e sua precisão na reprodução são freqüentemente usados para classificar os diferentes tipos de articuladores.

Marko (1986) relatou sobre a diferença entre articuladores semi-ajustáveis e nãoajustáveis em cirurgia ortognática e destacou que o arco facial registra o posicionamento anteroposterior do modelo maxilar em relação ao eixo terminal da mandíbula; ajuda no posicionamento vertical dos modelos em relação ao plano horizontal de referência e permite uma simulação mais precisa dos movimentos excursivos da mandíbula. O autor também afirma que mesmo um registro do arco facial impreciso combinado com um registro de relação cêntrica espesso resulta em somente 0,2 milímetros de erro no segundo molar. Simultaneamente, a própria orientação horizontal do plano oclusal maxilar relativa aos côndilos é segura e dispõe de habilidade no ajuste da orientação vertical do plano oclusal maxilar idêntica àquela do paciente em relação ao plano de Frankfort ou ao real plano horizontal postural.

De acordo com McMillan e McMillan (1986), comparando os movimentos mandibulares e as funções do articulador, os erros inerentes das montagens em articuladores ajustáveis são decorrentes do registro do paciente ou dos ajustes do articulador, ou ainda ambos, além da validade dos conceitos geométricos em que se baseia o projeto do articulador.

Goska e Christensen (1988) fizeram um estudo comparativo da posição do primeiro molar superior esquerdo e direito, utilizando quatro diferentes arcos faciais em dez estudantes de Odontologia (5 mulheres e 5 homens), com idades entre 22 e 28 anos que não 
apresentavam sinais e sintomas no sistema articular. No estudo foram utilizados um arco facial cinemático (Hanau Kinematic Face-bow) e três arcos faciais arbitrários (Hanau Facebow, Hanau 159 Earpiece Face-bow e Hanau Twirl Earpiece Face-bow) montados no articulador Hanau H2 (Teledyne Hanau). A posição ocupada pelo primeiro molar superior esquerdo e direito quando montados no espaço tridimensional do articulador foram analisadas. Os resultados apresentaram grandes variações entre os pacientes, mas não mostraram diferenças significantes entre as quatro montagens de um mesmo paciente, demonstrando que não há superioridade clínica entre os arcos faciais utilizados.

Desde a sua concepção e introdução na Odontologia, a primeira proposta dos articuladores é simular os movimentos mandibulares. A efetividade pode ser determinada por comparação de sobreposição dos traçados pantográficos dos movimentos mandibulares registrados dos pacientes com os movimentos análogos do articulador. Santos Júnior e Ash (1988) fizeram um estudo onde investigaram as diferenças lineares e angulares de 6 diferentes articuladores semi-ajustáveis, sendo 3 do tipo arcon e 3 do tipo não-arcon, registrados por um pantógrafo eletrônico (Cyberhoby) acoplado ao computador. O equipamento foi usado para registrar a precisão dos ajustes dos articuladores pelo método convencional, comparando os movimentos de três pacientes. Dentro dos limites do projeto experimental, os autores concluíram que houve uma diferença estatística de 0,05 \% entre o registro nos articuladores e nos pacientes. Quando o método Scheffe’s de múltiplas comparações foi usado para checar a performance dos articuladores, verificou-se que o tipo arcon pode simular melhores os movimentos mandibulares e que o registro dos movimentos mandibulares executado pelo pantógrafo eletrônico não pode ser duplicado pelos articuladores semi-ajustáveis.

Shillingburg, Hobo e Whitsett (1988) descreveram que o eixo terminal de rotação é uma referência importante e reprodutível. Além disso, se os modelos são montados de tal forma que o articulador fecha ao redor de um eixo diferente do eixo de rotação mandibular do 
paciente, os dentes ocluem no articulador em posição diferente do que na boca, por isso é importante transferir corretamente estas relações para o articulador. A transferência desta relação é feita com o arco facial e quanto mais precisa for a localização do eixo terminal de rotação, mais exata será a montagem dos modelos.

Segundo Strohaver e Ryan (1988) o arco facial móvel foi desenhado para orientar o plano oclusal, tendo como referência o plano horizontal de Frankfort. A parte alta do ouvido aproxima-se do ponto cefalométrico (pório), localizado pela parte externa do meato acústico. O pório é o ponto de referência posterior do plano horizontal de Frankfort de ambos os lados. O ponto de referência anterior é localizado quando uma ponteira é ajustada ao orbital (terceiro ponto) que constitui o ponto mais baixo do rebordo infra-orbital. Quando corretamente localizado, a borda superior do arco facial móvel é a representação visual do plano horizontal de Frankfort. Para os autores, os erros de orientação do plano oclusal podem ser a causa das discrepâncias excêntricas oclusais após reabilitações orais.

Strohaver e Ryan (1988) relataram também que o uso do plano horizontal de Frankfort como um plano de referência é bem estabelecido, apesar de erros em tentar transferir marcas radiográficas de uma pele para um articulador. As vantagens do terceiro ponto de referência incluem a habilidade para controlar a orientação do plano oclusal e fatores estéticos que relacionam-se à inclinação axial dos dentes anteriores.

A reprodutividade dos articuladores semi-ajustáveis Whip-Mix, Denar Mark II e Hanau 158 foram estudadas por Gross, Nemcovsky e Friedlander (1990) que compararam o posicionamento dos modelos superiores com cefalometrias laterais. Os autores determinavam o ângulo formado pelo plano de referência craniométrico eixo orbital com o plano oclusal maxilar de cada montagem e das respectivas cefalometrias. Concluíram neste estudo que havia uma diferença significativa entre os articuladores. 
Kitzis, Millstein e Nathanson (1991) calibraram 20 articuladores (Denar D5-A e Mark II), utilizando um dispositivo de inspeção esférico Denar. Registros em silicona interoclusal e splints dos modelos foram feitos, para que ocorressem transferências perfeitas dos modelos montados de um articulador para outro. As montagens foram avaliadas por três diferentes observadores. Cada observador avaliou o grau de reprodutibilidade das transferências do modelo superior por meio de microscópio óptico. Entre os dois modelos não podia passar um fio de calibração. Estas análises foram efetuadas nas três dimensões. Os resultados indicaram que os modelos montados em articuladores calibrados podem ser posicionados em qualquer um dos articuladores.

Um conceito fundamental da prótese dental é o fato do plano eixo orbital ser usualmente paralelo ao plano de referência horizontal. Muitos sistemas de articuladores têm incorporado o conceito, designado e usado o orbital como ponto de referência anterior para transferir a posição vertical do maxilar para o articulador. Contudo, nem mesmo com o uso da ponteira orbital em conjunto com as olivas auriculares, o plano eixo orbital correto era transportado para os articuladores e isto resultava em erros durante as montagens. Pitchford (1991) reavaliando o plano eixo-orbital e o uso do orbital em um registro de transferência do arco facial examinou a causa e corrigiu os erros de montagem resultantes do uso do orbital como ponto de referência anterior. O autor usou uma ponteira orbital na haste anterior do arco facial auricular e um jogo de quatro níveis, sendo que dois situados na ponteira orbital e outros dois situados na forquilha do garfo de mordida. Com estas alterações no arco facial transferiu-se uma posição de referência mais funcional para o articulador.

Piehslinger et al. (1991) descreveram as vantagens da pantografia computadorizada sobre o dispositivo mecânico. Segundo os autores, as maiores vantagens do método computadorizado estão em se poder visualizar os traçados no computador, oferecer um 
sistema matemático integrado de avaliação e ainda permitir comparações num espaço de tempo entre os diversos registros.

Ellis, Tharanon e Gambrell (1992), investigando a precisão da transferência do arco facial, concluíram que para a montagem do modelo maxilar, no mínimo dois aspectos devem ser observados: o relacionamento radial entre os dentes maxilares e o eixo terminal, e o relacionamento angular entre o plano oclusal e a face do paciente. Para os autores, a transferência do modelo maxilar para o articulador pelo uso de um arco facial fornece uma estimativa confiável da distância entre a dentição e o eixo intercondilar. Dois tipos de arco facial são disponíveis, o arbitrário e o cinemático. Um arco facial cinemático é um dispositivo preso à dentição mandibular que localiza o verdadeiro eixo intercondilar, ou um eixo do movimento mandibular onde os movimentos são puramente rotatórios dos côndilos. Usando este tipo de arco facial, o arco de fechamento do modelo mandibular no articulador simulará muito próximo do arco mandibular real de fechamento do paciente. Já o arco facial arbitrário relaciona a dentição maxilar a uma estimada posição do eixo intercondilar mandibular. Dois tipos de arco facial arbitrário estão disponíveis. Um requer a localização dos côndilos mandibulares pela palpação e pela marcação na superfície da pele antes de fazer a transferência do arco facial. No outro tipo de arco facial arbitrário, o qual é popularmente mais usado na odontologia, o arco maxilar é relacionado ao meato auditivo externo por meio das hastes do arco. Ambos os tipos de arco facial arbitrário fornecem uma localização estimada do ponto médio dos côndilos mandibulares. Os autores ainda afirmam que quando se usa algum tipo de arco facial, um terceiro ponto de referência é necessário para relacionar o ângulo do plano oclusal ao plano de referência horizontal, normalmente o plano de Frankfort. O terceiro ponto de referência, que é usado mais freqüentemente, é o orbital, registrado por um ponteiro orbital no arco facial, ou o násio, representado por um descanso nasal no arco facial. 
Ho e Leung (1992) substituíram o ponteiro eixo orbital do arco facial por uma bolha de nível. Segundo os autores esta modificação proporciona um correto relacionamento da direção do plano eixo horizontal.

Alexander, Moore e DuBois (1993) avaliaram a fidelidade da posição mandibular observando a existência de diferentes posições mandibulares em articuladores por meio de imagens de ressonância magnética (IRM). Neste estudo foram avaliados 28 homens com idade variando entre 23 e 34 anos, sem sinais e sintomas de disfunção temporomandibular e relação molar de classe I de Angle. O eixo de rotação mandibular foi localizado com o arco facial cinemático e o modelo superior foi montado no articulador SAM (modelo de articulador norte-americano). Registros de relação cêntrica (RC), com o auxílio de “leaf-gauge”, máxima intercuspidação habitual (MIH) e posição retruída da mandíbula (PR) foram realizados e, com eles fez-se a montagem do modelo mandibular. Após as montagens, comparou-se a posição da maxila com a mandíbula entre as montagens feitas em RC, MIH e PR. Posteriormente, os autores analisaram a posição condilar nas IRM com a mandíbula em RC, MIH e PR. Os autores concluíram que o côndilo mandibular está centralizado em metade da amostra e permanece compatível em RC, MIH e PR; em $13 \%$ da amostra o disco articular estava anteriorizado, mas não influenciava a posição condilar posterior.

Abdullah (1995) em seu estudo da aceitabilidade dos registros laterais interoclusais por um articulador, cita que articuladores semi-ajustáveis são usados para procedimentos restauradores de rotina e ele ressalta que antes da oclusão ser estabilizada, o mecanismo condilar destes instrumentos é ajustado com o uso de registros interoclusais laterais do paciente. Para minimizar os erros oclusais, muitos articuladores semi-ajustáveis atuais vêm munidos com uma trajetória condilar curva. É mais provável que estas trajetórias de deslocamento curvas permitem uma maior porcentagem de aceitabilidade de registros interoclusais. 
Para Ash e Ramfjord (1995) alguns arcos faciais são por si mesmo centralizados ou posicionados manualmente. Quando o posicionador auricular do arco facial e o garfo de mordida estão em posição, o eixo terminal é automaticamente determinado para a transferência.

O efeito da montagem arbitrária dos modelos superiores sobre o relacionamento oclusal foi estudado por Piehslinger, Bauer e Schmiedmayer (1995). Neste estudo, os autores utilizaram o modelo maxilar de 31 estudantes de Odontologia, os quais foram montados em articulador. Primeiramente montou-se com arco facial arbitrário e depois com arco facial ajustável, após localizar o eixo de rotação pelo gráfico computadorizado. Três pontos de referência foram definidos e mensurados sobre cada um dos modelos maxilares, com o digitalizador tridimensional. As mensurações foram tomadas dos modelos montados de acordo com o eixo de rotação. Os resultados revelaram que a localização do eixo do articulador difere em $5 \mathrm{~mm}$ do eixo de rotação do paciente em $77 \%$ dos casos, quando se utilizam os arcos faciais arbitrários, resultando em erros de oclusão. O erro na montagem vai depender do ângulo de rotação e da diferença entre o eixo de rotação mandibular do paciente e o eixo do articulador.

Pessina, Bosco e Vinci (1995) consideraram que para poder examinar e reproduzir os movimentos mandibulares, devemos dispor de coordenadas espaciais de referência: os planos e eixos ortogonais e os planos e pontos de referência cranianos. Estes pontos de referência devem ser utilizados de forma habitual pelos cirurgiões-dentistas na prática diária. Há muito tempo tem-se proposto e adotados muitos pontos de referência cranial, sendo utilizados principalmente na Ortodontia, Prótese e Gnatologia.

Adrien e Schouver (1997) estudando métodos para minimizar os erros na montagem do modelo mandibular em articulador relataram que um erro na orientação do plano oclusal tem somente uma pequena incidência na localização do modelo da mandíbula. Quando o real 
eixo de rotação está localizado em 5 mm (valor de limite) do eixo de rotação arbitrário do articulador e a espessura do registro é de $3 \mathrm{~mm}$, causa erros maiores do que 0,2 $\mathrm{mm}$ na localização do modelo mandibular, porque a posição real do eixo de rotação é aleatória, e é impossível clinicamente estimar o tamanho do erro devido a uma determinação arbitrária do eixo de rotação. A cera de impressão para registro de relacionamento em relação cêntrica causa um erro que é diretamente proporcional à sua espessura, e este é o fator principal na localização do erro. Uma mudança de $1 \mathrm{~mm}$ na espessura da cera pode causar um erro extra de 0,130 mm. Os autores concluíram que, na montagem em articulador, a localização do verdadeiro eixo de rotação evita um erro quando do uso da cera de registro para relacionamentos intermaxilares. Quando o eixo de rotação é determinado arbitrariamente, o registro sem cera evita o erro. Mas isto requer que o contato máximo das cúspides ocorra com o eixo centralizado e que a posição dos modelos se apresente estável. Em todos os casos restantes, a cera da impressão deve ser usada. Assim, a fim de minimizar o erro, é importante usar um arco facial de localização do eixo e transferência a fim de se obter um plano de oclusão tão próximo quanto possível àquele do paciente. Além disso, a cera usada para registro de impressão deve ser tão fina o possível entre os molares. Mas esta cera não deve ser perfurada para evitar contatos indesejáveis e deve também apresentar rigidez e ótima fidelidade como qualidades.

Zanetti e Ribas (1997) investigando um novo método para simplificar e aumentar a precisão do procedimento de montagem do modelo maxilar em articuladores totalmente ajustável ou semi-ajustável, adaptaram nas moldeiras de estoque uma haste de modo a registrar o relacionamento da maxila com a base do crânio durante a moldagem, pois esta haste era fixada à junta universal do arco facial dos articuladores semi-ajustáveis ou totalmente ajustáveis. Com isso os autores obtinham o modelo dos arcos dentais ao mesmo 
tempo em que o arco facial transportava o relacionamento da maxila à base do crânio ao articulador.

Tamaki et al. (1997) ao analisarem a reprodução dos contatos dentais excursivos em um articulador relataram que a capacidade do cirurgião-dentista é importante na avaliação clínica e na utilização dos articuladores para muitos aspectos da Odontologia Restauradora, incluindo análise, diagnóstico, plano de tratamento e o tratamento propriamente dito. Limitações inerentes ao articulador devem ser compensadas pelo senso crítico do profissional.

De acordo com Shillingburg et al. (1998), para se obter o maior grau possível de precisão com o articulador, os modelos nele montados devem fechar-se em torno de um eixo de rotação que seja o mais próximo possível do eixo terminal da mandíbula do paciente. É necessário transferir a relação entre os dentes superiores, o eixo terminal e um terceiro ponto de referência do crânio do paciente para o articulador. Com o dispositivo de referência anterior que dá a orientação vertical do arco facial, ele poderá ser usado para montar com precisão o modelo do arco dental superior no articulador.

Ercoli et al. (1999) relataram que a precisão na montagem do modelo maxilar é conseguida pela transferência do relacionamento tridimensional espacial do arco maxilar para o articulador, pelo uso de um arco facial. Isto tradicionalmente é conseguido pelo uso de três pontos de referências. Ainda para o autor, os membros superiores e inferiores do articulador são, na maioria dos articuladores, paralelos um ao outro, e ao plano horizontal. Os componentes funcionais de um articulador são as inserções condilares e a mesa guia incisal. Estes elementos são ajustados em relacionamentos angulares específicos com o membro superior do articulador. O membro superior do articulador é horizontal, quando o pino da guia incisal estiver zerado, e é a provável razão porque os clínicos tentam relacionar a posição espacial do arco maxilar e a inclinação do trajeto condilar a um plano horizontal ideal no paciente. 
O ponto orbital é amplamente descrito como referência anterior nas montagens em articuladores. Como sua localização e determinação clínica eram muito subjetivas, Silva (1999) validou uma técnica de localização clínica do ponto orbital que denominou de Nunes. Segundo o autor, este método reproduz o ponto orbital em $80 \%$ dos casos e os demais se aproximam muito do ponto orbital radiográfico. Diante da validade do ponto orbital clínico de Nunes, fez duas modificações estruturais no arco facial (relator násio milimetrado e ponteira orbital). O autor acoplou uma plataforma orbital individualizadora no articulador e comparou montagens convencionais e montagens feitas com estas modificações com medidas radiográficas que mostraram uma grande fidelidade da montagem modificada em relação à radiografia, destoando da convencional.

Fernandes, Silva e Nunes (2000) avaliaram o grau de reprodução do relacionamento do eixo terminal de rotação ao plano oclusal utilizando quatro arcos faciais auriculares por meio de geometria analítica. Verificaram que o uso dos dispositivos auriculares distancia os dentes dos modelos superiores montados no articulador do eixo terminal de rotação do mesmo e sugeriram mudanças no arco facial no sentido de melhorar o transporte das relações anatômicas.

Segundo Okeson (2000), a maioria dos arcos faciais dos articuladores semi-ajustáveis não permite a localização exata do eixo terminal de rotação dos pacientes, conta apenas com um ponto predeterminado que tem se mostrado muito próximo do eixo terminal de rotação da maioria dos pacientes e a referência anterior é um ponto arbitrário e geralmente estabelecido pelo fabricante. Sendo assim o modelo superior é montado no articulador seguindo padrões arbitrários. Em contrapartida, o articulador totalmente ajustável é o instrumento mais sofisticado da Odontologia no que diz respeito à reprodução dos movimentos mandibulares. Devido aos inúmeros ajustes disponíveis, este articulador é capaz de reproduzir com precisão os movimentos articulares do paciente. O autor ainda considerou que a precisão do articulador 
também depende da habilidade do operador. Quando cuidados não são tomados durante o registro da relação da maxila com a base do crânio ou os modelos não forem adequadamente montados, a precisão de qualquer articulador é grandemente diminuída. Em outras palavras, o articulador semi-ajustável nas mãos de um clínico que domina o seu manuseio pode ser de grande valia na assistência do tratamento comparado com um articulador totalmente ajustável nas mãos de um operador inexperiente.

Clark, Hutchinson e Sandy (2001) narraram em seu trabalho sobre o papel dos articuladores em ortodontia que os articuladores semi-ajustáveis têm um trajeto condilar que é em uma linha reta, ao contrário do trajeto condilar verdadeiro, o qual segue um trajeto em curva. Os articuladores totalmente ajustáveis têm um número de inserções permutáveis que representam a fossa glenóide, e permitem os movimentos protrusivo e laterais curvos das junções temporomandibulares a serem reproduzidos. Em pacientes parcialmente dentados e edêntulos, a orientação da mandíbula durante a função é determinada, na maior parte, pelo movimento do côndilo na fossa glenóide. Em sujeitos dentados há uma tendência de desoclusão dos dentes posteriores durante excursões laterais, isto é, o movimento mandibular é guiado pelos dentes anteriores e o trajeto condilar tem pouca influência. O uso de um articulador semi-ajustável em sujeitos dentados fornecerá uma representação adequada da verdadeira oclusão do paciente.

Ainda de acordo com Clark, Hutchinson e Sandy (2001), o registro do arco facial relaciona o plano oclusal maxilar a um plano fixo na cabeça de modo que este relacionamento possa ser transferido para o articulador. O plano fixo é encontrado usando três pontos de referência: dois pontos posteriores, através do qual passa pelo eixo dos côndilos, e um terceiro ponto anterior; a localização depende do articulador que está sendo usado. O eixo é uma linha imaginária que passa entre os côndilos da mandíbula e que aparece anterior ao meato auditivo externo, se projetado lateralmente. A localização deste eixo pode ser arbitrariamente 
determinada usando dados médios ou, localizado mais precisamente, usando um localizador cinemático do eixo. Alguns investigadores mostraram que há uma discrepância considerável entre uma posição do eixo encontrada arbitrariamente e cinematicamente. Se uma discrepância existir entre o verdadeiro eixo e o eixo do articulador, um contato prematuro ocorrerá no trajeto retruído de fechamento no modelo articulado, o qual não está presente clinicamente. Esta discrepância oclusal será pequena, mas não introduz imprecisões na técnica de articulação e no diagnóstico oclusal do articulador montado.

Gateno, Forrest e Camp (2001) comparando três métodos de registro de transferência do arco facial afirmaram que o primeiro passo na tomada do arco facial é adaptar o garfo de mordida aos dentes maxilares. Isto é feito prestando atenção no alinhamento do garfo de mordida com o plano sagital.

Nagy, Smithy e Wirth (2002) pesquisando a precisão de um eixo transversal horizontal mandibular ressaltaram que a precisão na montagem de modelos tem sido um desafio e um procedimento difícil em Odontologia por causa de muitas variáveis que podem levar a erros. O modelo maxilar deve ser relacionado à base do crânio utilizando três pontos de referências.

Ferrario et al. (2002), em seu estudo da avaliação tridimensional da confiabilidade da transferência de um arco facial postural, consideraram que a orientação tridimensional do modelo maxilar e sua relação com as estruturas do crânio são geralmente transferidas para o articulador por meio de um sistema de arco facial. A precisão de um arco facial tem sido questionada porque o modelo maxilar é montado em relação a medidas arbitrárias e limites anatômicos que variam entre os indivíduos. Diferentes sistemas de arco facial demonstraram reprodutibilidade precária com significantes mudanças na posição do modelo maxilar.

Gracis (2003) analisando as considerações clínicas e as razões para a utilização de articulador semi-ajustável, considerou que na realização de uma reabilitação protética, sendo na construção de uma coroa única ou na reconstrução da boca completa, um dos principais 
objetivos dos clínicos é simplificar os procedimentos e reduzir o tempo necessário para ajustes dentro da boca do paciente. A seleção do articulador e as informações disponíveis contidas nele, que serão transferidas para o técnico de laboratório, irão minimizar as diferenças inevitáveis deste instrumento e criar restaurações que não requerem ajustes oclusais extensos.

Engelmeier e Starcke (2006) ressaltaram a necessidade de selecionar e de transferir exatamente um plano de referência do crânio para o articulador para orientar corretamente o plano oclusal no espaço. O plano oclusal poderia somente ser transferido exatamente a um instrumento após ele ter sido relacionado ao outro plano de referência (na cabeça do paciente) que tinha sido estabelecido já no articulador.

Hindle e Craddock (2006) avaliando o uso dos articuladores em escolas de Odontologia no Reino Unido, relataram que o articulador deve, idealmente, fornecer a reprodução suficiente de uma oclusão estática e dinâmica do paciente para permitir que o laboratório produza uma restauração que esteja na harmonia com o sistema mastigatório do paciente. Os autores concluíram que o articulador predominantemente recomendado pelas escolas de Odontologia para a maioria dos procedimentos foi o tipo semi-ajustável por causa de seu elevado grau de flexibilidade, combinado com a sua relativa facilidade de uso.

Baseado nos dados e pesquisas da literatura citados, pode-se observar que existe um consenso entre autores no que se refere à transferência exata da relação maxila/crânio ser de fundamental importância para a correta montagem dos modelos no articulador. A correta execução deste procedimento inicia-se com a montagem do modelo superior no articulador, para a qual necessitamos do registro do garfo de mordida, a fixação e transferência do arco facial.

Um bom aprendizado e treinamento deste procedimento é iniciado durante a graduação em Odontologia, e desde então, o profissional consciente observa os resultados que 
obtém em função da sua capacitação e experiências vividas. Porém, durante o processo ensino/aprendizado, estudantes incorrem em erros involuntários e também se deparam com diferentes técnicas de execução do mesmo procedimento.

Ao longo de vários anos de atividades acadêmicas, professores da Faculdade de Odontologia de Ribeirão Preto notaram que pequenos erros, ou seja, pequenas inclinações do garfo de mordida para anterior ou para posterior em relação ao plano oclusal do paciente, são introduzidas na tomada do arco facial de forma realmente involuntárias.

A alta freqüência destes pequenos erros ou inclinações gerou dúvidas sobre sua influência na transferência do conjunto garfo de mordida/arco facial tanto para o articulador semi-ajustável arcon como para o não arcon, que são os dois tipos de articuladores semiajustáveis usados na prática clínica, assim como sobre a capacidade do articulador de compensar ou não este erro involuntariamente introduzido no procedimento. 
Diante dos fatos observados em ambiente acadêmico durante os procedimentos de tomada do arco facial e transferência para o articulador, este trabalho foi realizado com o intuito de avaliar a influência das inclinações do garfo de mordida para anterior e para posterior em relação ao plano oclusal durante a tomada do arco facial, na montagem do modelo maxilar em articulador semi-ajustável do tipo arcon e do tipo não-arcon. 
Para a realização deste trabalho, foram selecionados aleatoriamente 20 pacientes, alunos pós-graduandos da Faculdade de Odontologia de Ribeirão Preto da Universidade de São Paulo, sendo dez pacientes do sexo feminino e dez pacientes do sexo masculino, com idades entre 25 e 35 anos e todos com dentição permanente completa.

Realizou-se a moldagem do arco maxilar dos pacientes com moldeira de estoque lisa de inox (Tecnodent, São Paulo, S.P., Brasil) e hidrocolóide irreversível (Jeltrate, Dentsply Ind. e Comércio Ltda. Petrópolis, R.J., Brasil). Os modelos foram confeccionados, na região dos dentes, em gesso tipo IV (Durone, Dentsply, Ind. e Comércio Ltda., Petrópolis, R.J., Brasil) e na base, com gesso tipo III (Durone, Dentsply, Ind. e Comércio Ltda., Petrópolis, R.J., Brasil).

Em cada modelo foram realizadas duas marcações com grafite 0,7 mm (Faber-Castell, São Paulo, S.P., Brasil), uma na aresta vestibular do canino direito e outra na aresta vestibular da cúspide mésio-vestibular do primeiro molar direito (Fig. 1).

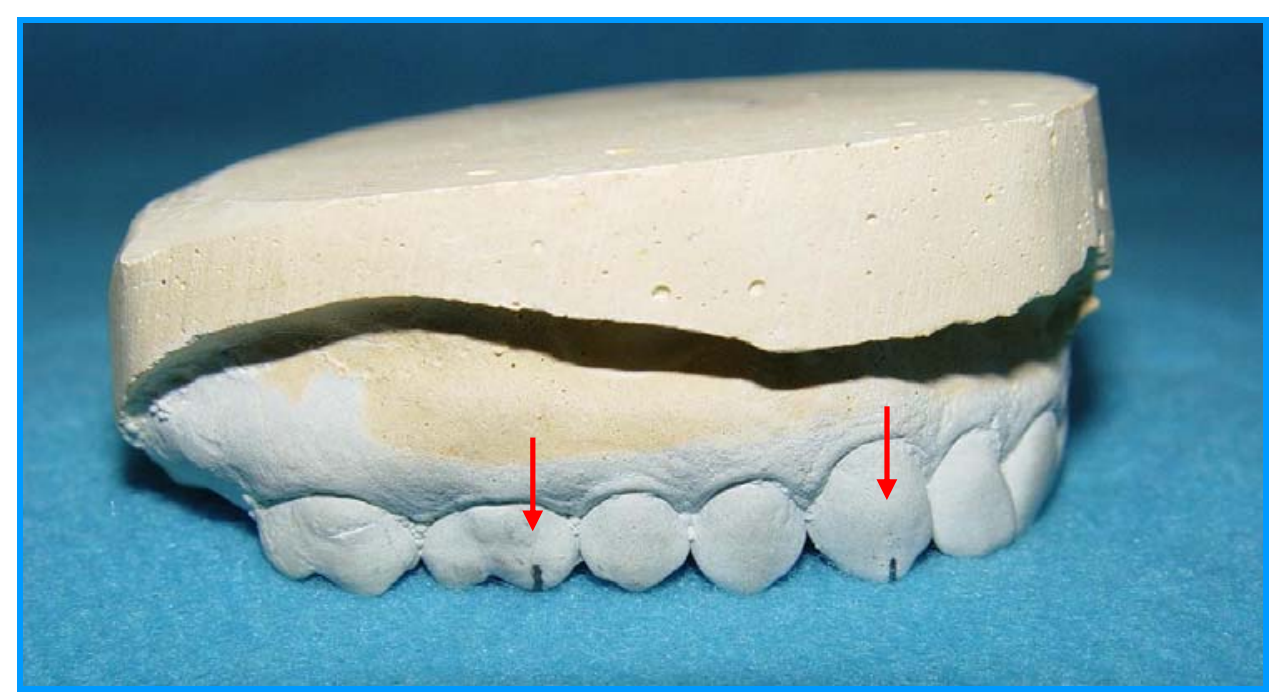

Figura 1. Marcações realizadas nos modelos com grafite $0,7 \mathrm{~mm}$, uma na aresta vestibular do canino direito e outra na aresta vestibular da cúspide mésio-vestibular do primeiro molar direito. 
Em cada paciente realizou-se o mesmo procedimento que se descreve a seguir: godiva de baixa fusão (Kerr Manufacturing Company, Califórnia, USA) foi inicialmente plastificada e colocada em três regiões (molares direitos, molares esquerdos e incisivos) de um garfo de mordida (acessório do arco facial), que é intercambiável tanto para o articulador semi-ajustável do tipo arcon Gnatus 8600 como para o articulador semi-ajustável do tipo nãoarcon Gnatus JP 30 (Equipamentos Médico-Odontológicos Ltda., Ribeirão Preto, São Paulo, Brasil), que são os dois tipos de articuladores usados na pesquisa (Figs. 2 e 3).

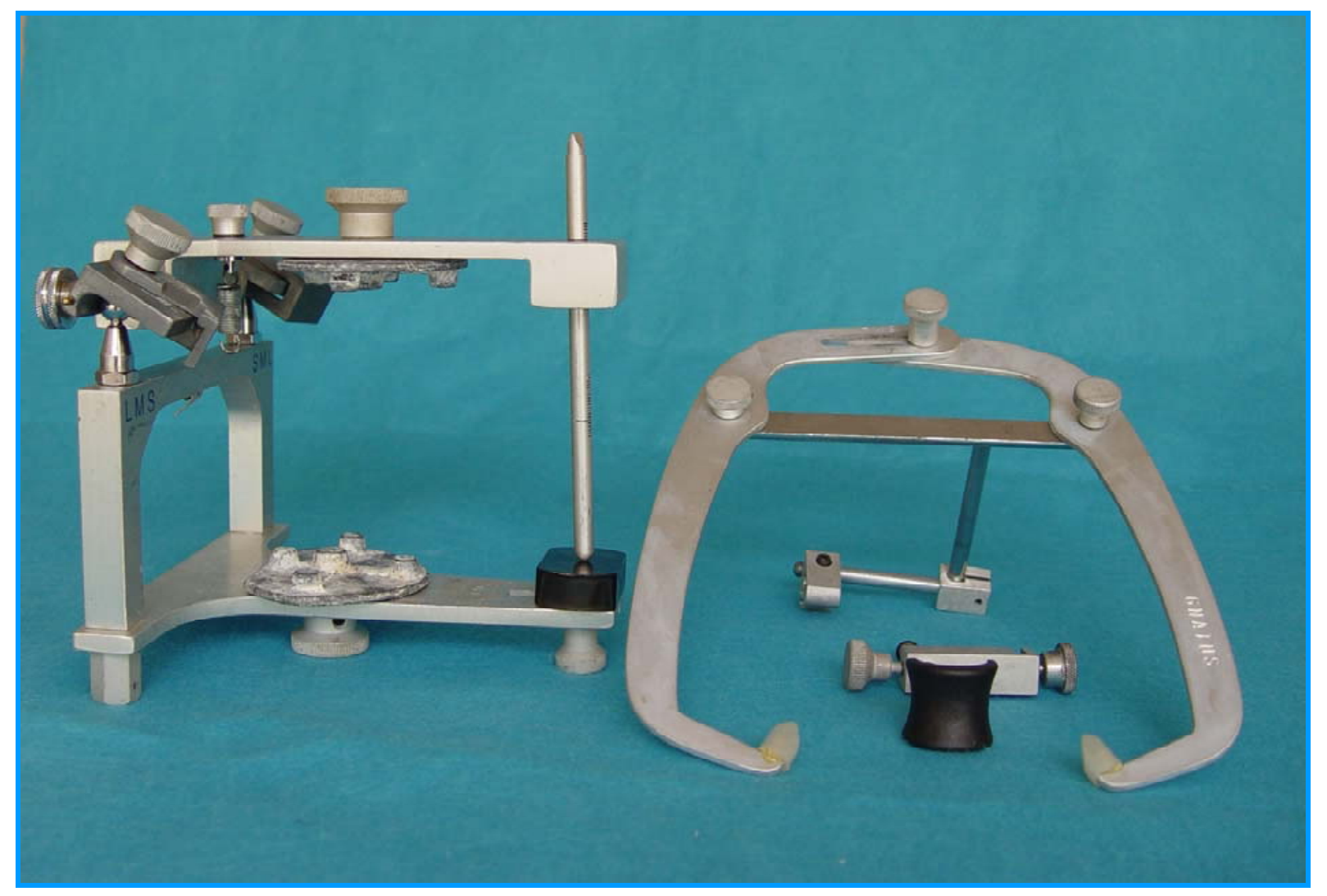

Figura 2. Articulador semi-ajustável do tipo arcon e seu respectivo arco facial. 


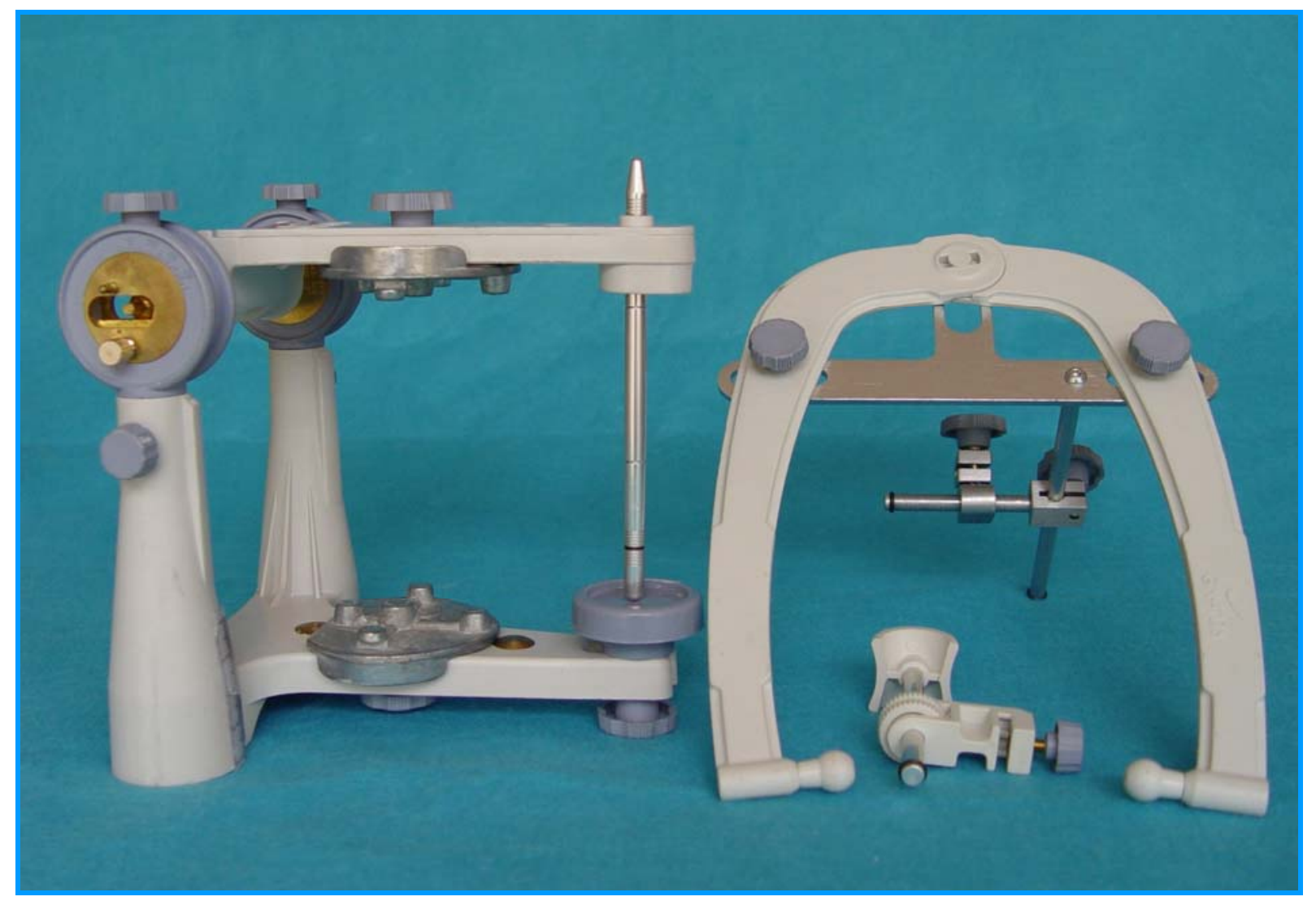

Figura 3. Articulador semi-ajustável do tipo não-arcon e seu respectivo arco facial.

O modelo maxilar, previamente hidratado, foi então posicionado sobre a godiva de baixa fusão plastificada, de forma suave até a obtenção da impressão das pontas de cúspides e borda incisal dos dentes citados, de maneira que o garfo de mordida estivesse paralelo ao plano oclusal do modelo (Fig. 4). 


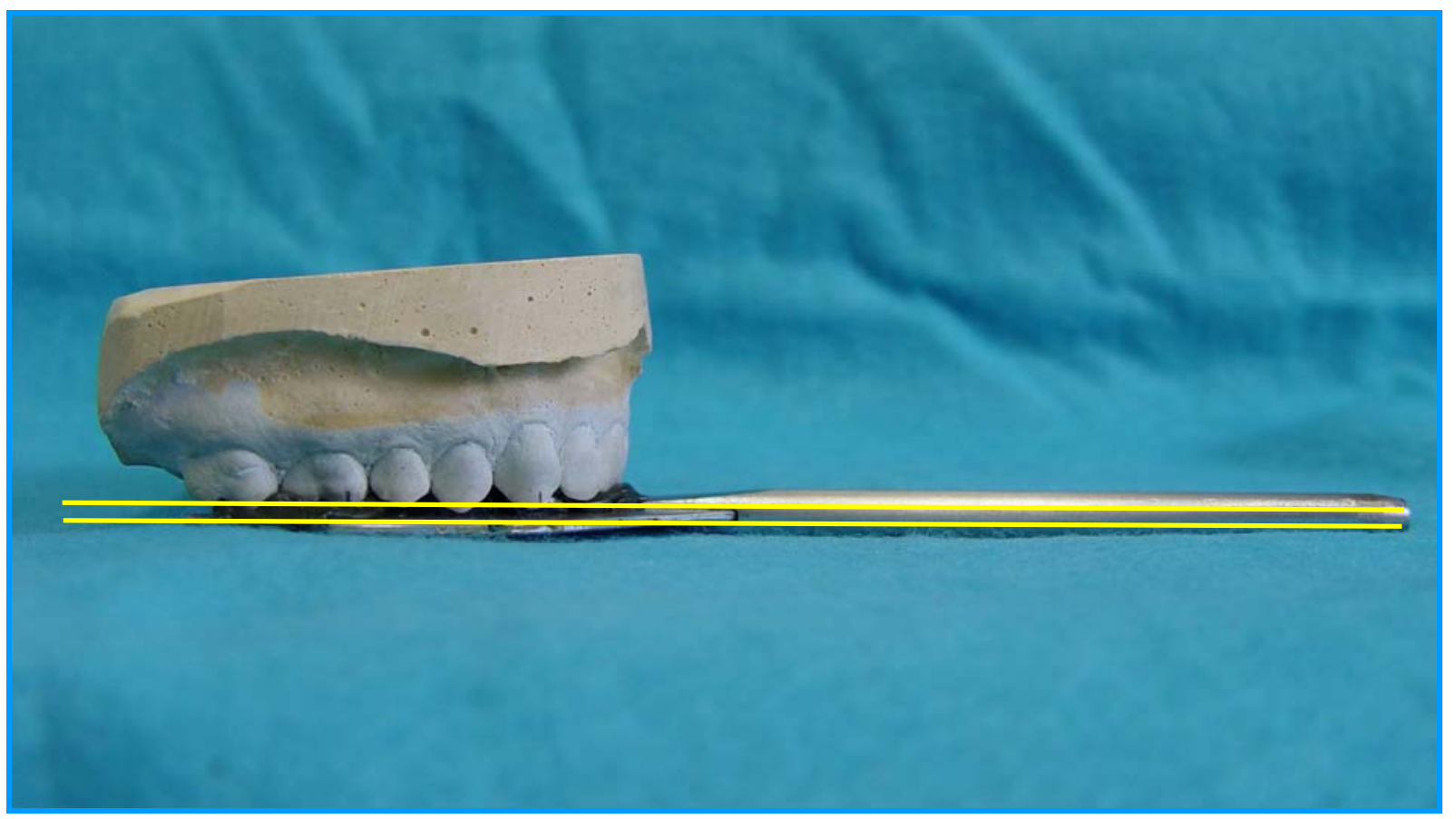

Figura 4. Garfo de mordida paralelo ao plano oclusal do modelo.

Com as godivas do garfo de mordida nesta posição, realizou-se a tomada do arco facial do articulador do tipo arcon Gnatus 8600 no paciente. O conjunto garfo de mordida/arco facial foi então posicionado no ramo superior do articulador que, por sua vez, foi acoplado ao ramo inferior, o qual estava fixado num suporte especial para os registros fotográficos. Este suporte permitiu a padronização da distância da máquina fotográfica digital Sony Cyber-Shot DSC-F717 (Sony Corporation,Tóquio, Japão) ao articulador (Fig. 5). 


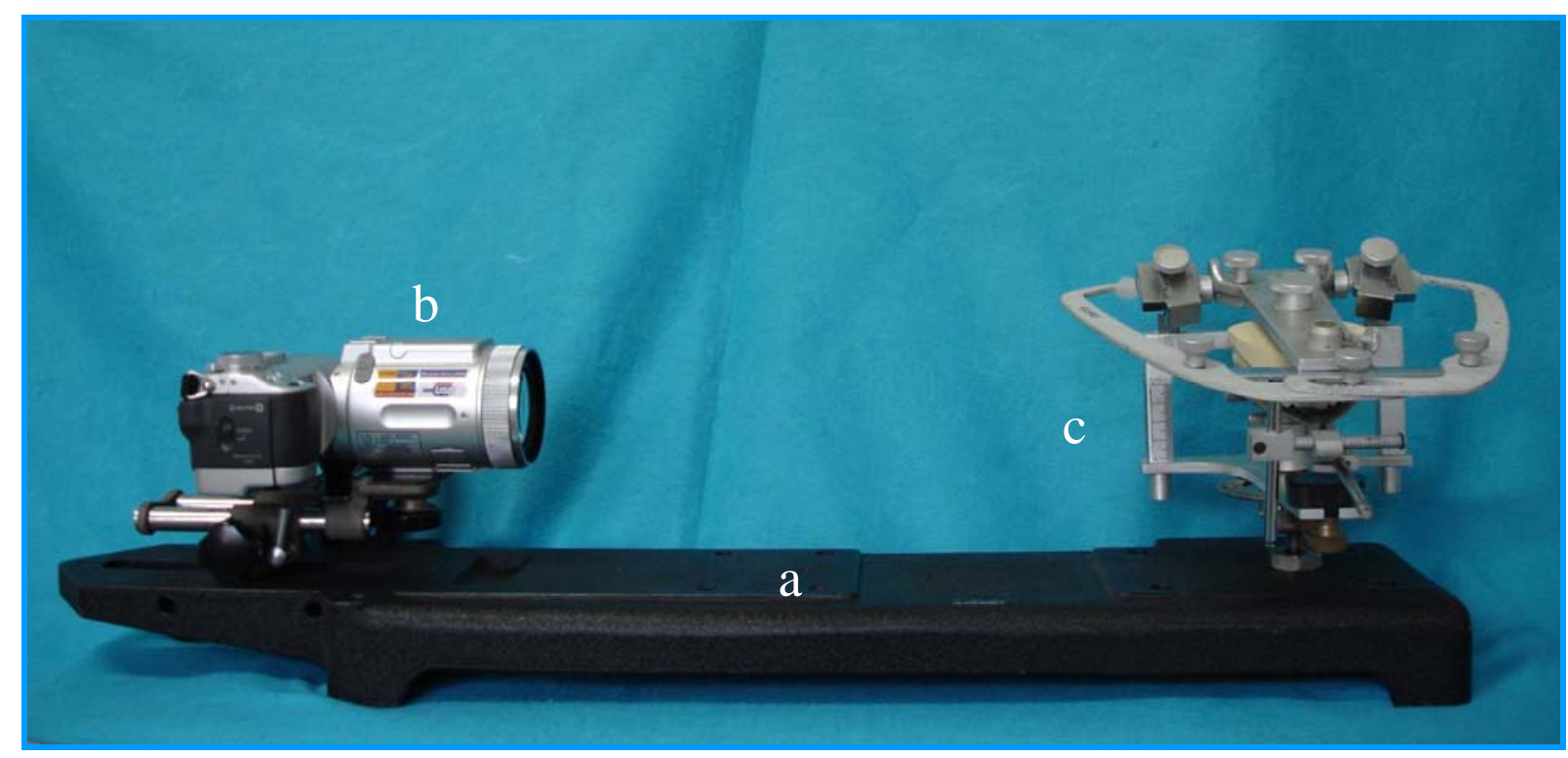

Figura 5. Suporte (a) para manutenção da distância padronizada entre a câmara fotográfica (b) e o conjunto articulador arcon/arco facial (c). Vista do dispositivo montado para registro lateral.

Com o garfo de mordida assim preparado (paralelo ao plano oclusal) foram realizadas cinco tomadas do arco facial do articulador arcon e conseqüentes transferências para o articulador arcon e a cada transferência as respectivas fotografias foram executadas.

Conforme verificado na Figura 5, os registros fotográficos foram realizados com vista lateral para a obtenção das medidas, a serem descritas adiante.

A seguir, foram realizadas mais cinco tomadas do arco facial no paciente com o garfo de mordida paralelo ao plano oclusal, sendo que desta vez foi utilizado o arco facial do articulador não-arcon e conseqüentes transferências para o articulador não-arcon e a cada transferência as respectivas fotografias (Fig. 6).

O articulador semi-ajustável do tipo não-arcon, por sua vez, necessitou da confecção de um apoio para o prolongamento do arco facial (haste vertical localizada na porção anterior do arco facial). Diferentemente do que acontece com o articulador semi-ajustável arcon, aquele modelo apóia-se na superfície da bancada sobre a qual está posicionado, enquanto o modelo arcon tem a haste do garfo de mordida escorado na própria mesa guia incisal, durante 
a transferência. Devido a esta característica do articulador semi-ajustável não-arcon, um apoio metálico foi fixado lateralmente (à esquerda, em vista frontal) no ramo inferior do articulador, de forma a reproduzir tanto a altura quanto o plano suposto da bancada de trabalho sugerida pela fixação do aparelho no suporte para registro fotográfico (Fig. 6d).

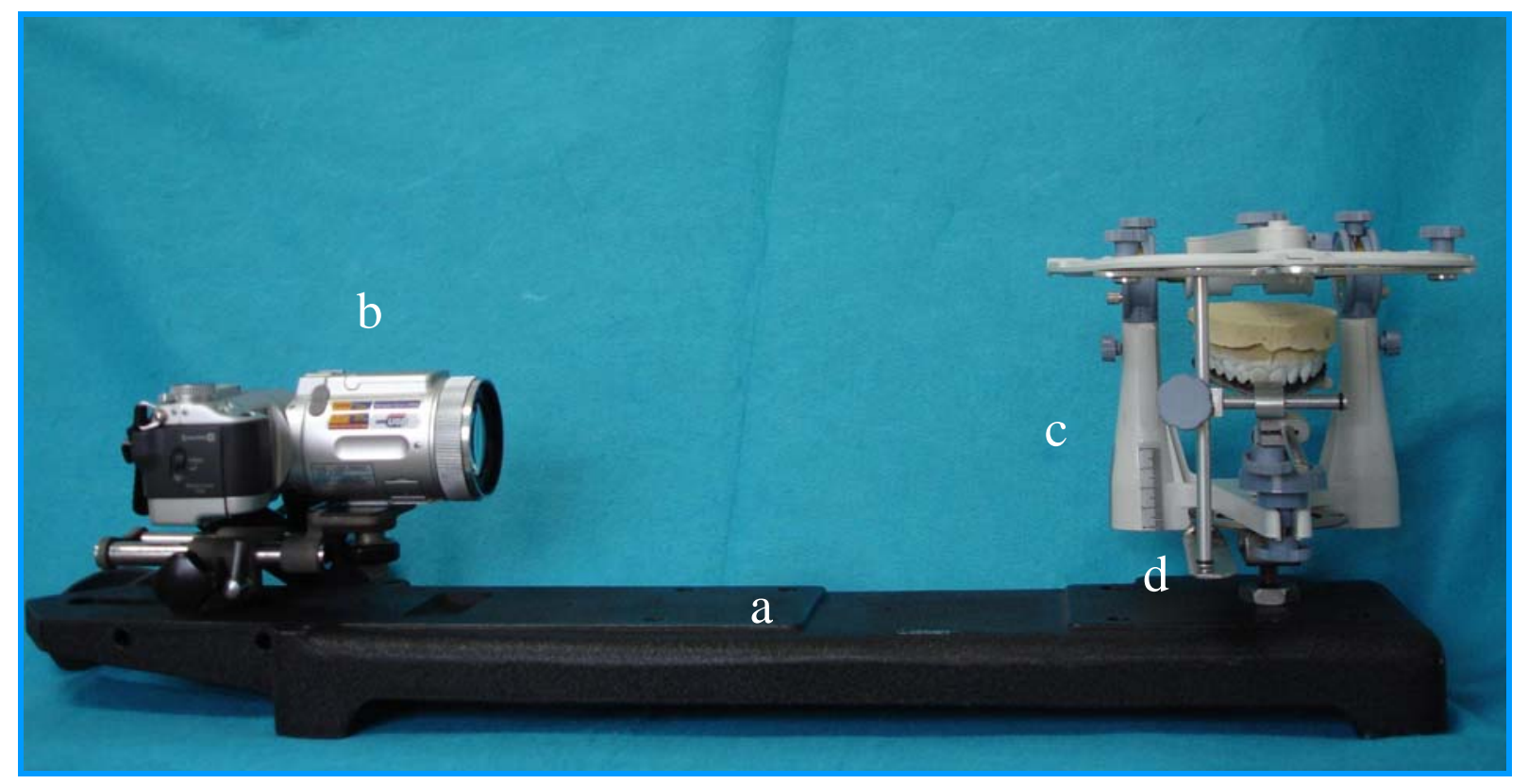

Figura 6. Suporte (a) para manutenção da distância padronizada entre a câmara fotográfica (b) e o conjunto articulador não-arcon/arco facial (c); apoio (d) do prolongamento do arco facial. Vista do dispositivo montado para registro lateral.

Após esta etapa, novas porções de godivas foram posicionadas no garfo de mordida, colocadas nas mesmas regiões citadas anteriormente. No entanto, o garfo de mordida foi posicionado inclinado para anterior em relação ao plano oclusal, de maneira que tivesse uma espessura maior de godiva na região dos dentes anteriores. Foi estabelecida uma inclinação de aproximadamente $5^{\circ}$, medido através de um transferidor plástico de $180^{\circ}$ simples (Indústria Bandeirante, São Paulo, S.P., Brasil), como pode ser observado na Figura 7. Com a godiva nesta posição, foram realizadas cinco tomadas com o arco facial do articulador arcon nos 
pacientes e conseqüentes transferências para o aparelho e seus registros fotográficos. A mesma seqüência foi realizada para o articulador não-arcon.

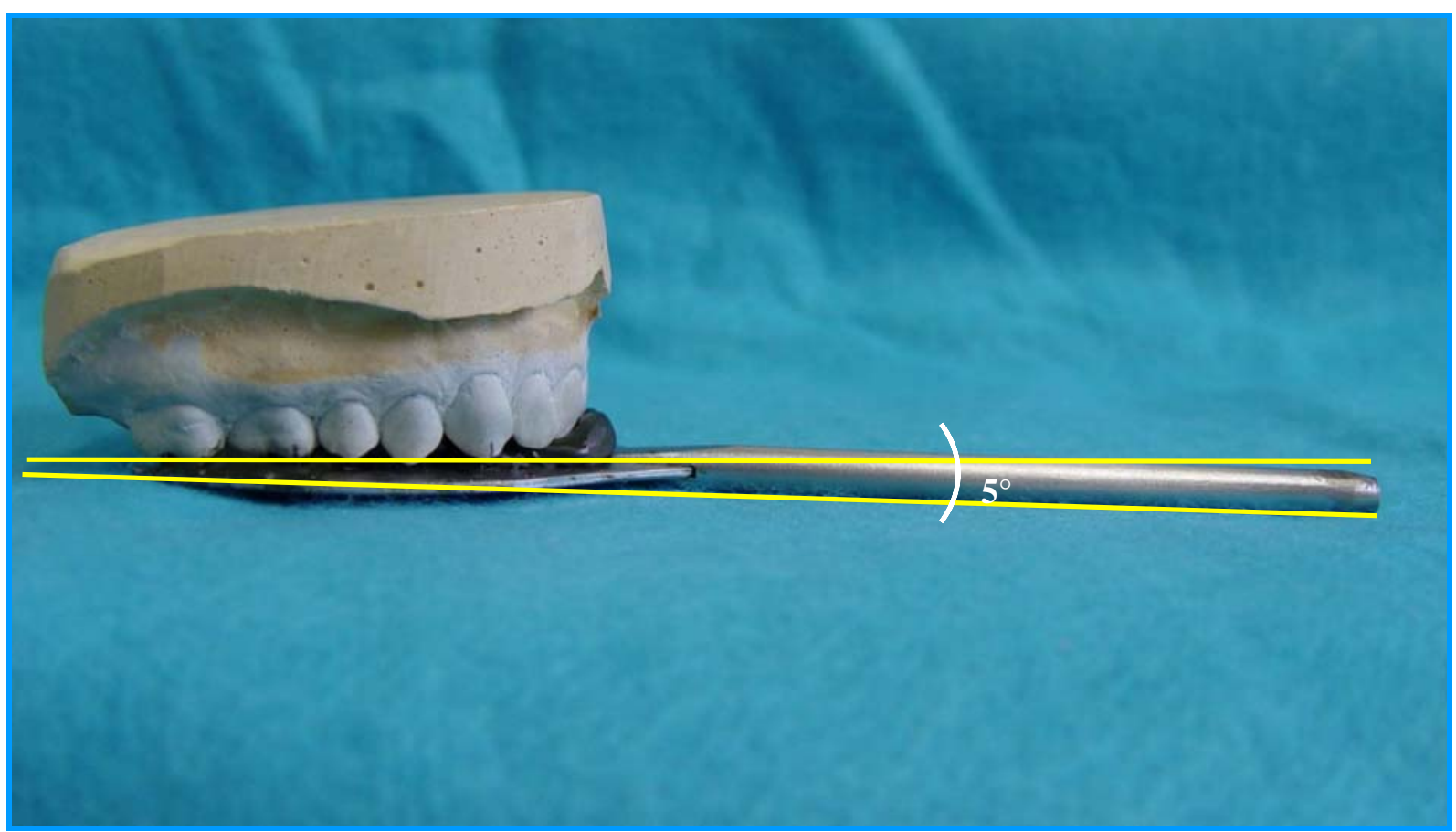

Figura 7. Garfo de mordida inclinado para anterior.

Da mesma maneira como mencionado anteriormente, novas porções de godiva foram posicionadas no garfo de mordida e, desta vez, o garfo de mordida foi posicionado inclinado para posterior em relação ao plano oclusal, de maneira que tivesse uma espessura maior de godiva na região dos dentes posteriores, também em aproximadamente $5^{\circ}$ (Fig. 8). Com as godivas nesta posição foram realizadas outras cinco tomadas do arco facial arcon e cinco tomadas do arco facial não-arcon nos pacientes e conseqüentes transferências para seus respectivos articuladores, e também os registros fotográficos. 


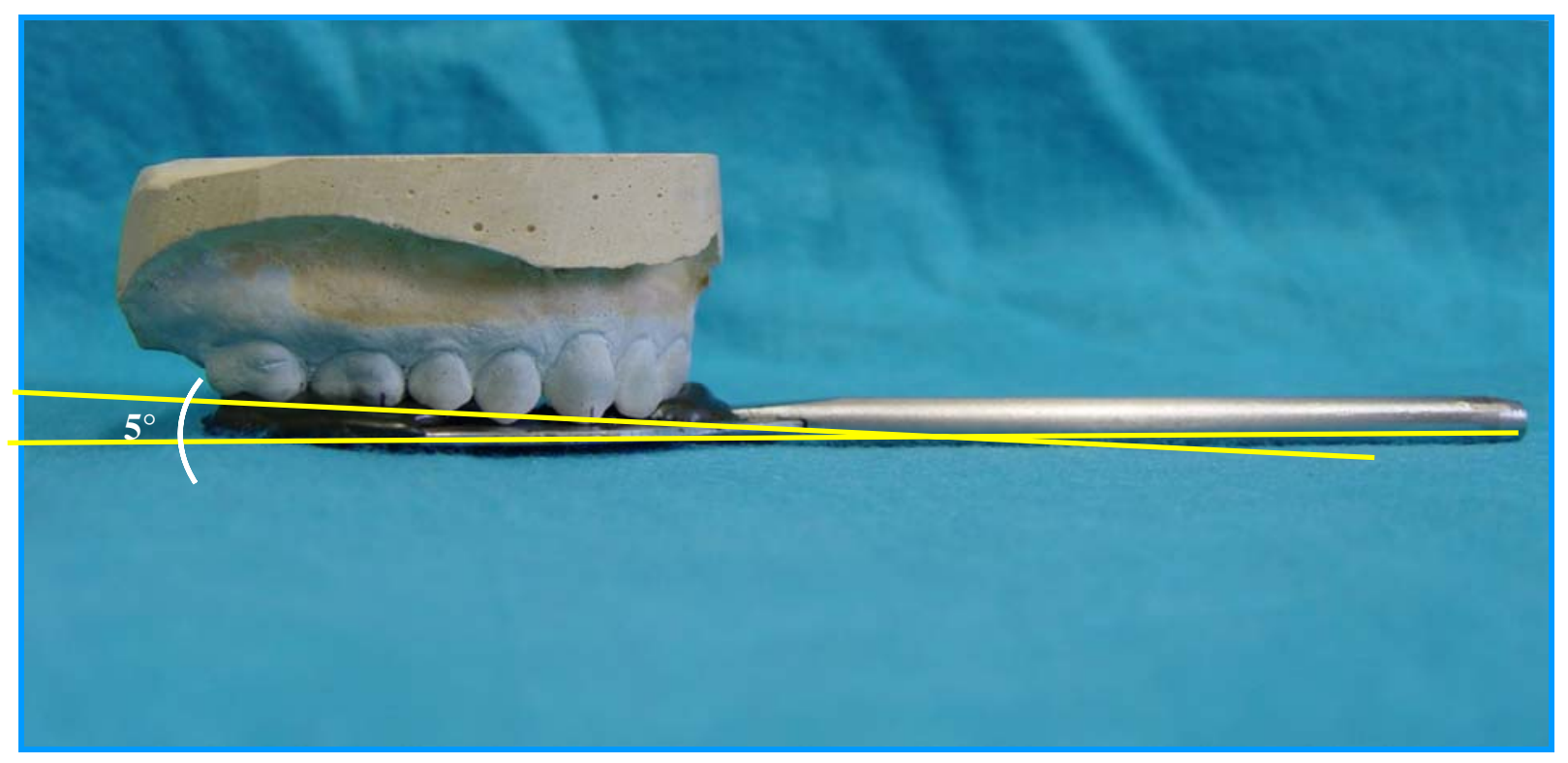

Figura 8. Garfo de mordida inclinado para posterior.

Para cada paciente foram realizadas então, quinze tomadas do arco facial, sendo cinco tomadas com o garfo de mordida paralelo ao plano oclusal, cinco tomadas com o garfo de mordida inclinado para anterior em relação ao plano oclusal e cinco tomadas com o garfo de mordida inclinado para posterior em relação ao plano oclusal, isto para cada articulador, o do tipo arcon e o do tipo não-arcon, totalizando então trinta tomadas do arco facial.

Os registros fotográficos foram armazenadas e analisadas com o software Auto CAD 2004 (Autodesk, Califórnia, USA), para o traçado de linhas de referências.

A partir dos registros fotográficos, foram obtidas cinco medidas, sendo uma angular (ângulo $\alpha$ ), formada pela reta determinada pela ponta de cúspide do dente canino direito e pela ponta da cúspide mésio-vestibular do primeiro molar direito e pela reta vertical que passa pelo cavalete do articulador (aresta posterior) e quatro medidas lineares, a primeira (X1) formada pelo ponto marcado no primeiro molar direito até a reta vertical do cavalete do articulador, a segunda (X2) formada pelo ponto marcado no canino direito até a reta vertical do cavalete do articulador, a terceira (X3) formada pelo ponto marcado no primeiro molar 
direito até a reta horizontal que passa no ramo inferior do articulador e a quarta (X4) formada pelo ponto marcado no canino direito até a reta horizontal que passa pelo ramo inferior do articulador (Figs. 9 e 10).

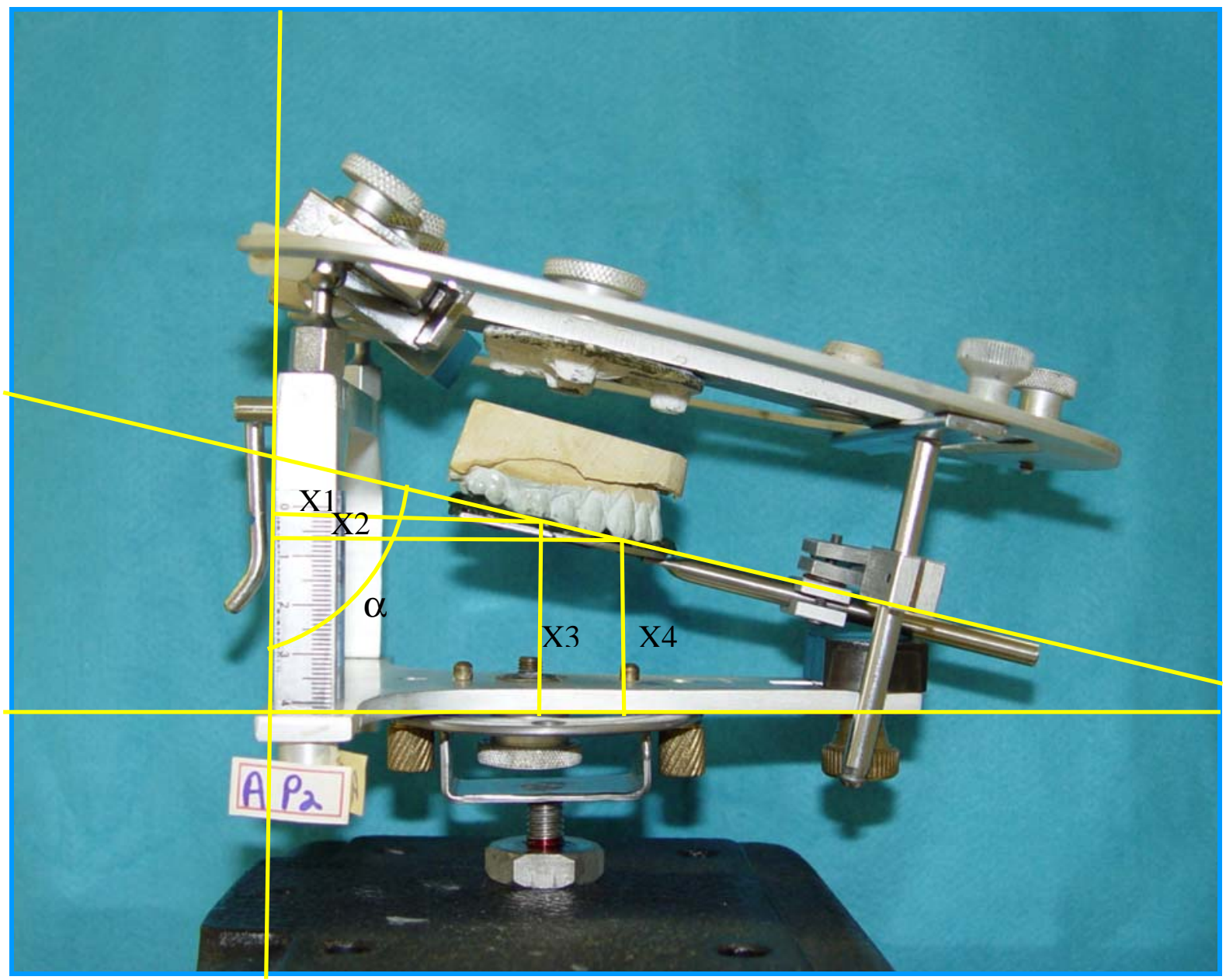

Figura 9. Medida angular e medidas lineares obtidas pelo software Auto CAD a partir de uma fotografia do conjunto arco facial/articulador arcon. $\alpha$ (medida angular formada pela reta determinada pela ponta de cúspide do dente canino direito e pela ponta da cúspide mésiovestibular do primeiro molar direito e pela reta vertical que passa pelo cavalete do articulador); X1 (medida linear formada pelo ponto marcado no primeiro molar direito até a reta vertical do cavalete do articulador); X2 (medida linear formada pelo ponto marcado no canino direito até a reta vertical do cavalete do articulador); X3 (medida linear formada pelo ponto marcado no primeiro molar direito até a reta horizontal que passa no ramo inferior do articulador); X4 (medida linear formada pelo ponto marcado no canino direito até a reta horizontal que passa pelo ramo inferior do articulador). 


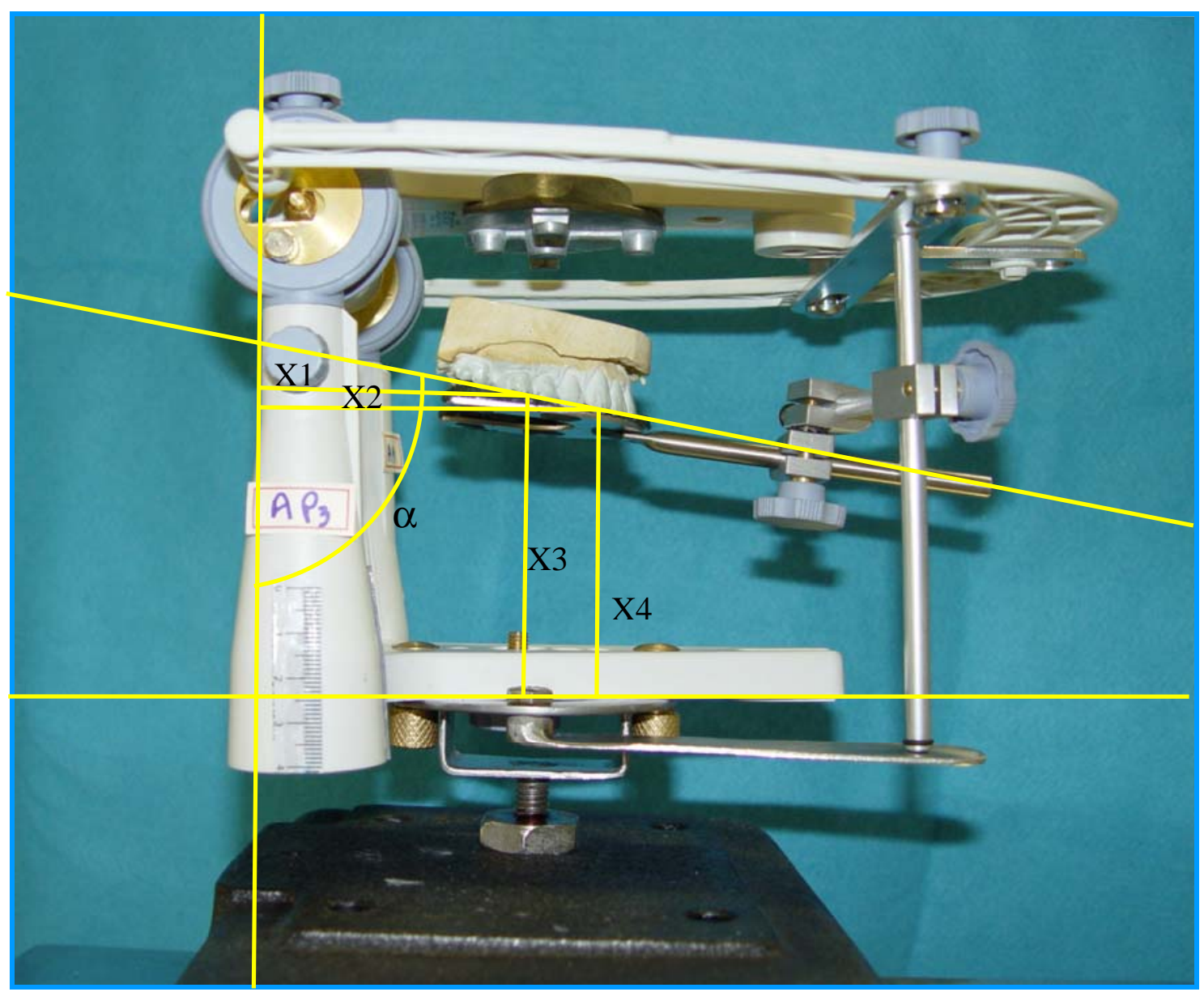

Figura 10. Medida angular e medidas lineares obtidas pelo software Auto CAD a partir de uma fotografia do conjunto arco facial/articulador não-arcon. $\alpha$ (medida angular formada pela reta determinada pela ponta de cúspide do dente canino direito e pela ponta da cúspide mésio-vestibular do primeiro molar direito e pela reta vertical que passa pelo cavalete do articulador); X1 (medida linear formada pelo ponto marcado no primeiro molar direito até a reta vertical do cavalete do articulador); X2 (medida linear formada pelo ponto marcado no canino direito até a reta vertical do cavalete do articulador); X3 (medida linear formada pelo ponto marcado no primeiro molar direito até a reta horizontal que passa no ramo inferior do articulador); X4 (medida linear formada pelo ponto marcado no canino até a reta horizontal que passa pelo ramo inferior do articulador).

De acordo com as Figuras 9 e 10, pode ser observada a presença de uma régua milimetrada acoplada ao cavalete de ambos os tipos de articuladores avaliados. Esta régua milimetrada registrada em todas as fotos realizadas, permitiu a transformação de todas as medidas lineares obtidas pelo programa Auto CAD em centímetros, utilizando-se de uma regra de três simples. 
Os dados obtidos foram tabelados (Apêndices A, B, C, D e E). De cada paciente foi obtida a média das repetições (cinco) para todas as medidas (uma angular e quatro lineares), os quais foram considerados valores originais, e então submetidos à análise estatística.

Todos os procedimentos citados foram realizados por um único operador. 
Como descrito anteriormente, para obtenção de cada medida linear e angular foram realizadas cinco tomadas do arco facial e conseqüentes transferências para cada tipo de articulador arcon e não-arcon, as quais permitiram a obtenção dos valores médios de cada um dos vinte pacientes (Apêndices A, B, C, D e E) a partir de registros fotográficos. Após a obtenção dos valores originais médios, os dados foram inseridos e analisados no software GMC-9.

A distribuição amostral de todas as medidas analisadas revelou-se normal e homogênea, permitindo assim, o uso da Análise de Variância.

Para a medida ângulo (ângulo formado pela reta determinada pela ponta de cúspide do dente canino direito e pela ponta da cúspide mésio-vestibular do primeiro molar direito e pela reta vertical que passa pelo cavalete do articulador) foi realizada a análise de variância a partir dos valores originais médios. Na análise de variância (Tabela 1) evidenciou que no fator de variação inclinação do garfo de mordida (anterior, paralelo e posterior) não houve diferença estatisticamente significante. Para o fator de variação tipos de articuladores (arcon e não-arcon) e na interação entre os dois fatores de variação houve diferença estatisticamente significante $(\mathrm{p}<0,01)$. Foram calculadas as médias amostrais e os desvios-padrão dos fatores de variação (Tabelas 2 e 3) e da interação entre os fatores de variação (Tabela 4) para a medida ângulo. Da Tabela 4 foi construído o gráfico da Figura 11 que demonstra a interação entre os fatores de variação tipos de articuladores versus inclinação do garfo de mordida para a medida angular. 
Tabela 1 - Análise de variância dos dados originais médios para a medida angular.

\begin{tabular}{|c|c|c|c|c|c|}
\hline Fonte de Variação & $\begin{array}{c}\text { Soma de } \\
\text { Quadrados }\end{array}$ & $\begin{array}{l}\text { Graus de } \\
\text { Liberdade }\end{array}$ & $\begin{array}{c}\text { Quadrados } \\
\text { Médios }\end{array}$ & (F) & $\begin{array}{l}\text { Prob. } \\
\text { (H0) }\end{array}$ \\
\hline $\begin{array}{l}\text { Inclinação do garfo de } \\
\text { mordida (I) }\end{array}$ & 53.8875 & 2 & 26.9438 & 1.40 & $25.272 \%^{\text {ns }}$ \\
\hline Resíduo I & 1093.3000 & 57 & 19.1807 & & \\
\hline Tipos de articuladores (A) & 337.6542 & 1 & 337.6542 & 77.45 & $0.0001 \% *$ \\
\hline Interação I x A & 89.8458 & 2 & 44.9229 & 10.30 & $0.032 \% *$ \\
\hline Resíduo II & 248.5000 & 57 & 4.3596 & & \\
\hline Variação total & 1823.1875 & 119 & & & \\
\hline
\end{tabular}

Tabela 2 - Médias amostrais e desvios-padrão da medida angular calculadas para o fator de variação inclinação do garfo de mordida.

\begin{tabular}{cc}
\hline \hline Inclinação do garfo de mordida & Média $\left(^{\circ}\right)$ e desvios-padrão \\
\hline \hline Anterior & $72,157( \pm 4,466)$ \\
Paralelo & $71,452( \pm 3,836)$ \\
Posterior & $70,515( \pm 3,271)$ \\
\hline
\end{tabular}

Símbolos iguais: médias estatisticamente semelhantes

Tabela 3 - Médias amostrais e desvio padrão da medida angular calculadas para o fator de variação tipos de articuladores.

\begin{tabular}{cc}
\hline \hline Tipos de Articuladores & Média $\left({ }^{\circ}\right)$ e desvios-padrão \\
\hline \hline Arcon & $73,052( \pm 2,808)$ \\
Não-arcon & $69,696( \pm 4,158)$ \\
\hline
\end{tabular}

Símbolos diferentes: médias estatisticamente diferentes 
Tabela 4 - Médias amostrais em graus e desvios-padrão da medida angular calculadas para a interação tipos de articuladores x inclinação do garfo de mordida.

\begin{tabular}{cccc}
\hline \hline \multirow{2}{*}{ Tipos de Articuladores } & \multicolumn{2}{c}{ Inclinação do garfo de mordida } \\
& Anterior & Paralelo & Posterior \\
\hline \hline Arcon & $74,992( \pm 2,439)$ & $72,890( \pm 2,288)$ & $71,276( \pm 2,447)$ \\
Não-Arcon & $69,322( \pm 4,251)$ & $70,014( \pm 4,540)$ & $69,754( \pm 3,841)$ \\
\hline \hline
\end{tabular}

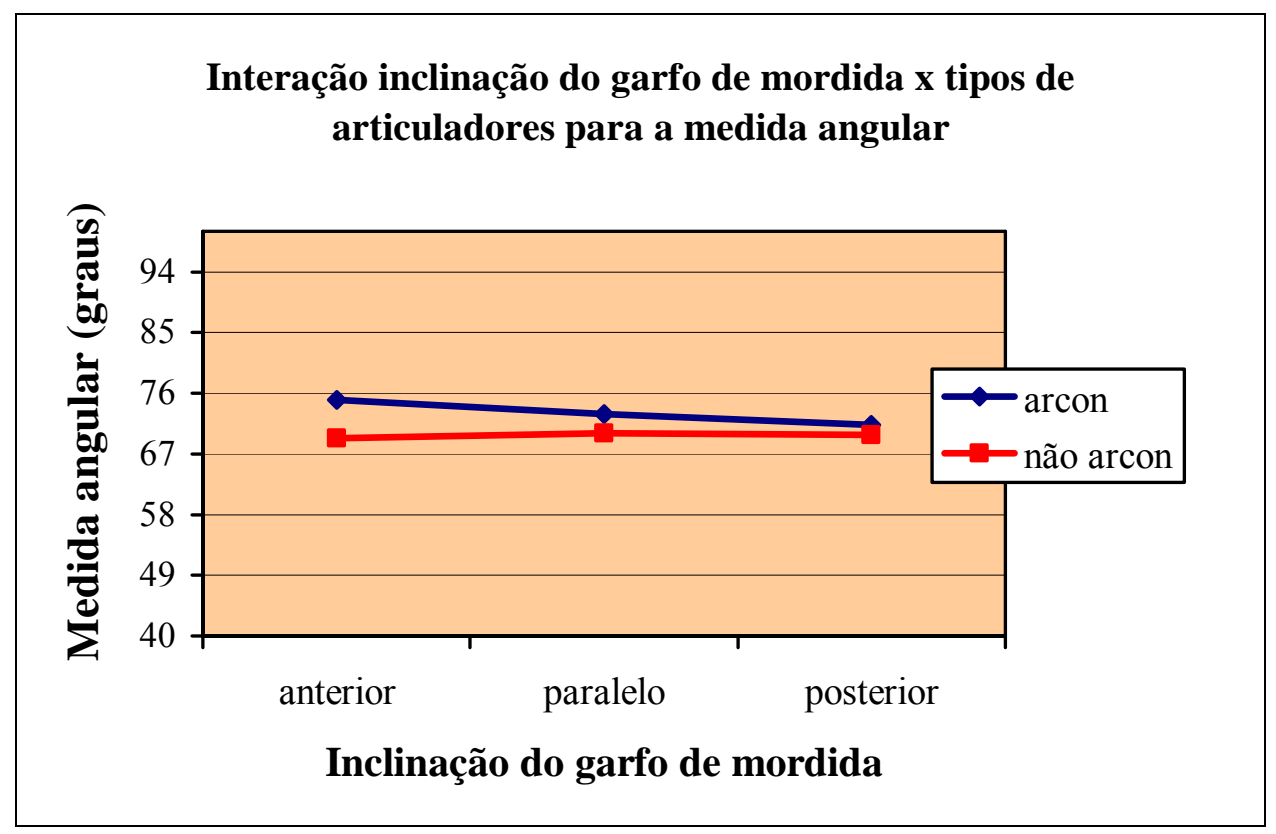

Figura 11. Gráfico da interação entre os fatores de variação inclinação do garfo de mordida $x$ tipos de articuladores da medida ângulo. 
Para a medida X1 (medida linear formada pelo ponto marcado no primeiro molar até a reta vertical do cavalete do articulador) foi realizada a análise de variância a partir dos valores originais médios. A análise de variância (Tabela 5) demonstrou que no fator de variação inclinação do garfo de mordida (anterior, paralelo e posterior) não houve diferença estatisticamente significante. Houve diferença estatisticamente significante $(p<0,01)$ no fator de variação tipos de articuladores (arcon e não-arcon) e na interação entre os fatores de variação. Foram calculadas as médias amostrais e os desvios-padrão dos fatores de variação (Tabelas 6 e 7) e para a interação entre os fatores (Tabela 8). O gráfico da Figura 12 construído a partir da Tabela 8 ilustra a interação entre os fatores de variação para a medida $\mathrm{X} 1$.

Tabela 5 - Análise de variância dos dados originais médios para a medida X1.

\begin{tabular}{lcccccc}
\hline \hline Fonte de Variação & $\begin{array}{c}\text { Soma de } \\
\text { Quadrados }\end{array}$ & $\begin{array}{c}\text { Graus de } \\
\text { Liberdade }\end{array}$ & $\begin{array}{c}\text { Quadrados } \\
\text { Médios }\end{array}$ & (F) & $\begin{array}{c}\text { Prob. } \\
\text { (Ho) }\end{array}$ \\
\hline \hline $\begin{array}{l}\text { Inclinação do garfo } \\
\text { mordida (I) }\end{array}$ & de & 0.7051 & 2 & 0.3526 & 1.66 & $19.788 \%$ \\
Resíduo I & 12.1201 & 57 & 0.2126 & & \\
Tipos de articuladores (A) & 135.2987 & 1 & 135.2987 & 4587.48 & $0.0001 \% *$ \\
Interação I x A & 0.4882 & 2 & 0.2441 & 8.28 & $0.1002 \% *$ \\
Resíduo II & 1.6811 & 57 & 0.0295 & & \\
Variação total & 150.2932 & 119 & & & \\
\hline \hline
\end{tabular}


Tabela 6 - Médias amostrais e desvios-padrão da medida X1 calculadas para o fator de variação inclinação do garfo de mordida.

\begin{tabular}{cc}
\hline \hline Inclinação do garfo de mordida & Média (cm) e desvios-padrão \\
\hline \hline Anterior & $3,790( \pm 1,217)$ \\
Paralelo & $3,692( \pm 1,108)$ \\
Posterior & $3,603( \pm 1,060)$ \\
\hline
\end{tabular}

Símbolos iguais: médias estatisticamente semelhantes

Tabela 7 - Médias amostrais e desvios-padrão da medida X1 calculadas para o fator de variação tipos de articuladores.

\begin{tabular}{cc}
\hline \hline Tipos de Articuladores & Média (cm) e desvios-padrão \\
\hline \hline Arcon & $4,757( \pm 0,357)$ \\
Não-arcon & $2,633( \pm 0,355)$ \\
\hline
\end{tabular}

Símbolos diferentes: médias estatisticamente diferentes

Tabela 8 - Médias amostrais em cm e desvios-padrão da medida X1 calculadas para a interação tipos de articuladores x inclinação do garfo de mordida.

\begin{tabular}{cccc}
\hline \hline \multirow{2}{*}{ Tipos de Articuladores } & \multicolumn{2}{c}{ Inclinação do garfo de mordida } \\
& Anterior & Paralelo & Posterior \\
\hline \hline Arcon & $4,937( \pm 0,378)$ & $4,737( \pm 0,312)$ & $4,596( \pm 0,305)$ \\
Não-Arcon & $2,643( \pm 0,356)$ & $2,647( \pm 0,354)$ & $2,609( \pm 0,372)$ \\
\hline \hline
\end{tabular}




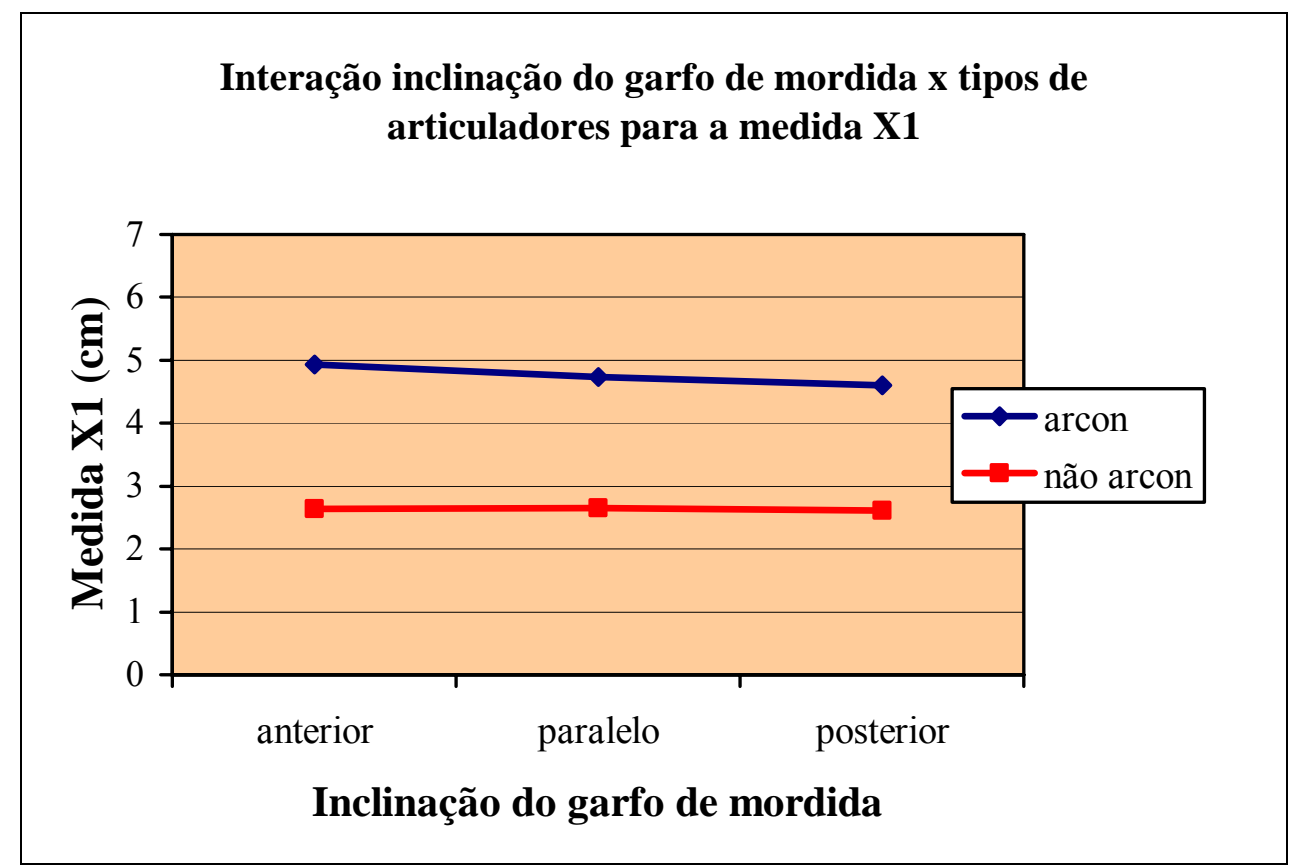

Figura 12. Gráfico da interação entre os fatores de variação inclinação do garfo de mordida $\mathrm{x}$ tipos de articuladores da medida $\mathrm{X} 1$.

Para a medida X2 (medida linear formada pelo ponto marcado no canino até a reta vertical do cavalete do articulador) foi realizada a análise de variância a partir dos valores originais médios. A análise de variância (Tabela 9) revelou que não houve diferença estatisticamente significante entre o fator de variação inclinação do garfo de mordida (anterior, paralelo e posterior) e que houve diferença estatisticamente significante $(\mathrm{p}<0,01)$ entre o fator de variação tipos de articuladores (arcon e não-arcon) e na interação dos dois fatores de variação. Foram calculadas as médias amostrais e os desvios-padrão dos fatores de variação (Tabelas 10 e 11) e também para a interação destes fatores (Tabela 12) para a medida X2. O gráfico da Figura 13 construído a partir da Tabela 12 demonstra a interação entre os dois fatores de variação. 
Tabela 9 - Análise de variância dos dados originais médios para a medida X2.

\begin{tabular}{|c|c|c|c|c|c|}
\hline Fonte de Variação & $\begin{array}{c}\text { Soma de } \\
\text { Quadrados }\end{array}$ & $\begin{array}{c}\text { Graus de } \\
\text { Liberdade }\end{array}$ & $\begin{array}{c}\text { Quadrados } \\
\text { Médios }\end{array}$ & (F) & $\begin{array}{l}\text { Prob. } \\
\text { (H0) }\end{array}$ \\
\hline $\begin{array}{l}\text { Inclinação do garfo de } \\
\text { mordida (I) }\end{array}$ & 0.8852 & 2 & 0.4426 & 1.77 & $17.696 \%{ }^{\text {ns }}$ \\
\hline Resíduo I & 14.2154 & 57 & 0.2494 & & \\
\hline Tipos de articuladores (A) & 136.4755 & 1 & 136.4755 & 3384.23 & $0.0001 \% *$ \\
\hline Interação I x A & 0.7424 & 2 & 0.3712 & 9.21 & $0.0582 \% *$ \\
\hline Resíduo II & 2.2986 & 57 & 0.0403 & & \\
\hline Variação total & 154.6172 & 119 & & & \\
\hline
\end{tabular}

Tabela 10 - Médias amostrais e desvios-padrão da medida X2 calculadas para o fator de variação inclinação do garfo de mordida.

\begin{tabular}{cc}
\hline \hline Inclinação do garfo de mordida & Média (cm) e desvios-padrão \\
\hline \hline Anterior & $6,330( \pm 1,248)$ \\
Paralelo & $6,236( \pm 1,129)$ \\
Posterior & $6,120( \pm 1,052)$ \\
\hline
\end{tabular}

Símbolos iguais: médias estatisticamente semelhantes

Tabela 11 - Médias amostrais e desvios-padrão da medida X2 calculadas para o fator de variação tipos de articuladores.

\begin{tabular}{cc}
\hline \hline Tipos de Articuladores & Média (cm) e desvios-padrão \\
\hline \hline Arcon & $7,295( \pm 0,380)$ \\
Não-arcon & $5,162( \pm 0,403)$ \\
\end{tabular}

Símbolos diferentes: médias estatisticamente diferentes 
Tabela 12 - Médias amostrais em cm e desvios-padrão da medida X2 calculadas para a interação tipos de articuladores x inclinação do garfo de mordida.

\begin{tabular}{cccc}
\hline \hline \multirow{2}{*}{ Tipos de Articuladores } & \multicolumn{2}{c}{ Inclinação do garfo de mordida } \\
& Anterior & Paralelo & Posterior \\
\hline \hline Arcon & $7,496( \pm 0,391)$ & $7,294( \pm 0,336)$ & $7,094( \pm 0,313)$ \\
Não-Arcon & $5,163( \pm 0,425)$ & $5,178( \pm 0,384)$ & $5,145( \pm 0,419)$ \\
\hline \hline
\end{tabular}

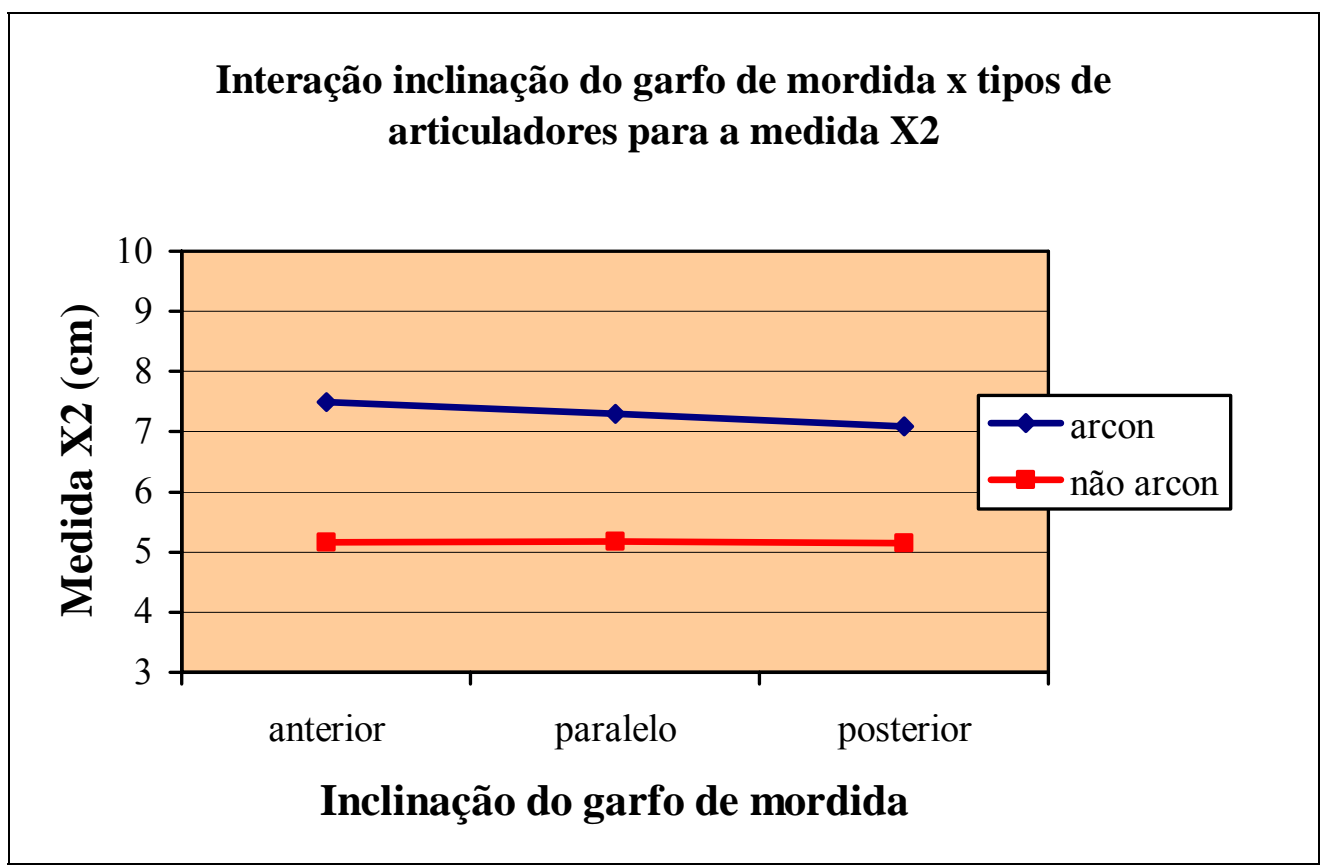

Figura 13. Gráfico da interação entre os fatores inclinação do garfo de mordida $x$ tipos de articuladores da medida X1. 
Para a medida X3 (medida linear formada pelo ponto marcado no primeiro molar até a reta horizontal que passa no ramo inferior do articulador) também foi realizada a análise de variância a partir dos valores originais médios. De acordo com a análise de variância (Tabela 13) foi evidenciado que no fator de variação inclinação do garfo de mordida (anterior, paralelo e posterior) não houve diferença estatisticamente significante. No fator de variação tipos de articuladores (arcon e não-arcon) e na interação dos fatores de variação inclinação do garfo de mordida e tipos de articuladores houve diferença estatisticamente significante $(\mathrm{p}<$ 0,01). As Tabelas 14 e 15 revelaram as médias amostrais e desvios-padrão dos fatores de variação, assim como a Tabela 16 mostrou as médias amostrais e desvios-padrão da interação dos fatores de variação para a medida X3. O gráfico da Figura 14 traduz a interação entre tipos de articuladores e inclinação do garfo de mordida construído a partir da Tabela 16.

Tabela 13 - Análise de variância dos dados médios para a medida X3.

\begin{tabular}{|c|c|c|c|c|c|}
\hline Fonte de Variação & $\begin{array}{c}\text { Soma de } \\
\text { Quadrados }\end{array}$ & $\begin{array}{l}\text { Graus de } \\
\text { Liberdade }\end{array}$ & $\begin{array}{c}\text { Quadrados } \\
\text { Médios }\end{array}$ & (F) & $\begin{array}{l}\text { Prob. } \\
\text { (H0) }\end{array}$ \\
\hline $\begin{array}{l}\text { Inclinação do garfo de } \\
\text { mordida (I) }\end{array}$ & 0.2588 & 2 & 0.1294 & 0.87 & $42.906 \%{ }^{\text {ns }}$ \\
\hline Resíduo I & 8.5142 & 57 & 0.1494 & & \\
\hline Tipos de articuladores (A) & 179.5221 & 1 & 179.5221 & 6026.54 & $0.0001 \% *$ \\
\hline Interação I x A & 0.3811 & 2 & 0.1905 & 6.40 & $0.3469 \% *$ \\
\hline Resíduo II & 1.6979 & 57 & 0.0298 & & \\
\hline Variação total & 190.3740 & 119 & & & \\
\hline
\end{tabular}


Tabela 14 - Médias amostrais e desvios-padrão da medida X3 calculadas para o fator de variação inclinação do garfo de mordida.

\begin{tabular}{cc}
\hline \hline Inclinação do garfo de mordida & Média (cm) e desvios-padrão \\
\hline \hline Anterior & $5,923( \pm 1,215)$ \\
Paralelo & $5,841( \pm 1,260)$ \\
Posterior & $5,814( \pm 1,345)$ \\
\hline
\end{tabular}

Símbolos iguais: médias estatisticamente semelhantes

Tabela 15 - Médias amostrais e desvios-padrão da medida X3 calculadas para o fator de variação tipos de articuladores.

\begin{tabular}{cc}
\hline \hline Tipos de Articuladores & Média (cm) e desvios-padrão \\
\hline \hline Arcon & $4,636( \pm 0,276)$ \\
Não-arcon & $7,082( \pm 0,328)$ \\
\hline \hline
\end{tabular}

Símbolos diferentes: médias estatisticamente diferentes

Tabela 16 - Médias amostrais em cm e desvios-padrão da medida X3 calculadas para a interação tipos de articuladores x inclinação do garfo de mordida.

Tipos de Articuladores

\section{Inclinação do garfo de mordida}

\begin{tabular}{cccc} 
& Anterior & Paralelo & Posterior \\
\hline \hline Arcon & $4,759( \pm 0,241)$ & $4,634( \pm 0,272)$ & $4,515( \pm 0,270)$ \\
Não-Arcon & $7,087( \pm 0,349)$ & $7,047( \pm 0,349)$ & $7,112( \pm 0,296)$ \\
\hline \hline
\end{tabular}




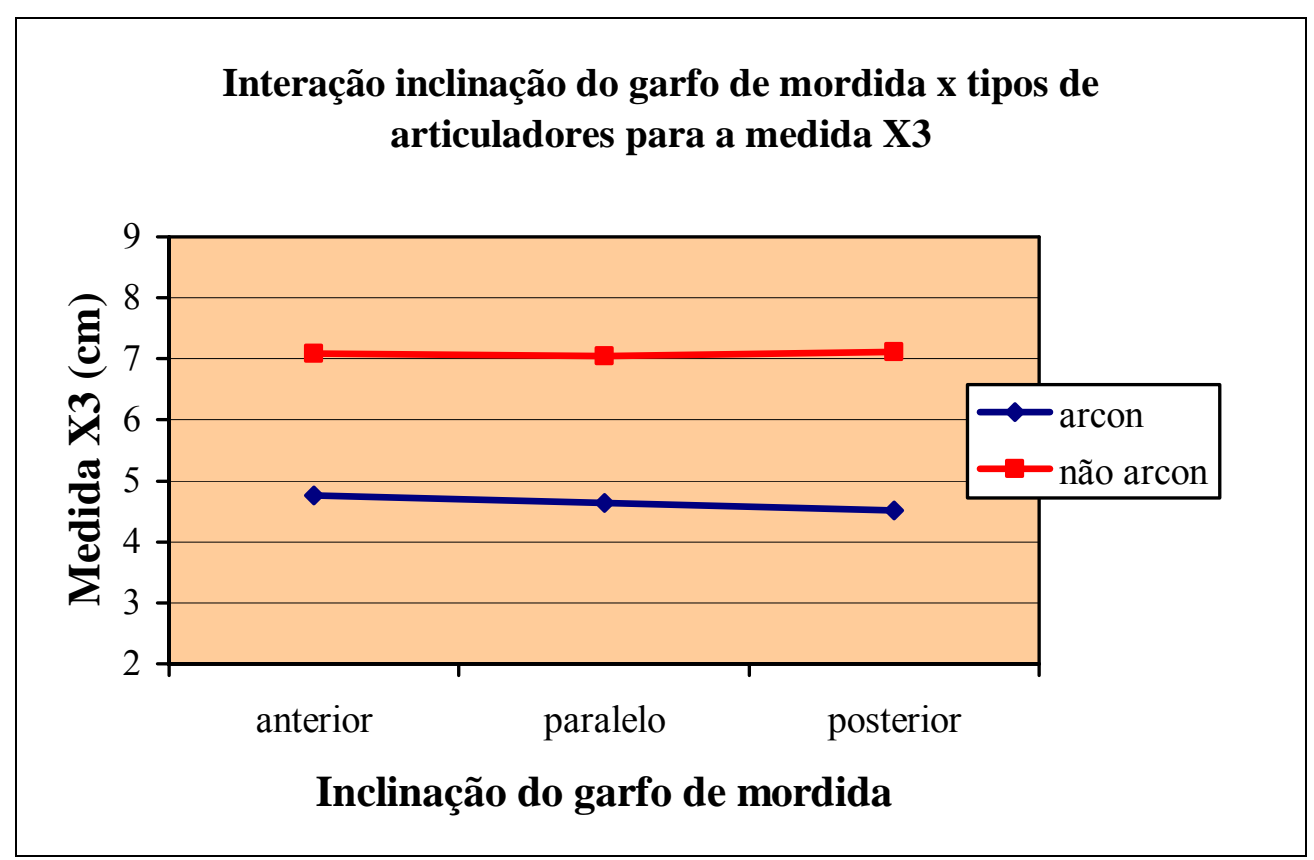

Figura 14. Gráfico da interação entre os fatores de variação inclinação do garfo de mordida $x$ tipos de articuladores da medida X3.

Para a medida X4 (medida linear formada pelo ponto marcado no canino até a reta horizontal que passa pelo ramo inferior do articulador), a análise de variância (Tabela 17) demonstrou que no fator de variação inclinação do garfo de mordida (anterior, paralelo e posterior) não houve diferença estatisticamente significante. No fator tipos de articuladores (arcon e não-arcon) e na interação entre tipos de articuladores e inclinação do garfo de mordida houve diferença estatisticamente significante $(\mathrm{p}<0,01)$. As médias amostrais e desvios-padrão dos fatores de variação para a medida X4 estão reveladas nas Tabelas 18 e 19 e na Tabela 20 estão expostas as médias e desvios-padrão da interação entre os fatores de variação. O gráfico da Figura 15 demonstra a interação entre os fatores de variação construído a partir da Tabela 20 . 
Tabela 17 - Análise de variância dos dados médios para a medida X4.

\begin{tabular}{|c|c|c|c|c|c|}
\hline Fonte de Variação & $\begin{array}{c}\text { Soma de } \\
\text { Quadrados }\end{array}$ & $\begin{array}{l}\text { Graus de } \\
\text { Liberdade }\end{array}$ & $\begin{array}{c}\text { Quadrados } \\
\text { Médios }\end{array}$ & (F) & $\begin{array}{c}\text { Prob. } \\
\text { (H0) }\end{array}$ \\
\hline $\begin{array}{l}\text { Inclinação do garfo de } \\
\text { mordida (I) }\end{array}$ & 0.9082 & 2 & 0.4541 & 2.78 & $6.847 \%^{\mathbf{n s}}$ \\
\hline Resíduo I & 9.2945 & 57 & 0.1631 & & \\
\hline Tipos de articuladores (A) & 162.9145 & 1 & 162.9145 & 2932.70 & $0.0001 \% *$ \\
\hline Interação I x A & 1.0470 & 2 & 0.5235 & 9.42 & $0.0515 \% *$ \\
\hline Resíduo II & 3.1664 & 57 & 0.0556 & & \\
\hline Variação total & 177.3306 & 119 & & & \\
\hline
\end{tabular}

Tabela 18 - Médias amostrais e desvios-padrão da medida X4 calculadas para o fator de variação inclinação do garfo de mordida.

\begin{tabular}{cc}
\hline \hline Inclinação do garfo de mordida & Média (cm) e desvios-padrão \\
\hline \hline Anterior & $5,085( \pm 1,118)$ \\
Paralelo & $4,961( \pm 1,221)^{\cdot}$ \\
Posterior & $4,873( \pm 1,334)$ \\
\hline
\end{tabular}

Símbolos iguais: médias estatisticamente semelhantes

Tabela 19 - Médias amostrais e desvios-padrão da medida X4 calculadas para o fator de variação tipos de articuladores.

\begin{tabular}{cc}
\hline \hline Tipos de Articuladores & Média (cm) e desvios-padrão \\
\hline \hline Arcon & $3,808( \pm 0,295)$ \\
Não-arcon & $6,139( \pm 0,396)$ \\
\hline \hline
\end{tabular}


Tabela 20 - Médias amostrais em cm e desvios-padrão da medida X4 calculadas para a interação tipos de articuladores x inclinação do garfo de mordida.

\begin{tabular}{cccc}
\hline \hline \multirow{2}{*}{ Tipos de Articuladores } & \multicolumn{2}{c}{ Inclinação do garfo de mordida } \\
& Anterior & Paralelo & Posterior \\
\hline \hline Arcon & $4,029( \pm 0,195)$ & $3,806( \pm 0,280)$ & $3,589( \pm 0,229)$ \\
Não-Arcon & $6,141( \pm 0,427)$ & $6,117( \pm 0,416)$ & $6,158( \pm 0,360)$ \\
\hline \hline
\end{tabular}

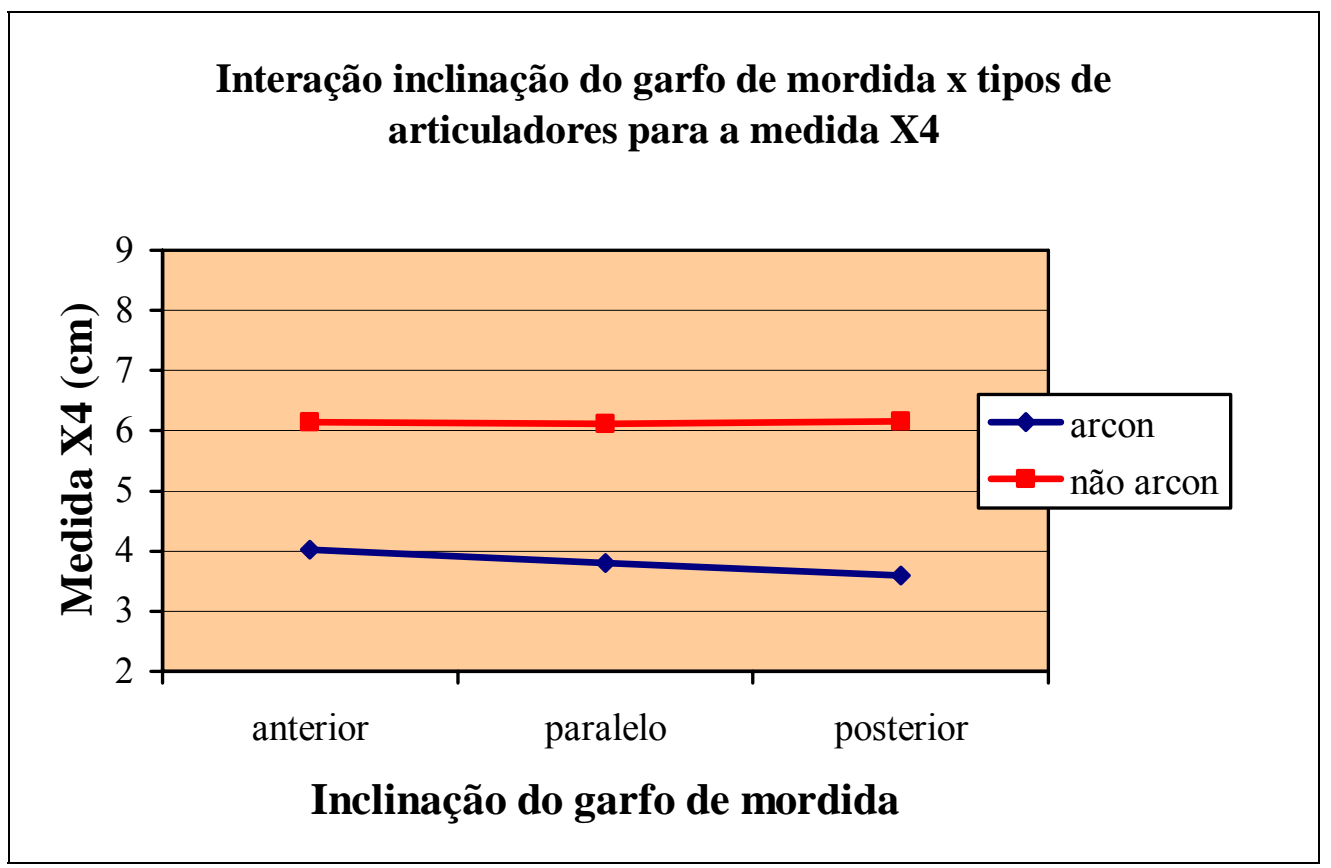

Figura 15. Gráfico da interação entre os fatores de variação inclinação do garfo de mordida $x$ tipos de articuladores da medida X4. 
O articulador é um dispositivo mecânico que representa as articulações temporomandibulares e os maxilares, ao qual são fixados os modelos dos arcos maxilares e mandibulares. O arco facial, dispositivo auxiliar que acompanha o articulador, é um instrumento relativamente simples, usado para obter o registro de transferência do arco maxilar, com a finalidade de orientar o modelo maxilar no instrumento de articulação (HENDERSON; STEFFEL, 1979).

De acordo com Nagy, Smithy e Wirth (2002) a precisão da articulação e a montagem dos modelos têm sido um desafio e um procedimento de difícil execução em Odontologia, por causa de muitas variáveis que podem levar a erros.

Muitos estudos têm apresentado procedimentos clínicos diferentes para a montagem de modelos dentais em articulador com objetivo de introduzir melhoras para minimizar a possibilidade de erros durante o procedimento (ELLIS; THARANON; GAMBRELL, 1992; HICKEY; LUNDEEN; BOHANNAN, 1967; ZANETTI; RIBAS, 1997; ZUCKERMAN, 1985).

Ferrario et al. (2002) ressalta que o objetivo do procedimento de transferência do arco facial é detectar o relacionamento anteroposterior e vertical da maxila ao eixo horizontal transversal e transferir este relacionamento ao articulador. Diferentes fatores podem produzir o alinhamento incorreto do modelo maxilar: variação individual nos pontos de referência anatômica, o ajuste impróprio do arco facial no paciente ou no articulador durante o procedimento de transferência, e o ajuste do plano horizontal de Frankfort no membro superior do articulador.

Quando usamos algum tipo de arco facial, o terceiro ponto de referência é necessário para relacionar o ângulo do plano oclusal com o plano de referência horizontal, usualmente o plano de Frankfort. Quando usamos um articulador, é imperativo que o ângulo entre o plano oclusal e o plano de Frankfort no paciente seja o mesmo que o ângulo entre o plano oclusal do 
modelo maxilar com o membro (horizontal) superior do articulador (ELLIS; THARANON; GAMBRELL, 1992).

Ainda de acordo com Ellis, Tharanon e Gambrell (1992), o ângulo entre o plano oclusal maxilar e um plano de referência horizontal, geralmente o plano de Frankfort horizontal, deve ser transferido ao articulador durante a montagem do modelo maxilar. Este ângulo varia consideravelmente entre pacientes. Se este ângulo for diferente no paciente comparado ao articulador, o modelo maxilar estará montado em uma posição espacial diferente no articulador daquela realmente existente em relação ao crânio do paciente.

A seleção de um ponto de referência anterior orienta o plano horizontal de referência, e por sua vez, a inclinação do plano oclusal que é reproduzido pelo articulador. A reprodução incorreta da inclinação do plano oclusal afeta a função e a estética. Uma mudança na posição vertical do ponto de referência anterior altera o ângulo da guia condilar e resulta em alterações na inclinação e altura das cúspides (O’MALLEY; MILOSEVIC, 2000).

A observação que tem sido feita em relação ao ensino/aprendizagem do tema aqui estudado refere-se a que os alunos de graduação, ou mesmo os profissionais recém formados, com base nos estudos de literatura, supervalorizam a importância da tomada do registro do garfo de mordida. Desenvolvem o conceito que se houver uma tomada de registro em que o garfo de mordida não respeite o paralelismo em relação ao plano oclusal, plano de Franfort e mesmo em relação à linha média, a posição do modelo superior resultará irremediavelmente equivocada.

Este estudo, de acordo com sua proposição, fundamentou-se em registros desviados propositalmente para anterior e para posterior em relação ao plano oclusal do modelo do paciente, comparando-os ao registro paralelo ao plano oclusal do modelo superior do paciente, em dois tipos de articuladores semi-ajustáveis, arcon e não-arcon. 
Como pode ser observado no capítulo Resultados, os valores das médias não demonstraram significância estatística para todas as medidas adotadas para comparação (uma angular e quatro lineares) entre inclinações para anterior e para posterior do garfo de mordida e a posição paralela do mesmo. Assim sendo, os achados deste trabalho indicam que, na eventualidade da ocorrência de pequenas inclinações realizadas com o garfo de mordida, sejam de forma voluntária ou involuntária, estas não irão interferir na orientação da montagem do modelo superior no articulador semi-ajustável do tipo arcon e não-arcon.

Esta pesquisa, considerando a metodologia empregada e seu objetivo, é de difícil comparação com os trabalhos encontrados na literatura, pois não foram encontrados estudos delineados de maneira semelhante. Em que pesem as diferentes metodologias das pesquisas relatadas no Capítulo de Revisão da Literatura, algumas pesquisas revelam dados e considerações afins e/ou interessantes.

Kitzis, Millstein e Nathanson (1991), mesmo usando articuladores diferentes, porém calibrados, demonstraram posicionamentos de modelos corretos, havendo reprodutibilidade a partir de transferências perfeitas do modelo superior.

Por sua vez, Goska e Christensen (1988) referenciaram resultados parcialmente comparáveis a este estudo, ao avaliarem a posição ocupada pelo primeiro molar superior esquerdo e direito quando montados com arcos faciais diferentes. Os resultados dos referidos autores apresentaram grandes variações entre os pacientes, mas não demonstraram diferenças significantes entre as quatro montagens realizadas para um mesmo paciente, ou seja, este procedimento foi considerado reprodutível, o que corrobora os achados deste estudo.

Por outro lado, a literatura é rica em fornecer subsídios para o melhor conhecimento dos articuladores e da montagem de modelos, tentando abordar de forma clara e simples os fatores e aspectos envolvidos nestes temas, considerados de difícil compreensão e domínio. 
Assim, para o melhor entendimento dos resultados deste estudo, alguns aspectos devem ser destacados em relação à tomada do arco facial.

O arco facial transfere a relação entre os dentes superiores, o eixo terminal e um terceiro ponto de referência do crânio do paciente para o articulador. Para se obter o maior grau possível de precisão, os modelos devem fechar-se em torno de um eixo de rotação que seja o mais próximo possível do eixo terminal da mandíbula do paciente.

Zuckerman (1982) relatou que os modelos são montados em posição diferente da anatômica quando ocorrem erros na localização e transferência do eixo terminal de rotação.

Para finalidades de diagnóstico e particularmente em técnicas de próteses fixas, os modelos montados em articuladores devem reproduzir a mesma relação do plano eixo-orbital do paciente. Esta relação pode ser conseguida localizando a eixo terminal do paciente e transferindo o modelo maxilar com um arco facial para o articulador. Quando um arco facial arbitrário é usado, o articulador é fechado em torno de um eixo arbitrário, levando a um desvio dos contatos oclusais quando os dentes do arco mandibular alcançam seus antagonistas, consideraram Piehslinger, Bauer e Schmiedmayer (1995).

Craddock e Symmons (1952) evidenciaram que os vários erros que existem na montagem dos modelos em relação ao eixo de um articulador, alguns são de tão pequena significância que podem ser ignorados. Um exemplo refere-se aos casos de assimetria facial revelada na transferência do arco facial, que de fato é uma característica anatômica e de tal forma será incorporada na montagem dos modelos. Isto pode ser explicado que desvios observados são sempre pequenos (4 ou 5 graus) e que seus efeitos na relação oclusal dos dentes assumem pequena amplitude de movimento. Estes erros resultantes nas relações oclusais são tão pequenos que são incapazes de detecção clínica.

A montagem do modelo maxilar em articulador pelo uso de um arco facial apresenta uma confiança relativa da distância real entre a dentição e o eixo intercondilar. Quando os 
modelos são montados no articulador, estes são espacialmente análogos à dentição maxilar e mandibular em relação ao crânio do paciente (ELLIS; THARANON; GAMBRELL, 1992). Para a obtenção de êxito, a incorporação de um terceiro ponto de referência possibilita a transferência da elevação do modelo superior, permitindo que o mesmo esteja corretamente orientado num espaço do articulador comparável à relação da maxila ao plano horizontal de Frankfort do paciente (HENDERSON; STEFFEL, 1979).

Shillingburg et al. (1998) afirmaram que quanto mais precisa a localização do eixo terminal, mais precisas serão a transferência e a montagem dos modelos. Ressaltaram ainda que, com o dispositivo de referência anterior que dá a orientação vertical do arco facial, este poderá ser usado para montar com precisão o modelo do arco dental superior no articulador.

Ercoli et al. (1999) e Nagy, Smithy e Wirth (2002) relataram que a precisão na montagem de modelos dentais é conseguida pela transferência da relação espacial tridimensional do arco maxilar para o articulador, freqüentemente obtida pelo uso do arco facial. Isto é tradicionalmente feito pelo uso de três pontos de referência. Dois pontos são localizados na área da articulação temporomandibular e o terceiro ponto é selecionado anteriormente a esta articulação, que definem um plano de referência, o qual é orientado no articulador de tal forma que a posição tridimensional do modelo superior é reproduzida tal qual se apresenta no paciente.

As pesquisas citadas ressaltam, portanto, aspectos que padronizem e permitam a reprodução do procedimento de tomada do arco facial, assim como sua transferência ao articulador, destacando a importância do uso de três pontos de referência. O mesmo ocorreu com o método deste estudo e os resultados podem estar relacionados com a reprodução padronizada, em todos os registros de arco facial em cada um dos vinte pacientes selecionados, da posição tridimensional do modelo superior por meio do uso dos três pontos de referência constantes, ou seja, meatos auditivos externos direito e esquerdo e násio. Assim 
sendo, os resultados obtidos sugeriram que quando há a transferência dos modelos para o articulador, o importante é transferir a distância entre o eixo terminal de rotação e os dentes para o articulador e que qualquer inclinação erroneamente introduzida no registro do garfo de mordida não influenciará a montagem final do modelo superior em articulador.

Este fato destaca a grande importância do desenvolvimento do modelo do arco facial que faz uso dos meatos auditivos externos e násio na tentativa de solucionar o problema de identificação anatômica do eixo arbitrário. Este sistema tornou-se largamente popular depois da introdução do QuickMount face-bow (Whip Mix Corp, Louisville, Ky) em 1960 (NAGY; SMITHY; WIRTH, 2002) e vários renomados pesquisadores, ao longo do tempo, confirmaram esta constatação.

Shillingburg, Hobo e Whitsett (1988) relataram que o eixo terminal de rotação é uma referência importante e reprodutível e que a transferência desta relação é feita com o arco facial; quanto mais precisa for a localização do eixo terminal de rotação, mais exata será a montagem dos modelos.

Para Ash e Ramfjord (1995), quando o posicionador auricular do arco facial está em uso e o garfo de mordida estabilizado, o eixo convencional do paciente é determinado automaticamente, e assim é transferido para o articulador.

De acordo com Ellis, Tharanon e Gambrell (1992), durante a montagem do modelo maxilar, deve ser observado o relacionamento radial entre os dentes maxilares e o eixo terminal intercondilar e isto é simplesmente obtido pela transferência do arco facial.

Pitchford (1991) ressaltou que a ocorrência de falha na transferência do relacionamento anteroposterior do modelo pode resultar em erros graves na reconstrução da oclusão final de uma prótese, enquanto falhas na transferência do correto relacionamento vertical podem resultar em erros estéticos. O autor ainda considera que a consequiência poderá 
ser a obtenção de um plano oclusal no qual os dentes posteriores maxilares parecem estar abaixo dos dentes anteriores.

De acordo com o método deste estudo, a transferência do eixo rotacional de todos os pacientes, em todos os registros (repetições), foi realizada de forma similar considerando os mesmos pontos referenciais. Assim, houve reprodutibilidade com confiança dos registros do arco facial e sua transferência para o articulador, mesmo quando foram introduzidas as inclinações para anterior e para posterior em relação ao plano oclusal dos pacientes.

Além disso, outro aspecto que deve ser considerado é que a haste do garfo de mordida é fixada ao arco facial por meio de juntas universais as quais permitem vários tipos de movimentos. A presença de inclinações diversas induzidas do garfo de mordida em relação ao plano oclusal do paciente durante a tomada do arco facial pode ter sido compensada por este tipo de junta universal, a qual possui a capacidade de se adaptar a qualquer posicionamento permitindo com que o arco facial continue estabilizado na mesma posição durante o procedimento. O dois arcos faciais utilizados apresentam somente este tipo de junção.

Como exemplo da possibilidade de movimentação e adaptação da junta universal, Zanetti e Ribas (1997) adaptaram nas moldeiras de estoque uma haste que era fixada à junta universal do arco facial de modo a registrar o relacionamento da maxila com a base do crânio durante a moldagem. Os autores, devido à versatilidade de movimentos permitida pela junta universal, foi possível obter o modelo dos arcos dentais ao mesmo tempo em que o arco facial transportava o relacionamento da maxila à base do crânio ao articulador.

Ainda de acordo com o estudo apresentado e resultados obtidos, também observou-se que houve diferença estatisticamente significante quando da análise da medidas angular e das lineares entre os dois tipos de articuladores arcon e não-arcon, porém sem nenhum significado prático. Estas diferenças podem ser somente atribuídas ao desenho e às dimensões singulares 
e diferentes de cada tipo de articulador, claramente observadas. O fator relevante a ser destacado trata-se da transferência do arco facial para o articulador com confiabilidade, devido à manutenção da distância entre os dentes e o eixo terminal de rotação, de forma similar para ambos articuladores.

Ainda assim, se os modelos maxilares são montados em relação a pontos anatômicos que diferem de sujeito a sujeito, não é possível estabelecer uma superioridade clínica de um arco facial sobre outro (GOSKA; CHRISTENSEN, 1988). Somado a isso, as atividades acadêmicas relativas ao ensino, pesquisa, além do treinamento de alunos e profissionais, revelaram ao longo dos anos a clara tendência para o uso do articulador do tipo arcon, que é considerado superior por Gross e Gazit (1985) para suas finalidades quando comparado ao do tipo não-arcon.

Porém cabe ressaltar que os resultados deste estudo revelaram que os articuladores não-arcon apresentaram similar reprodutibilidade do procedimento avaliado se comparado ao articulador arcon, destacando ter apresentado menores variações nas medidas testadas. Estes achados possivelmente indicam sua adequada confiabilidade para utilização, uma vez que recentemente foi reintroduzido na prática odontológica com o intuito da popularização de seu uso.

Finalmente, os resultados deste estudo demonstraram de forma inequívoca não haver interferências de pequenas inclinações do garfo de mordida constituinte do arco facial, tanto para o articulador semi-ajustável do tipo arcon como para o não-arcon. Este achado é de grande relevância, pois indica que existe confiabilidade em registros realizados com a introdução involuntária de pequenas inclinações do garfo de mordida durante a montagem do modelo superior em articuladores semi-ajustáveis, e transmite segurança aos acadêmicos durante o seu treinamento e aprendizagem, assim como aos profissionais durante a execução deste procedimento tão importante na obtenção do 
sucesso em tratamentos odontológicos reabilitadores. Constitui, portanto, material didático que auxilia o estudante a visualizar a ausência de relação entre a inclinação do garfo de mordida e a posição resultante do modelo que é, sim, dependente do correto ajuste do arco facial nos pontos anatômicos de referência. 
7 CONCLUSÃO 
Com base na proposição, na metodologia e nos resultados obtidos por este estudo podemos concluir que durante a tomada do registro com arco facial e transferência para o articulador para a montagem do modelo superior:

- a presença de inclinações do garfo de mordida, tanto para anterior como para posterior em relação ao plano oclusal não influencia a montagem do modelo maxilar em articulador semiajustável do tipo arcon e do tipo não-arcon;

- a transferência do arco facial para o articulador semi-ajustável sugere confiabilidade na montagem do modelo superior, quando da ocorrência de “erros” introduzidos involuntariamente por estudantes de graduação durante o processo ensino/aprendizagem. 


\section{REFERÊNCIAS BIBLIOGRÁFICAS ${ }^{1}$}

ABDULLAH, M.A. Study of the acceptability of lateral interocclusal records by a modular articulator. J. Prosthet. Dent., v.74, n.4, p.408-411, October, 1995.

ADRIEN, P.; SCHOUVER, J. Methods for minimizing the errors in mandibular model mounting on an articulator. J. Oral Rehabil., v.24, n.12, p.929-935, December, 1997.

ALEXANDER, S.R.; MOORE, R.N.; DuBOIS, L.M. Mandibular condyle position: Comparison of articulator mountings and magnetic resonance imaging. Am. J. Orthod. Dentofacial Orthop., v.104, n.3, p.230-239, September, 1993.

ASH, M.M.; RAMFJORD, S.P. An introduction to functional occlusion. Philadelphia: W.B. Saunders Company, 1985. 1598p.

ASH, M.M.; RAMFJORD, S. Occlusion. Fourth edition. Philadelphia: W.B. Saunders Company, 1995. 664p.

AUGSBURger, R.H. Occlusal plane relation to facial type. J. Prosthet. Dent., v.3, n.6, p.755-770, November, 1953.

AZARMEHR, P.; YARMAND, M.A. The use of lateral interocclusal records in semiadjustable articulators. J. Prosthet. Dent., v.29, n.3, p.330-333, March, 1973.

BAILEY, J.O.JR.; NOWLIN, T.P. Evaluation of the third point of reference for mounting maxillary casts on the Hanau articulator. J. Prosthet. Dent., v.51, n.2, p.199-201, February, 1984.

\footnotetext{
${ }^{1}$ Referências de acordo com a UNIVERSIDADE DE SÃO PAULO, sistema integrado de Bibliotecas Diretrizes para apresentação de Dissertações e Teses da USP - documento eletrônico e impresso, São Paulo: SIBi/USP, 2004, 100p, e com a Associação Brasileira de Normas Técnicas - NBR 6023, Agosto 2002.
} 
BALSHI, T.J.; MINGLEDORFF, E.B.; OLBRYS, B.H.; CANTOR, S.J. Restorative occlusion utilizing a custom incisal guide table. J. Prosthet. Dent., v.36, n.4, p.468-471, October, 1976.

BAMBER, M.A.; FIROUZAI, R.; HARRIS, M.; LINNEY, A. A comparative study of two arbitrary face-bow transfer systems for orthognathic surgery planning. Int. J. Oral Maxillofac. Surg., v.25, n.5, p.339-343, October, 1996.

BELLANTI, N.D. The significance of articulator capabilities. Part I. Adjustable vs. semiadjustable articulators. J. Prosthet. Dent., v.29, n.3, p.269-275, March, 1973.

BOYARSKY, H.P.; LOOS, L.G.; LEKNIUS, C. Occlusal refinement of mounted casts before crown fabrication to decrease clinical time required to adjust occlusion. J. Prosthet. Dent., v.82, n.5, p.591-594, November, 1999.

BRANDRUP-WOGNSEN, T. The face-bow, its significance and application. J. Prosthet. Dent., v.3, n.5, p.618-630, September, 1953.

BROOMELL, I.N. The value of temperamental indications in the correct prosthesis of entire dentures. Dent. Cosmos, v.39, n.1, p.1-20, January, 1897.

CALLISON, G.M. Bitefork modification to aid in orientating the tentative occlusal plane. J. Prosthet. Dent., v.54, n.3, p.448, September, 1985.

CAMPION, C.G. A method of recording graphically the mandibular condyles in living subjects. Br. Dent. J., v.23, p.713-716, 1902.

CARVALHO, O.T. de. A new fully adjustable articulator system and procedure. J. Prosthet. Dent., v.80, n.3, p.376-386, September, 1998.

CHOW, T.W.; CLARK, R.K.F.; COOKE, M.S. Errors in mounting maxillary casts using face-bow records as a result of an anatomical variation. J. Dent., v.13, n.4, p.277-282, December, 1985. 
CHRISTIANSEN, R.L. Rationale of the face-bow in maxillary cast mounting. J. Prosthet. Dent., v.9, n.3, p.388-398, May-June, 1959.

CLARK, J.R.; HUTCHINSON, I.; SANDY, J.R. Functional Occlusion: II. The Role of Articulators in Orthodontics. J. Orthod., v.28, n.2, p.173-177, June, 2001.

COLLETT, H.A. The movements of the temporomandibular joint and their relation to the problems of occlusion. J. Prosthet. Dent., v.5, n.4, p.486-496, July, 1955.

CRADDOCK, F.W; SYMMONS, H.F. Evaluation of the face-bow. J. Prosthet. Dent v.2, n.5, p.633-642, September, 1952.

DIKEMA, R.W.; GOODACRE, C.J.; PHILLIPS, R.W. Johnston's Modern Practice in Fixed Prosthodontics. Fourth Edition. Philadelphia: W.B. Saunders Company, 1986. 372p.

DRISCOLL, W.E. Articulation of artificial teeth with a view to their better retention in position. D. Intems. Interest., v.4, n.6, p.311-313, 1884.

ELLIS, E.; THARANON, W.; GAMBRELL, K. Accuracy of face-bow transfer: effect on surgical prediction and postsurgical result. J. Oral Maxillofac. Surg. v.50, n.6, p.562-567, June, 1992.

ENGELMEIER, R.L.; STARCKE, E.N. History of Articulators: Henry L. Harry Page and the Transograph. J. Prosthodont. v.15, n.6, p.374-380, November-December, 2006.

ERCOLI, C.; GRASER, G.N., TALLENTS, R.H., GALINDO,D. Face-bow record without a third point of reference: Theoretical considerations and an alternative technique. J. Prosthet. Dent. v.82, n.2, p.237-241, August, 1999.

FERNANDES, R.S.M.; SILVA, M.A.M.R.; NUNES, L.J.; Geometrics analisis of models placement in articulator. J. Dent. Res., v.79, n.5, p.1163, 2000. 
FERRARIO, V.F.; SFORZA, C.; SERRAO, G.; SCHMITZ, J.H. Three-dimensional assessment of the reliability of a postural face-bow transfer. J. Prosthet. Dent., v.87, n.2, p.210-215, February, 2002.

GATENO, J.; FORREST, K.K.; CAMP, B. A Comparison of 3 Methods of Face-Bow Transfer Recording: Implications for Orthognathic Surgery. J. Oral Maxillofac. Surg., v.59, n.6, p.635-640, June, 2001.

GOLD, B.R.; SETCHELL, D.J. An investigation of the reproducibility of face-bow transfers. J. Oral Rehab., v.10, n.6, p.495-503, November, 1983.

GOSKA, J.R.; CHRISTENSEN, L.V. Comparison of cast positions by using four face-bows. J. Prosthet. Dent., v.59, n.1, p.42-44, January, 1988.

GRACIS, S. Clinical Considerations and Rationale for the use of simplified instrumentation in occlusal Rehabilitation. Part 2: Setting of the articulator and occlusal optimization. Int. J. Periodontics Restorative Dent., v.23, n.2, p.139-145, April, 2003.

GROSS, M. D.; GAZIT, E. Articulators used in North American dental Schools. J. Dent. Educ., v.49, n.10, p.710-711, October, 1985.

GROSS, M.; NEMCOVSKY, C.; FRIEDLANDER, L.D. Comparative study of condylar settings of three semiadjustable articulators. Int. J. Prosthodont., v.3, n.2, p.135-141, MarchApril, 1990.

GYSI, A. The problem of articulation. Parte 1; Dent. Cosmos, v.52, n.1, p.1-19, January, 1910.

HALL, R.E. An analysis of the development of the articulator. J. Am. Dent. Assoc., v.17, n.1, p.3-51, 1930.

HANAU, R.L. Full denture prosthesis intraoral technique for Hanau articulator model H. $4^{\mathrm{a}}$ ed. New York: Hanau Engineering Buffalo, 1930. 
HARRIS, C.A. The principles and practice of dentistry. Philadelphia: Lindsay and Blakiston, 1892.

HENDERSON, D.; STEFFEL, V.L. Mc cracken's - Prótese Parcial Removível. $5^{\text {aed. São }}$ Paulo: Editora Artes Médicas, 1979. 453p.

HICKEY, J.C.; LUNDEEN, H.C.; BOHANNAN, H.M. A new articulator for use in teaching and general dentistry. J. Prosthet. Dent., v.18, n.5, p.425-437, November, 1967.

HINDLE, J.R.; CRADDOCK, H.L. The use of articulators in UK dental schools. Eur. J. Dent. Educ., v.10, n.4, p.197-203, November, 2006.

HO, G.F.C.; LEUNG, S.F. Replace axis-orbital pointer with level point in face-bow transfer. J Prosthet. Dent., v.68, n.6, p.982, December, 1992.

HOBO, S.; SHILLINGBURG, H.T.; WHITSETT, L.D. Articulator selection for restorative dentistry. J. Prosthet Dent., v.36, n.1, p.35-43, July, 1976.

JAMIESON, C.H. A modern concept of complete dentures. J. Prosthet. Dent., v.6, n.5, p.582-592, September, 1956.

JORDAN, L.G. Mounting master and refractory casts in the articulator in partial denture construction. J. Prosthet. Dent. , v.2, n.1, p.108-116, January, 1952.

KITZIS, G.D.; MILLSTEIN, P.L.; NATHANSON, D. Determining the accuracy of articulator interchangeability. J. Prosthet. Dent., v.65, n.6, p.845-848, June, 1991.

KORNFELD, M. Mouth rehabilitation: clinical and laboratory procedures. Saint Louis: CV Mosby Company, 1967.

LAZZARI, J.B. Application of the Hanau model “C” face-bow. J. Prosthet. Dent. , v.5, n.5, p.626-628, September, 1955. 
LUCIA, V.O. The fundamentals of oral physiology and their practical application in the securing and reproducing of records to be used in restorative dentistry. J. Prosthet. Dent., v.3, n.2, p.213-231, March, 1953.

LUCIA, V.O. Modern Gnathological Concepts. Saint Louis: CV Mosby Company, 1961. 264p.

MARKO, J.V. Simple hinge and semiadjustable articulators in orthognathic surgery. Am. J. Orthod. Dentofac. Orthop., v.90, n.1, p. 37-44, July, 1986.

McCOLLUM, B.B. Considering the mouth as a functioning unit as the basis of a dental diagnosis. J. SO. Calif. Dent. Assoc., v.5, p.268-276, 1938.

McCRACKEN, W.L. Partial denture construction. 1st ed. Saint Louis: CV Mosby Company, 1960.

McMILLAN, D.R., McMilLAN, A.S. A comparison of habitual jaw movements and articulator function. Acta Odontol. Scand., v.44, n.5, p.291-299, October, 1986.

MEZZOMO, E. Reabilitação Oral para o Clínico. $3^{\text {a }}$ edição. São Paulo: Livraria Santos Editora, 1997. 561p.

MEZZOMO, E.; SUZUKI, R.M. e cols. Reabilitação Oral Contemporânea. São Paulo: Livraria Santos Editora, 2006. 873p.

MIRANDA, C.C. Atlas de reabilitação bucal. São Paulo: Editora Santos, 1984.

MORITA, O.; MIYAGAWA, Y.; LANG, B.R. Determining the pathway of protrusive movement on arcon and nonarcon articulators by mathematical equations. J. Prosthet. Dent. v.47, n.3, p.330-334, March, 1982.

NAGY, W.W.; SMITHY, T.J.; WIRTH, C.G. Accuracy of a predetermined transverse horizontal mandibular axis point. J. Prosthet. Dent. v.87, n.4, p.387-394, April, 2002. 
NICHOLS, I.G. Prosthetic Dentistry - An Encyclopedia of Full and Partial Denture Prosthesis. Saint Louis: CV Mosby Company, 1930. 686p.

NUNES, L.J. O ponto infraorbital como referência antropológica aplicada a prótese dental: contribuição para o seu estudo. Ribeirão Preto, 1968. p.73, Tese (Doutorado) Faculdade de Farmácia e Odontologia de Ribeirão Preto, Universidade de São Paulo.

NUNES, L.J. Identidade de posicionamento do modelo superior no articulador em relação ao maxilar no crânio - método clínico, geométrico e radiográfico. Ribeirão Preto, 1973. Tese (Livre Docência) - Faculdade de Odontologia de Ribeirão Preto, Universidade de São Paulo.

OKANE, H.; YAMASHINA, T.; NAGASAWA, T.; TSURU, H. The effect of anteroposterior inclination of the occlusal plane on biting force. J. Prosthet. Dent., v.42, n.5, p.497-501, November, 1979.

OKESON, J.P. O uso dos articuladores In: Tratamento das Desordens Temporomandibulares e Oclusão. $4^{\text {a }}$ ed. Porto Alegre: Artes Médicas, 2000. Cap.18, p.41532.

OLIVEIRA, W. Disfunções Temporomandibulares. São Paulo: Artes Médicas, 2002. 472p.

O’MALLEY, A.M.; MILOSEVIC, A. Comparison of three facebow/semi-adjustable articulator systems for planning orthognathic surgery. Br. J. Oral Maxillofac. Surg., v. 38, n.3, p.185-190, June, 2000.

PALIK, J.F.; NELSON, D.R.; WHITE, J.T. Accuracy of an earpiece face-bow. J. Prosthet. Dent., v.53, n.6, p.800-804, June, 1985.

PESSINA, E.; BOSCO, M.; VINCI, A.M. Articuladores e arcos faciales em prótesis odontológica y gnatológica. Barcelona: Masson, 1995. 234p. 
PIEHSLINGER, E.; BAUER, W.; SCHMIEDMAYER, H.B. Computer simulation of occlusal discrepancies resulting from different mounting techniques. J. Prosthet Dent., v.74, n.3 p.279-283, September, 1995.

PIEHSLINGER, E.; CELAR, A.G.; CELAR, R.M.; SLAVICEK, R. Computadorized axiography: principles and methods. Cranio, v.9, n.4, p.344-55, October, 1991.

PITCHFORD, J.H. A reevaluation of the axis-orbital plane and the use of orbitale in a facebow transfer record. J. Prosthet. Dent., v.66, n.3, p.349-355, September, 1991.

POSSELT, U. Physiology of Occlusion and Rehabilitation. Oxford: Blackwell Scientific Publications, 1962.

PRESTON, J.D. A reassessment of the mandibular transverse horizontal axis theory. J. Prosthet. Dent., v.41, n.6, p.605-613, June, 1979.

SANTOS JÚNIOR, J. Oclusão: seus fundamentos e conceitos. Rio de Janeiro: Guanabara Koogan, 1982. p.55-71.

SANTOS JÚNIOR, J.; ASH, M. M. Jr. A comparison of the equivalence of jaw and articulator movements. J. Prosthet. Dent., v.59, n.1, p.36-42, January, 1988.

SCHLOSSER, R.O.; GEHL, D.H. Protesis completa. $3^{\mathrm{a}}$ ed. Buenos Aires: Editorial Company, 1959.

SCHUYLER, C.H. Factors of occlusion applicable to restorative dentistry. J. Prosthet. Dent., v.3, n.6, p.772-782, November, 1953.

SHILlingBURG, H.T.; HOBO, S.; WHITSETT, L.D. Fundamentos de prótese fixa. Tradução de Maria Terezinha F. de Oliveira. Rio de Janeiro: Quintessence Books, 1988. 340p.

SHILLINGBURG, H.T.; HOBO, S.; WHITSETT, L.D.; JACOBI, R.; BRACKETT, S.E. Fundamentos de Prótese Fixa. $3^{\text {a }}$ ed. São Paulo: Quintessence Editora ltda., 1998. 472p. 
SILVA, M.A.M.R. Determinação do ponto orbital clínico de Nunes como contribuição para a montagem de modelos no articulador, comparação com o ponto orbital radiográfico. Ribeirão Preto, 1999, 74p. Tese (Livre Docência) - Faculdade de Odontologia de Ribeirão Preto, Universidade de São Paulo.

SLOANE, R.B.; COOK, J. A guide to the orientation of the plane of occlusion. J. Prosthet. Dent. v.3, n.1, p.53-65, January, 1953.

SOUZA, A.C. Prótese dentária. $5^{\mathrm{a}}$ ed. Rio de Janeiro: Editora Henrique Velho \& Braga, 1917.

STADE, E.H.; HANSON, J.G.; BAKER, C.L. Esthetic considerations in the use of facebows. J. Prosthet. Dent. v.48, n.3, p.253-256, September, 1982.

STROHAVER, R.A.; RYAN, J.R. New face-bow simplifies routine use and dental laboratory cooperation. J. Prosthet. Dent. v.60, n.5, p.638-641, November, 1988.

STUART, C.E.; Accuracy in measuring functional dimensions and relations in oral prosthesis. J. Prosthet. Dent. v.9, n.2, p.220-236, March-April, 1959.

SWENSON, M.G. Swenson's complete denture. 5aed. Saint Louis: CV Mosby Company, 1964.

TAMAKI, T. Dentaduras completas, 4ªed. São Paulo: Sarvier Editora, 1983. 252p.

TAMAKI, K.; CELAR, A.G.; BEYRER, S.; AOKI, H. Reproduction of excursive tooth contact in an articulator with computadorized axiography data. J. Prosthet Dent. v.78, n.4, p.373-378, October, 1997.

TETERUCK, W.R.; LUNDEEN, H.C. The accuracy of an ear face-bow. J. Prosthet Dent. v.16, n.6, p.1039-1046, November-December, 1966.

TYLMANN, S.D.; TYLMANN, S.G. Theory and practice of crown and bridge prosthodontics. $4^{\mathrm{a}} \mathrm{ed}$. Saint Louis: CV Mosby Company, 1960. 1043p. 
ULRICH, J. The human temporomandibular joint: kinematics and actions of the masticatory muscles. J. Prosthet. Dent. v.9, n.3, p.399-406, May-June, 1959.

WALKER, P.M. Discrepancies between arbitrary and true hinge axes. J. Prosthet. Dent. v.43, n.3, p.279-285, March, 1980.

WALKER, W.E.; CHRISTIAN, P. Prosthetic dentistry: the glenoid fossa: the movements of the mandible, the cusps of the teeth. Dent. Cosmos. v.38, n.1, p.34-43, 1896.

WEINBerG, L.A. An evaluation of the face-bow mounting. J. Prosthet. Dent. v.11, n.1, p.32-42, January-February, 1961.

WEINBERG, L.A. An evaluation of basic articulators and their concepts. Part I. Basic Concepts. J. Prosthet. Dent. v.13, n.4, p.622-644, July-August, 1963a.

WEINBERG, L.A. An evaluation of basic articulators and their concepts. Part II. Arbitrary, Positional, Semiadjustable Articulators. J. Prosthet. Dent. v.13, n.4, p.645-663, July-August, 1963b.

WINSTANLEY, R.B. Observations on the use of the Denar pantography and articulator. J. Prosthet. Dent. v.38, n.6, p.660-672, December, 1977.

WIRTH, C.G. Interocclusal Centric Relation Records for articulator mounted casts. Dent. Clin. North. Am., v.15, n.3, p.627-640, July, 1971.

YANUS, M.; FINGER, I.M.; WEINBERG, R. Comparison of a universal mounting jig to a face-bow. J. Prosthet. Dent. v.49, n.5, p.623-627, May, 1983.

ZANETTI, A.L.; RIBAS, R. A new method to simplify and increase the precision of maxillary cast mounting procedures in fully adjustable or semiadjustable articulators. J. Prosthet. Dent. v.77, n.2, p.219-224, February, 1997.

ZUCKERMAN, G.R. The geometry of the arbitrary hinge axis as it relates to the occlusion. $\mathbf{J}$. Prosthet. Dent. v.48, n.6, p.725-733, December, 1982. 
ZUCKERMAN, G.R. Practical considerations for using the face-bow for complete denture prostodontics. J. Prosthet. Dent. v.53, n.2, p.219-221, February, 1985. 


\section{APÊNDICES}

Apêndice A - Valores originais e valores médios obtidos pelo programa Auto CAD, da medida ângulo dos pacientes de 1 a 20.

\begin{tabular}{|c|c|c|c|c|c|c|}
\hline \multirow{2}{*}{$\begin{array}{c}\text { ÂNGULO } \\
\text { Pacientes }\end{array}$} & \multicolumn{3}{|c|}{ ARCON } & \multicolumn{3}{|c|}{ NÃO-ARCON } \\
\hline & anterior & paralelo & posterior & anterior & paralelo & posterior \\
\hline \multirow{5}{*}{ 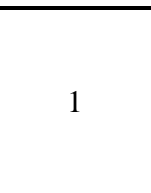 } & $78,01^{\circ}$ & $73,81^{\circ}$ & $74,16^{\circ}$ & $78,56^{\circ}$ & $80,17^{\circ}$ & $77,46^{\circ}$ \\
\hline & $78,38^{\circ}$ & $74,36^{\circ}$ & $71,85^{\circ}$ & $77,57^{\circ}$ & $81,44^{\circ}$ & $79,81^{\circ}$ \\
\hline & $79,23^{\circ}$ & $75,66^{\circ}$ & $73,11^{\circ}$ & $78,19^{\circ}$ & $77,82^{\circ}$ & $77,39^{\circ}$ \\
\hline & $78,67^{\circ}$ & $74,98^{\circ}$ & $72,76^{\circ}$ & $77,89^{\circ}$ & $80,23^{\circ}$ & $78,64^{\circ}$ \\
\hline & $78,41^{\circ}$ & $74,24^{\circ}$ & $73,32^{\circ}$ & $78,29^{\circ}$ & $79,39^{\circ}$ & $77,80^{\circ}$ \\
\hline $\mathbf{M}$ & $78,54^{\circ}$ & $74,61^{\circ}$ & $73,04^{\circ}$ & $78,10^{\circ}$ & $79,81^{\circ}$ & $78,22^{\circ}$ \\
\hline \multirow{5}{*}{2} & $73,62^{\circ}$ & $70,57^{\circ}$ & $68,41^{\circ}$ & $67,74^{\circ}$ & $68,19^{\circ}$ & $65,89^{\circ}$ \\
\hline & $72,24^{\circ}$ & $70,84^{\circ}$ & $68,39^{\circ}$ & $66,88^{\circ}$ & $66,61^{\circ}$ & $67,67^{\circ}$ \\
\hline & $74,1^{\circ}$ & $71,01^{\circ}$ & $69,99^{\circ}$ & $67,19^{\circ}$ & $67,81^{\circ}$ & $66,59^{\circ}$ \\
\hline & $73,36^{\circ}$ & $70,98^{\circ}$ & $68,97^{\circ}$ & $67,23^{\circ}$ & $66,93^{\circ}$ & $67,03^{\circ}$ \\
\hline & $73,28^{\circ}$ & $70,60^{\circ}$ & $68,89^{\circ}$ & $67,31^{\circ}$ & $68,11^{\circ}$ & $66,37^{\circ}$ \\
\hline $\mathbf{M}$ & $73,32^{\circ}$ & $70,80^{\circ}$ & $68,93^{\circ}$ & $67,27^{\circ}$ & $67,53^{\circ}$ & $66,71^{\circ}$ \\
\hline \multirow{5}{*}{3} & $71,17^{\circ}$ & $69,15^{\circ}$ & $67,63^{\circ}$ & $65,01^{\circ}$ & $66,59^{\circ}$ & $65,68^{\circ}$ \\
\hline & $71,18^{\circ}$ & $69,92^{\circ}$ & $68,37^{\circ}$ & $63,76^{\circ}$ & $64,44^{\circ}$ & $65,56^{\circ}$ \\
\hline & $71,28^{\circ}$ & $70,07^{\circ}$ & $68,77^{\circ}$ & $63,49^{\circ}$ & $65,34^{\circ}$ & $66,52^{\circ}$ \\
\hline & $71,26^{\circ}$ & $69,89^{\circ}$ & $68,15^{\circ}$ & $64,26^{\circ}$ & $64,98^{\circ}$ & $66,03^{\circ}$ \\
\hline & $71,16^{\circ}$ & $69,52^{\circ}$ & $68,33^{\circ}$ & $63,88^{\circ}$ & $65,90^{\circ}$ & $65,81^{\circ}$ \\
\hline $\mathbf{M}$ & $71,21^{\circ}$ & $69,71^{\circ}$ & $68,25^{\circ}$ & $64,08^{\circ}$ & $65,45^{\circ}$ & $65,92^{\circ}$ \\
\hline \multirow{5}{*}{4} & $74,43^{\circ}$ & $76,52^{\circ}$ & $72,41^{\circ}$ & $66,82^{\circ}$ & $68,75^{\circ}$ & $68,37^{\circ}$ \\
\hline & $73,76^{\circ}$ & $73,13^{\circ}$ & $72,22^{\circ}$ & $69,1^{\circ}$ & $66,65^{\circ}$ & $68,22^{\circ}$ \\
\hline & $74,81^{\circ}$ & $76,21^{\circ}$ & $72,08^{\circ}$ & $70,51^{\circ}$ & $68,35^{\circ}$ & $67,78^{\circ}$ \\
\hline & $73,99^{\circ}$ & $74,55^{\circ}$ & $72,15^{\circ}$ & $68,46^{\circ}$ & $67,23^{\circ}$ & $67,91^{\circ}$ \\
\hline & $74,66^{\circ}$ & $75,99^{\circ}$ & $72,29^{\circ}$ & $69,16^{\circ}$ & $68,57^{\circ}$ & $68,32^{\circ}$ \\
\hline $\mathbf{M}$ & $74,33^{\circ}$ & $75,28^{\circ}$ & $72,23^{\circ}$ & $68,81^{\circ}$ & $67,91^{\circ}$ & $68,12^{\circ}$ \\
\hline \multirow{5}{*}{5} & $77,25^{\circ}$ & $72,84^{\circ}$ & $72,9^{\circ}$ & $71,88^{\circ}$ & $69,10^{\circ}$ & $70,13^{\circ}$ \\
\hline & $75,37^{\circ}$ & $73,66^{\circ}$ & $74,24^{\circ}$ & $70,62^{\circ}$ & $68,79^{\circ}$ & $71,94^{\circ}$ \\
\hline & $76,4^{\circ}$ & $73,60^{\circ}$ & $74,42^{\circ}$ & $68,01^{\circ}$ & $70,49^{\circ}$ & $71,84^{\circ}$ \\
\hline & $75,97^{\circ}$ & $73,27^{\circ}$ & $73,53^{\circ}$ & $69,85^{\circ}$ & $69,61^{\circ}$ & $70,93^{\circ}$ \\
\hline & $76,71^{\circ}$ & $73,43^{\circ}$ & $74,16^{\circ}$ & $70,49^{\circ}$ & $69,31^{\circ}$ & $71,66^{\circ}$ \\
\hline $\mathbf{M}$ & $76,34^{\circ}$ & $73,36^{\circ}$ & $73,85^{\circ}$ & $70,17^{\circ}$ & $69,46^{\circ}$ & $71,30^{\circ}$ \\
\hline \multirow{5}{*}{6} & $73,39^{\circ}$ & $76,30^{\circ}$ & $72,59^{\circ}$ & $72,44^{\circ}$ & $71,13^{\circ}$ & $71,10^{\circ}$ \\
\hline & $75,79^{\circ}$ & $74,70^{\circ}$ & $72,48^{\circ}$ & $68,44^{\circ}$ & $70,98^{\circ}$ & $68,09^{\circ}$ \\
\hline & $75,48^{\circ}$ & $73,14^{\circ}$ & $71,19^{\circ}$ & $67,83^{\circ}$ & $71,52^{\circ}$ & $71,87^{\circ}$ \\
\hline & $74,56^{\circ}$ & $75,53^{\circ}$ & $71,98^{\circ}$ & $70,03^{\circ}$ & $71,26^{\circ}$ & $69,64^{\circ}$ \\
\hline & $75,18^{\circ}$ & $73,88^{\circ}$ & $72,16^{\circ}$ & $69,11^{\circ}$ & $71,16^{\circ}$ & $71,05^{\circ}$ \\
\hline $\mathbf{M}$ & $74,88^{\circ}$ & $74,71^{\circ}$ & $72,08^{\circ}$ & $69,57^{\circ}$ & $71,21^{\circ}$ & $70,35^{\circ}$ \\
\hline \multirow{5}{*}{7} & $71,67^{\circ}$ & $70,37^{\circ}$ & $67,26^{\circ}$ & $64,77^{\circ}$ & $67,58^{\circ}$ & $66,93^{\circ}$ \\
\hline & $73,90^{\circ}$ & $70,88^{\circ}$ & $68,92^{\circ}$ & $65,27^{\circ}$ & $64,55^{\circ}$ & $65,68^{\circ}$ \\
\hline & $73,80^{\circ}$ & $70,60^{\circ}$ & $67,83^{\circ}$ & $64,78^{\circ}$ & $65,55^{\circ}$ & $67,06^{\circ}$ \\
\hline & $72,65^{\circ}$ & $70,57^{\circ}$ & $67,54^{\circ}$ & $65,07^{\circ}$ & $66,63^{\circ}$ & $66,13^{\circ}$ \\
\hline & $73,58^{\circ}$ & $70,63^{\circ}$ & $68,45^{\circ}$ & $64,81^{\circ}$ & $65,14^{\circ}$ & $66,95^{\circ}$ \\
\hline $\mathbf{M}$ & $73,12^{\circ}$ & $70,61^{\circ}$ & $68,00^{\circ}$ & $64,94^{\circ}$ & $65,89^{\circ}$ & $66,55^{\circ}$ \\
\hline \multirow{5}{*}{8} & $76,85^{\circ}$ & $73,73^{\circ}$ & $71,13^{\circ}$ & $67,37^{\circ}$ & $69,23^{\circ}$ & $68,01^{\circ}$ \\
\hline & $76,05^{\circ}$ & $74,34^{\circ}$ & $71,12^{\circ}$ & $67,86^{\circ}$ & $67,26^{\circ}$ & $68,18^{\circ}$ \\
\hline & $76,18^{\circ}$ & $75,03^{\circ}$ & $71,73^{\circ}$ & $66,73^{\circ}$ & $67,54^{\circ}$ & $67,67^{\circ}$ \\
\hline & $76,61^{\circ}$ & $74,60^{\circ}$ & $71,54^{\circ}$ & $67,54^{\circ}$ & $68,36^{\circ}$ & $67,76^{\circ}$ \\
\hline & $76,11^{\circ}$ & $74,10^{\circ}$ & $71,08^{\circ}$ & $67,1^{\circ}$ & $67,66^{\circ}$ & $68,13^{\circ}$ \\
\hline $\mathbf{M}$ & $76,36^{\circ}$ & $74,36^{\circ}$ & $71,32^{\circ}$ & $67,32^{\circ}$ & $68,01^{\circ}$ & $67,95^{\circ}$ \\
\hline \multirow{5}{*}{9} & $70,98^{\circ}$ & $68,83^{\circ}$ & $68,68^{\circ}$ & $61,63^{\circ}$ & $60,36^{\circ}$ & $63,38^{\circ}$ \\
\hline & $75,68^{\circ}$ & $68,90^{\circ}$ & $68,06^{\circ}$ & $61,74^{\circ}$ & $62,24^{\circ}$ & $63,68^{\circ}$ \\
\hline & $72,36^{\circ}$ & $67,45^{\circ}$ & $68,33^{\circ}$ & $61,31^{\circ}$ & $62,57^{\circ}$ & $64,37^{\circ}$ \\
\hline & $73,85^{\circ}$ & $67,37^{\circ}$ & $68,42^{\circ}$ & $61,48^{\circ}$ & $61,64^{\circ}$ & $63,89^{\circ}$ \\
\hline & $72,13^{\circ}$ & $69,40^{\circ}$ & $68,26^{\circ}$ & $61,64^{\circ}$ & $61,79^{\circ}$ & $63,73^{\circ}$ \\
\hline \multirow[t]{2}{*}{$\mathbf{M}$} & $73,00^{\circ}$ & $68,39^{\circ}$ & $68,35^{\circ}$ & $61,56^{\circ}$ & $61,72^{\circ}$ & $63,81^{\circ}$ \\
\hline & $76,22^{\circ}$ & $75,74^{\circ}$ & $71,22^{\circ}$ & $69,66^{\circ}$ & $73,02^{\circ}$ & $72,87^{\circ}$ \\
\hline
\end{tabular}




\begin{tabular}{|c|c|c|c|c|c|c|}
\hline \multirow{4}{*}{10} & $77,06^{\circ}$ & $72,92^{\circ}$ & $70,94^{\circ}$ & $69,68^{\circ}$ & $74,32^{\circ}$ & $72,70^{\circ}$ \\
\hline & $76,04^{\circ}$ & $73,07^{\circ}$ & $72,69^{\circ}$ & $69,49^{\circ}$ & $72,22^{\circ}$ & $71,22^{\circ}$ \\
\hline & $76,87^{\circ}$ & $74,22^{\circ}$ & $72,05^{\circ}$ & $69,54^{\circ}$ & $72,99^{\circ}$ & $71,78^{\circ}$ \\
\hline & $77,01^{\circ}$ & $73,60^{\circ}$ & $71,15^{\circ}$ & $69,68^{\circ}$ & $73,35^{\circ}$ & $72,73^{\circ}$ \\
\hline $\mathbf{M}$ & $76,44^{\circ}$ & $73,91^{\circ}$ & $71,61^{\circ}$ & $69,61^{\circ}$ & $73,18^{\circ}$ & $72,26^{\circ}$ \\
\hline \multirow{5}{*}{11} & $75,89^{\circ}$ & $72,63^{\circ}$ & $72,59^{\circ}$ & $71,61^{\circ}$ & $73,60^{\circ}$ & $71,85^{\circ}$ \\
\hline & $74,86^{\circ}$ & $73,38^{\circ}$ & $73,78^{\circ}$ & $74,31^{\circ}$ & $71,87^{\circ}$ & $71,97^{\circ}$ \\
\hline & $75,04^{\circ}$ & $74,86^{\circ}$ & $71,40^{\circ}$ & $72,38^{\circ}$ & $72,62^{\circ}$ & $71,29^{\circ}$ \\
\hline & $75,67^{\circ}$ & $74,23^{\circ}$ & $73,12^{\circ}$ & $73,34^{\circ}$ & $73,08^{\circ}$ & $71,57^{\circ}$ \\
\hline & $74,84^{\circ}$ & $73,00^{\circ}$ & $72,06^{\circ}$ & $72,16^{\circ}$ & $72,28^{\circ}$ & $71,82^{\circ}$ \\
\hline $\mathbf{M}$ & $75,26^{\circ}$ & $73,62^{\circ}$ & $72,59^{\circ}$ & $72,76^{\circ}$ & $72,69^{\circ}$ & $71,70^{\circ}$ \\
\hline \multirow{5}{*}{12} & $70,37^{\circ}$ & $69,67^{\circ}$ & $70,58^{\circ}$ & $67,64^{\circ}$ & $67,06^{\circ}$ & $65,15^{\circ}$ \\
\hline & $70,47^{\circ}$ & $67,83^{\circ}$ & $66,26^{\circ}$ & $66,94^{\circ}$ & $66,12^{\circ}$ & $66,63^{\circ}$ \\
\hline & $69,66^{\circ}$ & $69,12^{\circ}$ & $65,89^{\circ}$ & $66,12^{\circ}$ & $65,63^{\circ}$ & $66,22^{\circ}$ \\
\hline & $69,97^{\circ}$ & $68,66^{\circ}$ & $68,32^{\circ}$ & $67,32^{\circ}$ & $65,89^{\circ}$ & $66,58^{\circ}$ \\
\hline & $70,33^{\circ}$ & $69,07^{\circ}$ & $66,80^{\circ}$ & $66,48^{\circ}$ & $66,65^{\circ}$ & $65,42^{\circ}$ \\
\hline $\mathbf{M}$ & $70,16^{\circ}$ & $68,87^{\circ}$ & $67,57^{\circ}$ & $66,90^{\circ}$ & $66,27^{\circ}$ & $66,00^{\circ}$ \\
\hline \multirow{5}{*}{13} & $74,43^{\circ}$ & $75,59^{\circ}$ & $70,66^{\circ}$ & $70,33^{\circ}$ & $71,80^{\circ}$ & $70,63^{\circ}$ \\
\hline & $74,96^{\circ}$ & $73,53^{\circ}$ & $73,47^{\circ}$ & $68,70^{\circ}$ & $71,07^{\circ}$ & $72,59^{\circ}$ \\
\hline & $74,66^{\circ}$ & $75,11^{\circ}$ & $74,29^{\circ}$ & $69,41^{\circ}$ & $72,34^{\circ}$ & $73,17^{\circ}$ \\
\hline & $74,57^{\circ}$ & $74,18^{\circ}$ & $71,67^{\circ}$ & $69,23^{\circ}$ & $71,54^{\circ}$ & $71,96^{\circ}$ \\
\hline & $74,78^{\circ}$ & $75,29^{\circ}$ & $73,91^{\circ}$ & $69,73^{\circ}$ & $71,90^{\circ}$ & $72,30^{\circ}$ \\
\hline $\mathbf{M}$ & $74,68^{\circ}$ & $74,74^{\circ}$ & $72,80^{\circ}$ & $69,48^{\circ}$ & $71,73^{\circ}$ & $72,13^{\circ}$ \\
\hline \multirow{5}{*}{14} & $75,43^{\circ}$ & $72,78^{\circ}$ & $69,89^{\circ}$ & $70,94^{\circ}$ & $66,71^{\circ}$ & $68,19^{\circ}$ \\
\hline & $74,77^{\circ}$ & $73,16^{\circ}$ & $69,30^{\circ}$ & $68,70^{\circ}$ & $70,23^{\circ}$ & $68,04^{\circ}$ \\
\hline & $74,78^{\circ}$ & $72,62^{\circ}$ & $68,47^{\circ}$ & $70,96^{\circ}$ & $70,07^{\circ}$ & $67,45^{\circ}$ \\
\hline & $75,16^{\circ}$ & $72,90^{\circ}$ & $68,75^{\circ}$ & $69,55^{\circ}$ & $68,89^{\circ}$ & $67,93^{\circ}$ \\
\hline & $74,81^{\circ}$ & $72,79^{\circ}$ & $69,69^{\circ}$ & $70,85^{\circ}$ & $69,10^{\circ}$ & $67,84^{\circ}$ \\
\hline $\mathbf{M}$ & $74,99^{\circ}$ & $72,85^{\circ}$ & $69,22^{\circ}$ & $70,20^{\circ}$ & $69,00^{\circ}$ & $67,89^{\circ}$ \\
\hline \multirow{5}{*}{15} & $77,64^{\circ}$ & $75,45^{\circ}$ & $76,38^{\circ}$ & $71,25^{\circ}$ & $72,01^{\circ}$ & $70,72^{\circ}$ \\
\hline & $78,81^{\circ}$ & $74,54^{\circ}$ & $75,46^{\circ}$ & $73,51^{\circ}$ & $72,93^{\circ}$ & $71,20^{\circ}$ \\
\hline & $77,93^{\circ}$ & $76,59^{\circ}$ & $74,50^{\circ}$ & $70,99^{\circ}$ & $72,36^{\circ}$ & $72,27^{\circ}$ \\
\hline & $78,73^{\circ}$ & $76,27^{\circ}$ & $74,89^{\circ}$ & $72,15^{\circ}$ & $72,56^{\circ}$ & $70,99^{\circ}$ \\
\hline & $77,49^{\circ}$ & $74,75^{\circ}$ & $75,97^{\circ}$ & $71,65^{\circ}$ & $72,29^{\circ}$ & $71,77^{\circ}$ \\
\hline $\mathbf{M}$ & $78,12^{\circ}$ & $75,52^{\circ}$ & $75,44^{\circ}$ & $71,91^{\circ}$ & $72,43^{\circ}$ & $71,39^{\circ}$ \\
\hline \multirow{5}{*}{16} & $77,95^{\circ}$ & $73,75^{\circ}$ & $74,10^{\circ}$ & $78,50^{\circ}$ & $80,11^{\circ}$ & $77,40^{\circ}$ \\
\hline & $78,32^{\circ}$ & $74,30^{\circ}$ & $71,79^{\circ}$ & $77,51^{\circ}$ & $81,38^{\circ}$ & $79,75^{\circ}$ \\
\hline & $79,17^{\circ}$ & $75,60^{\circ}$ & $73,05^{\circ}$ & $78,13^{\circ}$ & $77,76^{\circ}$ & $77,33^{\circ}$ \\
\hline & $78,61^{\circ}$ & $74,92^{\circ}$ & $72,70^{\circ}$ & $77,83^{\circ}$ & $80,17^{\circ}$ & $78,58^{\circ}$ \\
\hline & $78,35^{\circ}$ & $74,18^{\circ}$ & $73,26^{\circ}$ & $78,23^{\circ}$ & $79,33^{\circ}$ & $77,74^{\circ}$ \\
\hline $\mathbf{M}$ & $78,48^{\circ}$ & $74,55^{\circ}$ & $72,98^{\circ}$ & $78,04^{\circ}$ & $79,75^{\circ}$ & $78,16^{\circ}$ \\
\hline \multirow{5}{*}{17} & $71,20^{\circ}$ & $69,18^{\circ}$ & $67,66^{\circ}$ & $65,04^{\circ}$ & $66,62^{\circ}$ & $65,71^{\circ}$ \\
\hline & $71,21^{\circ}$ & $69,95^{\circ}$ & $68,40^{\circ}$ & $63,79^{\circ}$ & $64,47^{\circ}$ & $65,59^{\circ}$ \\
\hline & $71,31^{\circ}$ & $70,10^{\circ}$ & $68,80^{\circ}$ & $63,52^{\circ}$ & $65,37^{\circ}$ & $66,55^{\circ}$ \\
\hline & $71,29^{\circ}$ & $69,92^{\circ}$ & $68,18^{\circ}$ & $64,29^{\circ}$ & $65,02^{\circ}$ & $66,06^{\circ}$ \\
\hline & $71,19^{\circ}$ & $69,55^{\circ}$ & $68,36^{\circ}$ & $63,91^{\circ}$ & $65,93^{\circ}$ & $65,84^{\circ}$ \\
\hline $\mathbf{M}$ & $71,24^{\circ}$ & $69,74^{\circ}$ & $68,28^{\circ}$ & $64,11^{\circ}$ & $65,48^{\circ}$ & $65,95^{\circ}$ \\
\hline \multirow{5}{*}{18} & $76,73^{\circ}$ & $73,61^{\circ}$ & $71,01^{\circ}$ & $67,25^{\circ}$ & $69,11^{\circ}$ & $67,89^{\circ}$ \\
\hline & $75,93^{\circ}$ & $74,22^{\circ}$ & $71,00^{\circ}$ & $67,74^{\circ}$ & $67,14^{\circ}$ & $68,06^{\circ}$ \\
\hline & $76,06^{\circ}$ & $74,91^{\circ}$ & $71,61^{\circ}$ & $66,61^{\circ}$ & $67,42^{\circ}$ & $67,55^{\circ}$ \\
\hline & $76,49^{\circ}$ & $74,48^{\circ}$ & $71,42^{\circ}$ & $67,42^{\circ}$ & $68,24^{\circ}$ & $67,64^{\circ}$ \\
\hline & $75,99^{\circ}$ & $73,98^{\circ}$ & $70,96^{\circ}$ & $66,98^{\circ}$ & $67,54^{\circ}$ & $68,01^{\circ}$ \\
\hline $\mathbf{M}$ & $76,24^{\circ}$ & $74,25^{\circ}$ & $71,20^{\circ}$ & $67,20^{\circ}$ & $67,89^{\circ}$ & $67,83^{\circ}$ \\
\hline \multirow{5}{*}{19} & $75,85^{\circ}$ & $72,59^{\circ}$ & $72,55^{\circ}$ & $71,57^{\circ}$ & $73,56^{\circ}$ & $71,81^{\circ}$ \\
\hline & $74,82^{\circ}$ & $73,34^{\circ}$ & $73,74^{\circ}$ & $74,27^{\circ}$ & $71,83^{\circ}$ & $71,93^{\circ}$ \\
\hline & $75,00^{\circ}$ & $74,82^{\circ}$ & $71,36^{\circ}$ & $72,34^{\circ}$ & $72,58^{\circ}$ & $71,25^{\circ}$ \\
\hline & $75,63^{\circ}$ & $74,19^{\circ}$ & $73,08^{\circ}$ & $73,30^{\circ}$ & $73,04^{\circ}$ & $71,53^{\circ}$ \\
\hline & $74,80^{\circ}$ & $72,96^{\circ}$ & $72,02^{\circ}$ & $72,12^{\circ}$ & $72,24^{\circ}$ & $71,78^{\circ}$ \\
\hline $\mathbf{M}$ & $75,22^{\circ}$ & $73,58^{\circ}$ & $72,55^{\circ}$ & $72,72^{\circ}$ & $72,65^{\circ}$ & $71,66^{\circ}$ \\
\hline \multirow{5}{*}{20} & $77,43^{\circ}$ & $73,54^{\circ}$ & $76,17^{\circ}$ & $71,04^{\circ}$ & $71,80^{\circ}$ & $70,51^{\circ}$ \\
\hline & $78,60^{\circ}$ & $74,09^{\circ}$ & $75,25^{\circ}$ & $73,30^{\circ}$ & $72,72^{\circ}$ & $70,99^{\circ}$ \\
\hline & $77,72^{\circ}$ & $75,39^{\circ}$ & $74,29^{\circ}$ & $70,78^{\circ}$ & $72,15^{\circ}$ & $72,06^{\circ}$ \\
\hline & $78,52^{\circ}$ & $74,71^{\circ}$ & $74,68^{\circ}$ & $71,94^{\circ}$ & $72,35^{\circ}$ & $70,78^{\circ}$ \\
\hline & $77,28^{\circ}$ & $73,97^{\circ}$ & $75,76^{\circ}$ & $71,44^{\circ}$ & $72,08^{\circ}$ & $71,56^{\circ}$ \\
\hline $\mathbf{M}$ & $77,91^{\circ}$ & $74,34^{\circ}$ & $75,23^{\circ}$ & $71,70^{\circ}$ & $72,22^{\circ}$ & $71,18^{\circ}$ \\
\hline
\end{tabular}


Apêndice B - Valores originais e valores médios obtidos pelo programa Auto CAD, da medida X1 dos pacientes de 1 a 20.

\begin{tabular}{|c|c|c|c|c|c|c|}
\hline \multirow{2}{*}{$\begin{array}{l}\text { X1 }(\mathbf{c m}) \\
\text { Pacientes }\end{array}$} & \multicolumn{3}{|c|}{ ARCON } & \multicolumn{3}{|c|}{ NÃO-ARCON } \\
\hline & anterior & paralelo & posterior & anterior & paralelo & posterior \\
\hline \multirow{5}{*}{1} & 4,768 & 4,773 & 4,302 & 2,768 & 2,904 & 2,894 \\
\hline & 4,603 & 4,482 & 4,329 & 2,762 & 2,884 & 2,814 \\
\hline & 4,682 & 4,721 & 4,167 & 2,967 & 2,763 & 2,678 \\
\hline & 4,703 & 4,376 & 4,246 & 2,876 & 2,653 & 2,732 \\
\hline & 4,664 & 4,938 & 4,286 & 2,787 & 3,046 & 2,857 \\
\hline $\mathbf{M}$ & 4,684 & 4,658 & 4,266 & 2,832 & 2,850 & 2,795 \\
\hline \multirow{5}{*}{2} & 5,021 & 4,964 & 4,715 & 2,512 & 2,736 & 2,565 \\
\hline & 5,234 & 4,774 & 4,701 & 2,681 & 2,613 & 2,695 \\
\hline & 5,111 & 4,759 & 4,883 & 3,127 & 2,647 & 2,660 \\
\hline & 5,097 & 4,633 & 4,787 & 2,893 & 2,731 & 2,566 \\
\hline & 5,147 & 5,030 & 4,744 & 2,652 & 2,598 & 2,714 \\
\hline $\mathbf{M}$ & 5,122 & 4,832 & 4,766 & 2,773 & 2,665 & 2,640 \\
\hline \multirow{5}{*}{3} & 5,342 & 5,054 & 4,720 & 2,798 & 2,995 & 2,841 \\
\hline & 5,387 & 5,153 & 4,832 & 2,812 & 2,726 & 2,738 \\
\hline & 5,229 & 4,888 & 4,803 & 2,744 & 2,583 & 2,748 \\
\hline & 5,286 & 4,931 & 4,894 & 2,863 & 2,632 & 2,836 \\
\hline & 5,351 & 5,129 & 4,676 & 2,703 & 2,904 & 2,712 \\
\hline $\mathbf{M}$ & 5,319 & 5,031 & 4,785 & 2,784 & 2,768 & 2,775 \\
\hline \multirow{5}{*}{4} & 4,560 & 4,716 & 4,398 & 2,272 & 2,267 & 2,249 \\
\hline & 4,651 & 4,510 & 4,276 & 2,376 & 2,351 & 2,428 \\
\hline & 4,517 & 4,403 & 4,297 & 2,457 & 2,367 & 2,306 \\
\hline & 4,597 & 4,611 & 4,326 & 2,314 & 2,303 & 2,298 \\
\hline & 4,555 & 4,475 & 4,318 & 2,421 & 2,352 & 2,354 \\
\hline $\mathbf{M}$ & 4,576 & 4,543 & 4,323 & 2,368 & 2,328 & 2,327 \\
\hline \multirow{5}{*}{5} & 5,391 & 5,377 & 5,131 & 2,950 & 2,967 & 3,039 \\
\hline & 5,435 & 4,919 & 5,210 & 2,970 & 2,877 & 2,972 \\
\hline & 5,352 & 5,108 & 5,267 & 2,883 & 2,817 & 3,241 \\
\hline & 5,381 & 5,246 & 5,187 & 2,921 & 2,854 & 3,108 \\
\hline & 5,401 & 5,020 & 5,215 & 2,946 & 2,920 & 3,060 \\
\hline $\mathbf{M}$ & 5,392 & 5,134 & 5,202 & 2,934 & 2,887 & 3,084 \\
\hline \multirow{5}{*}{6} & 4,555 & 4,595 & 4,504 & 2,498 & 2,323 & 2,229 \\
\hline & 4,581 & 4,694 & 4,372 & 2,181 & 2,472 & 2,213 \\
\hline & 4,629 & 4,462 & 4,445 & 2,069 & 2,510 & 2,162 \\
\hline & 4,578 & 4,497 & 4,389 & 2,316 & 2,396 & 2,199 \\
\hline & 4,597 & 4,667 & 4,490 & 2,181 & 2,474 & 2,202 \\
\hline $\mathbf{M}$ & 4,588 & 4,583 & 4,440 & 2,249 & 2,435 & 2,201 \\
\hline \multirow{5}{*}{7} & 3,819 & 3,905 & 3,803 & 1,682 & 1,879 & 1,615 \\
\hline & 3,785 & 3,932 & 3,686 & 1,608 & 1,623 & 1,661 \\
\hline & 3,873 & 4,082 & 3,802 & 1,615 & 1,653 & 1,490 \\
\hline & 3,798 & 3,989 & 3,777 & 1,643 & 1,803 & 1,554 \\
\hline & 3,850 & 3,957 & 3,747 & 1,627 & 1,632 & 1,620 \\
\hline $\mathbf{M}$ & 3,825 & 3,973 & 3,763 & 1,635 & 1,718 & 1,588 \\
\hline \multirow{5}{*}{8} & 4,925 & 4,697 & 4,361 & 2,137 & 2,242 & 2,060 \\
\hline & 4,866 & 4,525 & 4,331 & 2,485 & 2,292 & 2,185 \\
\hline & 4,853 & 4,641 & 4,541 & 2,235 & 2,108 & 2,100 \\
\hline & 4,876 & 4,653 & 4,446 & 2,338 & 2,176 & 2,109 \\
\hline & 4,885 & 4,589 & 4,376 & 2,230 & 2,252 & 2,121 \\
\hline $\mathbf{M}$ & 4,881 & 4,621 & 4,411 & 2,285 & 2,214 & 2,115 \\
\hline \multirow{5}{*}{9} & 5,175 & 4,510 & 4,938 & 2,465 & 2,255 & 2,602 \\
\hline & 5,135 & 4,799 & 4,728 & 2,356 & 2,405 & 2,649 \\
\hline & 5,317 & 4,848 & 4,796 & 2,664 & 2,601 & 2,589 \\
\hline & 5,185 & 4,659 & 4,817 & 2,532 & 2,397 & 2,621 \\
\hline & 5,233 & 4,779 & 4,821 & 2,458 & 2,442 & 2,604 \\
\hline $\mathbf{M}$ & 5,209 & 4,719 & 4,820 & 2,495 & 2,420 & 2,613 \\
\hline \multirow{5}{*}{10} & 5,204 & 4,596 & 4,871 & 2,460 & 2,779 & 2,708 \\
\hline & 4,708 & 4,942 & 4,869 & 2,602 & 2,817 & 2,844 \\
\hline & 5,214 & 4,825 & 4,889 & 2,491 & 2,752 & 2,755 \\
\hline & 5,153 & 4,736 & 4,881 & 2,533 & 2,767 & 2,778 \\
\hline & 4,931 & 4,836 & 4,870 & 2,499 & 2,795 & 2,760 \\
\hline
\end{tabular}




\begin{tabular}{|c|c|c|c|c|c|c|}
\hline $\mathbf{M}$ & 5,042 & 4,787 & 4,876 & 2,517 & 2,782 & 2,769 \\
\hline \multirow{5}{*}{11} & 4,763 & 4,528 & 4,730 & 2,628 & 2,792 & 2,645 \\
\hline & 4,751 & 4,386 & 4,504 & 2,938 & 2,948 & 2,689 \\
\hline & 4,875 & 4,336 & 4,648 & 2,829 & 2,782 & 2,823 \\
\hline & 4,833 & 4,395 & 4,596 & 2,758 & 2,839 & 2,697 \\
\hline & 4,758 & 4,435 & 4,657 & 2,837 & 2,839 & 2,741 \\
\hline $\mathbf{M}$ & 4,796 & 4,416 & 4,627 & 2,798 & 2,840 & 2,719 \\
\hline \multirow{5}{*}{12} & 4,483 & 4,279 & 4,248 & 2,320 & 2,491 & 2,481 \\
\hline & 4,655 & 4,479 & 4,242 & 2,604 & 2,440 & 2,436 \\
\hline & 4,447 & 4,506 & 4,343 & 2,458 & 2,354 & 2,506 \\
\hline & 4,555 & 4,387 & 4,287 & 2,517 & 2,457 & 2,498 \\
\hline & 4,500 & 4,454 & 4,265 & 2,401 & 2,398 & 2,449 \\
\hline M & 4,528 & 4,421 & 4,277 & 2,460 & 2,428 & 2,474 \\
\hline \multirow{5}{*}{13} & 5,580 & 5,060 & 4,626 & 3,256 & 2,921 & 2,828 \\
\hline & 5,444 & 4,949 & 4,778 & 2,837 & 2,908 & 2,856 \\
\hline & 5,216 & 5,230 & 4,908 & 3,083 & 3,111 & 3,030 \\
\hline & 5,397 & 5,154 & 4,820 & 3,118 & 3,035 & 2,915 \\
\hline & 5,428 & 5,002 & 4,718 & 2,996 & 2,925 & 2,891 \\
\hline M & 5,413 & 5,079 & 4,770 & 3,058 & 2,980 & 2,904 \\
\hline \multirow{5}{*}{14} & 5,322 & 5,149 & 5,040 & 3,274 & 3,214 & 2,879 \\
\hline & 5,348 & 5,407 & 4,990 & 2,884 & 3,168 & 2,914 \\
\hline & 5,399 & 5,663 & 4,637 & 2,722 & 3,194 & 2,981 \\
\hline & 5,364 & 5,523 & 4,765 & 3,105 & 3,189 & 2,954 \\
\hline & 5,347 & 5,288 & 5,013 & 2,815 & 3,195 & 2,892 \\
\hline $\mathbf{M}$ & 5,356 & 5,406 & 4,889 & 2,960 & 3,192 & 2,924 \\
\hline \multirow{5}{*}{15} & 4,953 & 4,731 & 4,738 & 2,913 & 2,683 & 2,791 \\
\hline & 5,135 & 4,820 & 4,628 & 3,003 & 2,761 & 2,855 \\
\hline & 5,028 & 4,776 & 4,671 & 2,728 & 2,800 & 2,742 \\
\hline & 5,056 & 4,754 & 4,713 & 2,845 & 2,699 & 2,817 \\
\hline & 5,018 & 4,794 & 4,645 & 2,916 & 2,797 & 2,775 \\
\hline $\mathbf{M}$ & 5,038 & 4,775 & 4,679 & 2,881 & 2,748 & 2,796 \\
\hline \multirow{5}{*}{16} & 5,069 & 5,074 & 4,603 & 3,069 & 3,205 & 3,195 \\
\hline & 4,904 & 4,783 & 4,630 & 3,063 & 3,185 & 3,115 \\
\hline & 4,983 & 5,022 & 4,468 & 3,268 & 3,064 & 2,979 \\
\hline & 5,004 & 4,677 & 4,547 & 3,177 & 2,954 & 3,033 \\
\hline & 4,965 & 5,239 & 4,587 & 3,088 & 3,347 & 3,158 \\
\hline $\mathbf{M}$ & 4,985 & 4,959 & 4,567 & 3,133 & 3,151 & 3,096 \\
\hline \multirow{5}{*}{17} & 5,240 & 4,952 & 4,618 & 2,696 & 2,893 & 2,739 \\
\hline & 5,285 & 5,051 & 4,730 & 2,710 & 2,624 & 2,636 \\
\hline & 5,127 & 4,786 & 4,701 & 2,642 & 2,481 & 2,646 \\
\hline & 5,184 & 4,829 & 4,792 & 2,761 & 2,530 & 2,734 \\
\hline & 5,249 & 5,027 & 4,574 & 2,601 & 2,802 & 2,610 \\
\hline $\mathbf{M}$ & 5,217 & 4,929 & 4,683 & 2,682 & 2,666 & 2,673 \\
\hline \multirow{5}{*}{18} & 4,938 & 4,710 & 4,374 & 2,150 & 2,255 & 2,073 \\
\hline & 4,879 & 4,538 & 4,344 & 2,498 & 2,305 & 2,198 \\
\hline & 4,866 & 4,654 & 4,554 & 2,248 & 2,121 & 2,113 \\
\hline & 4,889 & 4,666 & 4,459 & 2,351 & 2,189 & 2,122 \\
\hline & 4,898 & 4,602 & 4,389 & 2,242 & 2,265 & 2,134 \\
\hline $\mathbf{M}$ & 4,894 & 4,634 & 4,424 & 2,298 & 2,227 & 2,128 \\
\hline \multirow{5}{*}{19} & 4,819 & 4,584 & 4,786 & 2,684 & 2,848 & 2,701 \\
\hline & 4,807 & 4,442 & 4,560 & 2,994 & 3,004 & 2,745 \\
\hline & 4,931 & 4,392 & 4,704 & 2,885 & 2,838 & 2,879 \\
\hline & 4,889 & 4,451 & 4,652 & 2,814 & 2,895 & 2,753 \\
\hline & 4,814 & 4,491 & 4,713 & 2,893 & 2,895 & 2,797 \\
\hline $\mathbf{M}$ & 4,852 & 4,472 & 4,683 & 2,854 & 2,896 & 2,775 \\
\hline \multirow{5}{*}{20} & 4,954 & 4,732 & 4,739 & 2,914 & 2,684 & 2,792 \\
\hline & 5,136 & 4,821 & 4,629 & 3,004 & 2,762 & 2,856 \\
\hline & 5,029 & 4,777 & 4,672 & 2,729 & 2,801 & 2,743 \\
\hline & 5,057 & 4,755 & 4,714 & 2,846 & 2,700 & 2,818 \\
\hline & 5,019 & 4,795 & 4,646 & 2,917 & 2,798 & 2,776 \\
\hline $\mathbf{M}$ & 5,039 & 4,776 & 4,680 & 2,882 & 2,749 & 2,797 \\
\hline
\end{tabular}


Apêndice $\mathbf{C}$ - Valores originais e valores médios obtidos pelo programa Auto CAD, da medida X2 dos pacientes de 1 a 20.

\begin{tabular}{|c|c|c|c|c|c|c|}
\hline \multirow{2}{*}{$\begin{array}{c}\text { X2 } \mathbf{( c m )} \\
\text { Pacientes }\end{array}$} & \multicolumn{3}{|c|}{ ARCON } & \multicolumn{3}{|c|}{ NÃO-ARCON } \\
\hline & anterior & paralelo & posterior & anterior & paralelo & posterior \\
\hline \multirow{5}{*}{1} & 7,440 & 7,651 & 6,991 & 5,527 & 5,494 & 5,646 \\
\hline & 7,334 & 7,108 & 7,004 & 5,554 & 5,592 & 5,599 \\
\hline & 7,413 & 7,462 & 6,796 & 5,821 & 5,418 & 5,524 \\
\hline & 7,369 & 7,377 & 6,821 & 5,716 & 5,407 & 5,560 \\
\hline & 7,419 & 7,437 & 7,038 & 5,552 & 5,594 & 5,616 \\
\hline $\mathbf{M}$ & 7,395 & 7,407 & 6,930 & 5,634 & 5,501 & 5,589 \\
\hline \multirow{5}{*}{2} & 7,517 & 7,594 & 7,197 & 5,080 & 5,254 & 4,905 \\
\hline & 7,807 & 7,251 & 7,109 & 5,272 & 5,125 & 5,188 \\
\hline & 7,696 & 7,270 & 7,228 & 5,347 & 5,074 & 5,105 \\
\hline & 7,723 & 7,432 & 7,154 & 5,176 & 5,168 & 5,170 \\
\hline & 7,622 & 7,308 & 7,202 & 5,290 & 5,134 & 4,962 \\
\hline $\mathbf{M}$ & 7,673 & 7,371 & 7,178 & 5,233 & 5,151 & 5,066 \\
\hline \multirow{5}{*}{3} & 7,990 & 7,568 & 7,169 & 5,309 & 5,710 & 5,469 \\
\hline & 8,006 & 7,772 & 7,405 & 5,435 & 5,224 & 5,282 \\
\hline & 7,828 & 7,424 & 7,305 & 5,261 & 4,992 & 5,343 \\
\hline & 7,907 & 7,618 & 7,221 & 5,338 & 5,463 & 5,381 \\
\hline & 7,974 & 7,558 & 7,365 & 5,332 & 5,151 & 5,345 \\
\hline $\mathbf{M}$ & 7,941 & 7,588 & 7,293 & 5,335 & 5,308 & 5,364 \\
\hline \multirow{5}{*}{4} & 7,233 & 7,263 & 6,966 & 4,766 & 4,816 & 4,778 \\
\hline & 7,226 & 7,132 & 6,762 & 4,878 & 4,903 & 5,020 \\
\hline & 7,116 & 7,082 & 6,799 & 5,021 & 4,907 & 4,817 \\
\hline & 7,197 & 7,178 & 6,845 & 4,923 & 4,888 & 4,935 \\
\hline & 7,183 & 7,140 & 6,838 & 4,852 & 4,861 & 4,805 \\
\hline M & 7,191 & 7,159 & 6,842 & 4,888 & 4,875 & 4,871 \\
\hline \multirow{5}{*}{5} & 8,199 & 8,301 & 7,770 & 5,624 & 5,782 & 5,670 \\
\hline & 8,175 & 7,633 & 7,958 & 5,584 & 5,647 & 5,694 \\
\hline & 8,116 & 7,841 & 7,988 & 5,530 & 5,604 & 5,910 \\
\hline & 8,153 & 8,033 & 7,826 & 5,595 & 5,714 & 5,802 \\
\hline & 8,172 & 7,817 & 7,983 & 5,562 & 5,638 & 5,714 \\
\hline $\mathbf{M}$ & 8,163 & 7,925 & 7,905 & 5,579 & 5,677 & 5,758 \\
\hline \multirow{5}{*}{6} & 7,035 & 7,097 & 6,905 & 4,815 & 4,647 & 4,555 \\
\hline & 7,083 & 7,241 & 6,741 & 4,478 & 4,964 & 4,668 \\
\hline & 7,115 & 6,894 & 6,882 & 4,336 & 4,915 & 4,575 \\
\hline & 7,106 & 7,106 & 6,795 & 4,616 & 4,797 & 4,610 \\
\hline & 7,046 & 7,047 & 6,887 & 4,470 & 4,887 & 4,587 \\
\hline $\mathbf{M}$ & 7,077 & 7,077 & 6,842 & 4,543 & 4,842 & 4,599 \\
\hline \multirow{5}{*}{7} & 6,272 & 6,530 & 6,343 & 4,026 & 4,450 & 4,134 \\
\hline & 6,381 & 6,565 & 6,187 & 4,092 & 4,172 & 4,248 \\
\hline & 6,520 & 6,703 & 6,404 & 4,204 & 4,188 & 3,940 \\
\hline & 6,421 & 6,623 & 6,265 & 4,123 & 4,235 & 3,997 \\
\hline & 6,361 & 6,574 & 6,356 & 4,090 & 4,305 & 4,216 \\
\hline $\mathbf{M}$ & 6,391 & 6,599 & 6,311 & 4,107 & 4,270 & 4,107 \\
\hline \multirow{5}{*}{8} & 7,490 & 7,247 & 6,878 & 4,545 & 4,871 & 4,592 \\
\hline & 7,471 & 7,079 & 6,840 & 5,020 & 4,748 & 4,803 \\
\hline & 7,389 & 7,177 & 7,112 & 4,753 & 4,539 & 4,708 \\
\hline & 7,432 & 7,135 & 6,965 & 4,866 & 4,654 & 4,689 \\
\hline & 7,468 & 7,197 & 6,920 & 4,676 & 4,783 & 4,713 \\
\hline $\mathbf{M}$ & 7,450 & 7,167 & 6,943 & 4,772 & 4,719 & 4,701 \\
\hline \multirow{5}{*}{9} & 7,670 & 6,895 & 7,407 & 4,750 & 4,511 & 4,941 \\
\hline & 7,603 & 7,292 & 7,084 & 4,677 & 4,732 & 5,071 \\
\hline & 7,656 & 7,273 & 7,115 & 4,969 & 4,951 & 4,990 \\
\hline & 7,639 & 7,098 & 7,321 & 4,835 & 4,678 & 4,989 \\
\hline & 7,647 & 7,207 & 7,083 & 4,759 & 4,783 & 5,009 \\
\hline $\mathbf{M}$ & 7,643 & 7,153 & 7,202 & 4,798 & 4,731 & 5,000 \\
\hline \multirow{5}{*}{10} & 7,941 & 7,197 & 7,401 & 5,021 & 5,523 & 5,336 \\
\hline & 7,241 & 7,626 & 7,371 & 5,116 & 5,466 & 5,434 \\
\hline & 7,822 & 7,371 & 7,514 & 4,965 & 5,504 & 5,491 \\
\hline & 7,757 & 7,412 & 7,416 & 4,997 & 5,478 & 5,448 \\
\hline & 7,579 & 7,411 & 7,438 & 5,071 & 5,514 & 5,391 \\
\hline
\end{tabular}




\begin{tabular}{|c|c|c|c|c|c|c|}
\hline $\mathbf{M}$ & 7,668 & 7,398 & 7,428 & 5,034 & 5,497 & 5,420 \\
\hline \multirow{5}{*}{11} & 7,224 & 6,991 & 7,077 & 5,032 & 5,201 & 4,985 \\
\hline & 7,117 & 6,827 & 6,945 & 5,515 & 5,424 & 5,084 \\
\hline & 7,312 & 6,817 & 7,019 & 5,311 & 5,297 & 5,291 \\
\hline & 7,189 & 6,876 & 6,998 & 5,431 & 5,396 & 5,153 \\
\hline & 7,243 & 6,879 & 7,026 & 5,141 & 5,217 & 5,087 \\
\hline $\mathbf{M}$ & 7,217 & 6,878 & 7,013 & 5,286 & 5,307 & 5,120 \\
\hline \multirow{5}{*}{12} & 7,035 & 6,770 & 6,713 & 4,851 & 5,099 & 4,963 \\
\hline & 7,283 & 6,932 & 6,702 & 5,253 & 5,010 & 4,893 \\
\hline & 6,977 & 7,032 & 6,780 & 4,992 & 4,922 & 4,928 \\
\hline & 7,154 & 6,889 & 6,746 & 5,153 & 4,976 & 4,937 \\
\hline & 7,041 & 6,932 & 6,714 & 4,911 & 5,043 & 4,919 \\
\hline $\mathbf{M}$ & 7,098 & 6,911 & 6,731 & 5,032 & 5,010 & 4,928 \\
\hline \multirow{5}{*}{13} & 8,121 & 7,591 & 7,134 & 5,785 & 5,262 & 5,301 \\
\hline & 7,983 & 7,415 & 7,292 & 5,272 & 5,450 & 5,428 \\
\hline & 7,697 & 7,817 & 7,448 & 5,485 & 5,710 & 5,573 \\
\hline & 8,007 & 7,710 & 7,311 & 5,625 & 5,526 & 5,517 \\
\hline & 7,857 & 7,502 & 7,270 & 5,403 & 5,422 & 5,351 \\
\hline $\mathbf{M}$ & 7,933 & 7,607 & 7,291 & 5,514 & 5,474 & 5,434 \\
\hline \multirow{5}{*}{14} & 7,626 & 7,582 & 7,345 & 5,581 & 5,480 & 5,238 \\
\hline & 7,607 & 7,779 & 7,274 & 5,167 & 5,503 & 5,245 \\
\hline & 7,745 & 8,113 & 6,840 & 5,083 & 5,594 & 5,303 \\
\hline & 7,703 & 7,925 & 6,963 & 5,323 & 5,537 & 5,276 \\
\hline & 7,614 & 7,721 & 7,343 & 5,231 & 5,511 & 5,248 \\
\hline $\mathbf{M}$ & 7,659 & 7,824 & 7,153 & 5,277 & 5,525 & 5,262 \\
\hline \multirow{5}{*}{15} & 7,429 & 7,211 & 7,291 & 5,478 & 5,188 & 5,333 \\
\hline & 7,680 & 7,311 & 7,124 & 5,594 & 5,329 & 5,371 \\
\hline & 7,595 & 7,204 & 7,121 & 5,293 & 5,306 & 5,225 \\
\hline & 7,465 & 7,267 & 7,212 & 5,388 & 5,265 & 5,279 \\
\hline & 7,671 & 7,217 & 7,142 & 5,522 & 5,282 & 5,337 \\
\hline $\mathbf{M}$ & 7,568 & 7,242 & 7,178 & 5,455 & 5,274 & 5,309 \\
\hline \multirow{5}{*}{16} & 7,741 & 7,952 & 7,292 & 5,828 & 5,795 & 5,947 \\
\hline & 7,635 & 7,409 & 7,305 & 5,855 & 5,893 & 5,900 \\
\hline & 7,714 & 7,763 & 7,097 & 6,122 & 5,719 & 5,825 \\
\hline & 7,670 & 7,678 & 7,122 & 6,017 & 5,708 & 5,861 \\
\hline & 7,720 & 7,738 & 7,339 & 5,853 & 5,895 & 5,917 \\
\hline $\mathbf{M}$ & 7,696 & 7,708 & 7,231 & 5,935 & 5,802 & 5,890 \\
\hline \multirow{5}{*}{17} & 7,888 & 7,466 & 7,067 & 5,207 & 5,608 & 5,367 \\
\hline & 7,904 & 7,670 & 7,303 & 5,333 & 5,122 & 5,180 \\
\hline & 7,726 & 7,322 & 7,203 & 5,159 & 4,890 & 5,241 \\
\hline & 7,805 & 7,516 & 7,119 & 5,236 & 5,361 & 5,279 \\
\hline & 7,872 & 7,456 & 7,263 & 5,230 & 5,049 & 5,243 \\
\hline $\mathbf{M}$ & 7,839 & 7,486 & 7,191 & 5,233 & 5,206 & 5,262 \\
\hline \multirow{5}{*}{18} & 7,503 & 7,260 & 6,891 & 4,558 & 4,884 & 4,605 \\
\hline & 7,484 & 7,092 & 6,853 & 5,033 & 4,761 & 4,816 \\
\hline & 7,402 & 7,190 & 7,125 & 4,766 & 4,552 & 4,721 \\
\hline & 7,445 & 7,148 & 6,978 & 4,879 & 4,667 & 4,702 \\
\hline & 7,481 & 7,210 & 6,933 & 4,689 & 4,796 & 4,726 \\
\hline $\mathbf{M}$ & 7,463 & 7,180 & 6,956 & 4,785 & 4,732 & 4,714 \\
\hline \multirow{5}{*}{19} & 7,280 & 7,047 & 7,133 & 5,088 & 5,257 & 5,041 \\
\hline & 7,173 & 6,883 & 7,001 & 5,571 & 5,480 & 5,140 \\
\hline & 7,368 & 6,873 & 7,075 & 5,367 & 5,353 & 5,347 \\
\hline & 7,245 & 6,932 & 7,054 & 5,487 & 5,452 & 5,209 \\
\hline & 7,299 & 6,935 & 7,082 & 5,197 & 5,273 & 5,143 \\
\hline $\mathbf{M}$ & 7,273 & 6,934 & 7,069 & 5,342 & 5,363 & 5,176 \\
\hline \multirow{5}{*}{20} & 7,460 & 7,242 & 7,322 & 5,509 & 5,219 & 5,364 \\
\hline & 7,711 & 7,342 & 7,155 & 5,625 & 5,360 & 5,402 \\
\hline & 7,626 & 7,235 & 7,152 & 5,324 & 5,337 & 5,256 \\
\hline & 7,496 & 7,298 & 7,243 & 5,419 & 5,296 & 5,310 \\
\hline & 7,702 & 7,248 & 7,173 & 5,553 & 5,313 & 5,368 \\
\hline $\mathbf{M}$ & 7,599 & 7,273 & 7,209 & 5,486 & 5,305 & 5,340 \\
\hline
\end{tabular}


Apêndice D - Valores originais e valores médios obtidos pelo programa Auto CAD, da medida X3 dos pacientes de 1 a 20.

\begin{tabular}{|c|c|c|c|c|c|c|}
\hline \multirow{2}{*}{$\begin{array}{c}\mathbf{X 3}(\mathbf{c m}) \\
\text { Pacientes } \\
\end{array}$} & \multicolumn{3}{|c|}{ ARCON } & \multicolumn{3}{|c|}{ NÃO-ARCON } \\
\hline & anterior & paralelo & posterior & anterior & paralelo & posterior \\
\hline \multirow{5}{*}{1} & 4,517 & 4,704 & 4,179 & 6,905 & 6,764 & 7,035 \\
\hline & 4,571 & 4,270 & 4,422 & 7,222 & 6,804 & 6,978 \\
\hline & 4,407 & 4,325 & 4,238 & 7,099 & 6,979 & 7,057 \\
\hline & 4,436 & 4,502 & 4,308 & 7,111 & 6,832 & 7,026 \\
\hline & 4,559 & 4,364 & 4,248 & 7,038 & 6,866 & 7,019 \\
\hline $\mathbf{M}$ & 4,498 & 4,433 & 4,279 & 7,075 & 6,849 & 7,023 \\
\hline \multirow{5}{*}{2} & 4,867 & 5,039 & 4,794 & 7,006 & 7,058 & 6,881 \\
\hline & 5,141 & 4,770 & 4,697 & 7,021 & 7,127 & 7,069 \\
\hline & 4,950 & 4,772 & 4,594 & 6,974 & 7,003 & 7,169 \\
\hline & 5,087 & 4,961 & 4,632 & 6,993 & 7,084 & 6,927 \\
\hline & 4,885 & 4,758 & 4,758 & 7,006 & 7,038 & 7,149 \\
\hline $\mathbf{M}$ & 4,986 & 4,860 & 4,695 & 7,000 & 7,062 & 7,039 \\
\hline \multirow{5}{*}{3} & 4,784 & 4,547 & 4,507 & 6,983 & 7,345 & 7,036 \\
\hline & 4,883 & 4,679 & 4,628 & 7,190 & 6,924 & 7,027 \\
\hline & 4,854 & 4,480 & 4,485 & 6,954 & 6,752 & 7,136 \\
\hline & 4,817 & 4,521 & 4,617 & 7,037 & 6,843 & 7,084 \\
\hline & 4,862 & 4,613 & 4,463 & 7,046 & 7,171 & 7,047 \\
\hline $\mathbf{M}$ & 4,840 & 4,568 & 4,540 & 7,042 & 7,007 & 7,066 \\
\hline \multirow{5}{*}{4} & 4,942 & 4,863 & 4,842 & 7,203 & 7,109 & 7,186 \\
\hline & 5,000 & 4,788 & 4,742 & 7,155 & 7,299 & 7,311 \\
\hline & 4,874 & 4,846 & 4,779 & 7,087 & 7,269 & 7,338 \\
\hline & 4,903 & 4,812 & 4,716 & 7,112 & 7,144 & 7,253 \\
\hline & 4,971 & 4,851 & 4,856 & 7,183 & 7,304 & 7,302 \\
\hline $\mathbf{M}$ & 4,938 & 4,832 & 4,787 & 7,148 & 7,225 & 7,278 \\
\hline \multirow{5}{*}{5} & 4,709 & 4,784 & 4,636 & 6,689 & 6,896 & 6,777 \\
\hline & 4,692 & 4,593 & 4,491 & 6,629 & 6,804 & 6,925 \\
\hline & 4,650 & 4,552 & 4,438 & 6,712 & 6,846 & 6,936 \\
\hline & 4,675 & 4,665 & 4,561 & 6,659 & 6,837 & 6,845 \\
\hline & 4,689 & 4,621 & 4,479 & 6,691 & 6,857 & 6,912 \\
\hline $\mathbf{M}$ & 4,683 & 4,643 & 4,521 & 6,676 & 6,848 & 6,879 \\
\hline \multirow{5}{*}{6} & 4,791 & 4,811 & 4,619 & 6,624 & 6,980 & 7,068 \\
\hline & 4,796 & 4,882 & 4,710 & 7,048 & 7,117 & 7,358 \\
\hline & 4,891 & 4,806 & 4,656 & 6,994 & 6,771 & 7,125 \\
\hline & 4,835 & 4,841 & 4,638 & 6,773 & 7,088 & 7,236 \\
\hline & 4,817 & 4,825 & 4,682 & 7,001 & 6,801 & 7,128 \\
\hline $\mathbf{M}$ & 4,826 & 4,833 & 4,661 & 6,888 & 6,945 & 7,183 \\
\hline \multirow{5}{*}{7} & 5,338 & 5,180 & 5,184 & 7,486 & 7,273 & 7,474 \\
\hline & 5,347 & 5,194 & 5,116 & 7,607 & 7,471 & 7,773 \\
\hline & 5,338 & 5,253 & 5,383 & 7,706 & 7,708 & 7,452 \\
\hline & 5,345 & 5,231 & 5,234 & 7,553 & 7,531 & 7,632 \\
\hline & 5,337 & 5,187 & 5,218 & 7,643 & 7,437 & 7,499 \\
\hline $\mathbf{M}$ & 5,341 & 5,209 & 5,227 & 7,599 & 7,484 & 7,566 \\
\hline \multirow{5}{*}{8} & 4,390 & 4,435 & 4,395 & 6,440 & 6,351 & 6,412 \\
\hline & 4,431 & 4,358 & 4,208 & 6,466 & 6,254 & 6,683 \\
\hline & 4,400 & 4,258 & 4,214 & 6,516 & 6,303 & 6,672 \\
\hline & 4,399 & 4,278 & 4,309 & 6,489 & 6,277 & 6,554 \\
\hline & 4,415 & 4,421 & 4,234 & 6,459 & 6,325 & 6,624 \\
\hline $\mathbf{M}$ & 4,407 & 4,350 & 4,272 & 6,474 & 6,302 & 6,589 \\
\hline \multirow{5}{*}{9} & 5,137 & 4,709 & 4,784 & 7,209 & 7,154 & 7,169 \\
\hline & 4,456 & 4,904 & 4,760 & 7,174 & 7,034 & 7,207 \\
\hline & 4,765 & 4,947 & 4,824 & 7,174 & 7,090 & 7,162 \\
\hline & 4,853 & 4,798 & 4,807 & 7,193 & 7,112 & 7,180 \\
\hline & 4,719 & 4,907 & 4,770 & 7,175 & 7,070 & 7,177 \\
\hline $\mathbf{M}$ & 4,786 & 4,853 & 4,789 & 7,185 & 7,092 & 7,179 \\
\hline \multirow{5}{*}{10} & 4,613 & 4,200 & 3,986 & 6,790 & 7,013 & 6,675 \\
\hline & 4,280 & 4,402 & 4,052 & 6,816 & 6,804 & 6,669 \\
\hline & 4,559 & 4,349 & 3,980 & 6,870 & 7,036 & 6,988 \\
\hline & 4,397 & 4,296 & 3,997 & 6,834 & 6,885 & 6,843 \\
\hline & 4,571 & 4,338 & 4,015 & 6,815 & 7,017 & 6,710 \\
\hline
\end{tabular}




\begin{tabular}{|c|c|c|c|c|c|c|}
\hline $\mathbf{M}$ & 4,484 & 4,317 & 4,006 & 6,825 & 6,951 & 6,777 \\
\hline \multirow{5}{*}{11} & 4,638 & 4,417 & 4,366 & 7,261 & 7,007 & 7,263 \\
\hline & 4,642 & 4,249 & 4,446 & 7,319 & 7,399 & 7,195 \\
\hline & 4,587 & 4,223 & 4,370 & 7,326 & 7,198 & 7,358 \\
\hline & 4,596 & 4,305 & 4,388 & 7,297 & 7,326 & 7,304 \\
\hline & 4,647 & 4,286 & 4,400 & 7,307 & 7,075 & 7,240 \\
\hline $\mathbf{M}$ & 4,622 & 4,296 & 4,394 & 7,302 & 7,201 & 7,272 \\
\hline \multirow{5}{*}{12} & 5,252 & 5,031 & 4,208 & 7,629 & 7,681 & 7,918 \\
\hline & 5,046 & 5,183 & 4,862 & 7,897 & 7,872 & 7,604 \\
\hline & 5,216 & 5,066 & 4,944 & 7,782 & 7,873 & 7,640 \\
\hline & 5,189 & 5,124 & 4,543 & 7,695 & 7,831 & 7,834 \\
\hline & 5,152 & 5,061 & 4,798 & 7,842 & 7,783 & 7,604 \\
\hline $\mathbf{M}$ & 5,171 & 5,093 & 4,671 & 7,769 & 7,808 & 7,720 \\
\hline \multirow{5}{*}{13} & 4,563 & 4,163 & 4,134 & 6,926 & 6,478 & 6,786 \\
\hline & 4,451 & 4,358 & 4,052 & 6,715 & 6,889 & 6,699 \\
\hline & 4,465 & 4,424 & 4,030 & 6,728 & 6,968 & 6,728 \\
\hline & 4,503 & 4,287 & 4,108 & 6,820 & 6,832 & 6,745 \\
\hline & 4,483 & 4,343 & 4,036 & 6,756 & 6,723 & 6,727 \\
\hline $\mathbf{M}$ & 4,493 & 4,315 & 4,072 & 6,789 & 6,778 & 6,737 \\
\hline \multirow{5}{*}{14} & 4,846 & 4,879 & 4,576 & 6,976 & 7,226 & 7,205 \\
\hline & 4,733 & 4,858 & 4,549 & 7,115 & 6,962 & 7,200 \\
\hline & 4,849 & 4,864 & 4,561 & 6,787 & 7,295 & 7,117 \\
\hline & 4,785 & 4,870 & 4,559 & 7,032 & 7,183 & 7,189 \\
\hline & 4,832 & 4,864 & 4,565 & 6,885 & 7,139 & 7,159 \\
\hline $\mathbf{M}$ & 4,809 & 4,867 & 4,562 & 6,959 & 7,161 & 7,174 \\
\hline \multirow{5}{*}{15} & 4,830 & 4,576 & 4,542 & 7,317 & 7,258 & 7,430 \\
\hline & 4,897 & 4,691 & 4,515 & 7,541 & 7,332 & 7,402 \\
\hline & 4,741 & 4,647 & 4,506 & 7,375 & 7,291 & 6,962 \\
\hline & 4,796 & 4,588 & 4,530 & 7,434 & 7,275 & 7,321 \\
\hline & 4,846 & 4,688 & 4,512 & 7,388 & 7,309 & 7,205 \\
\hline $\mathbf{M}$ & 4,822 & 4,638 & 4,521 & 7,411 & 7,293 & 7,264 \\
\hline \multirow{5}{*}{16} & 4,818 & 5,005 & 4,480 & 7,206 & 7,065 & 7,336 \\
\hline & 4,872 & 4,571 & 4,723 & 7,523 & 7,105 & 7,279 \\
\hline & 4,708 & 4,626 & 4,539 & 7,400 & 7,280 & 7,358 \\
\hline & 4,737 & 4,803 & 4,609 & 7,412 & 7,133 & 7,327 \\
\hline & 4,860 & 4,665 & 4,549 & 7,339 & 7,167 & 7,320 \\
\hline $\mathbf{M}$ & 4,799 & 4,734 & 4,580 & 7,376 & 7,150 & 7,324 \\
\hline \multirow{5}{*}{17} & 4,682 & 4,445 & 4,405 & 6,881 & 7,243 & 6,934 \\
\hline & 4,781 & 4,577 & 4,526 & 7,088 & 6,822 & 6,925 \\
\hline & 4,752 & 4,378 & 4,383 & 6,852 & 6,650 & 7,034 \\
\hline & 4,715 & 4,419 & 4,515 & 6,935 & 6,741 & 6,982 \\
\hline & 4,760 & 4,511 & 4,361 & 6,944 & 7,069 & 6,945 \\
\hline $\mathbf{M}$ & 4,738 & 4,466 & 4,438 & 6,940 & 6,905 & 6,964 \\
\hline \multirow{5}{*}{18} & 4,403 & 4,448 & 4,408 & 6,453 & 6,364 & 6,425 \\
\hline & 4,444 & 4,371 & 4,221 & 6,479 & 6,267 & 6,696 \\
\hline & 4,413 & 4,271 & 4,227 & 6,529 & 6,316 & 6,685 \\
\hline & 4,412 & 4,291 & 4,322 & 6,502 & 6,290 & 6,567 \\
\hline & 4,428 & 4,434 & 4,247 & 6,472 & 6,338 & 6,637 \\
\hline $\mathbf{M}$ & 4,420 & 4,363 & 4,285 & 6,487 & 6,315 & 6,602 \\
\hline \multirow{5}{*}{19} & 4,694 & 4,473 & 4,422 & 7,317 & 7,063 & 7,319 \\
\hline & 4,698 & 4,305 & 4,502 & 7,375 & 7,455 & 7,251 \\
\hline & 4,643 & 4,279 & 4,426 & 7,382 & 7,254 & 7,414 \\
\hline & 4,652 & 4,361 & 4,444 & 7,353 & 7,382 & 7,360 \\
\hline & 4,703 & 4,342 & 4,456 & 7,363 & 7,131 & 7,296 \\
\hline $\mathbf{M}$ & 4,678 & 4,352 & 4,450 & 7,358 & 7,257 & 7,328 \\
\hline \multirow{5}{*}{20} & 4,861 & 4,607 & 4,573 & 7,348 & 7,289 & 7,461 \\
\hline & 4,928 & 4,722 & 4,546 & 7,572 & 7,363 & 7,433 \\
\hline & 4,772 & 4,678 & 4,537 & 7,406 & 7,322 & 6,993 \\
\hline & 4,827 & 4,619 & 4,561 & 7,465 & 7,306 & 7,352 \\
\hline & 4,877 & 4,719 & 4,543 & 7,419 & 7,340 & 7,236 \\
\hline $\mathbf{M}$ & 4,853 & 4,669 & 4,552 & 7,442 & 7,324 & 7,295 \\
\hline
\end{tabular}


Apêndice E - Valores originais e valores médios obtidos pelo programa Auto CAD, da medida X4 dos pacientes de 1 a 20.

\begin{tabular}{|c|c|c|c|c|c|c|}
\hline \multirow{2}{*}{$\begin{array}{l}\mathbf{X} \mathbf{( \mathbf { c m } )} \\
\text { Pacientes }\end{array}$} & \multicolumn{3}{|c|}{ ARCON } & \multicolumn{3}{|c|}{ NÃO-ARCON } \\
\hline & anterior & paralelo & posterior & anterior & paralelo & posterior \\
\hline \multirow{5}{*}{1} & 3,929 & 3,855 & 3,373 & 6,405 & 6,333 & 6,499 \\
\hline & 3,985 & 3,520 & 3,576 & 6,556 & 6,470 & 6,546 \\
\hline & 3,851 & 3,629 & 3,432 & 6,581 & 6,435 & 6,434 \\
\hline & 3,876 & 3,703 & 3,513 & 6,494 & 6,397 & 6,508 \\
\hline & 3,964 & 3,633 & 3,406 & 6,534 & 6,425 & 6,478 \\
\hline $\mathbf{M}$ & 3,921 & 3,668 & 3,460 & 6,514 & 6,412 & 6,493 \\
\hline \multirow{5}{*}{2} & 4,130 & 4,078 & 3,794 & 5,891 & 6,076 & 5,867 \\
\hline & 4,326 & 3,852 & 3,675 & 5,971 & 6,089 & 6,032 \\
\hline & 4,181 & 3,903 & 3,645 & 5,947 & 6,030 & 6,063 \\
\hline & 4,238 & 3,898 & 3,721 & 5,933 & 6,058 & 5,913 \\
\hline & 4,185 & 3,989 & 3,685 & 5,938 & 6,072 & 6,060 \\
\hline $\mathbf{M}$ & 4,212 & 3,944 & 3,704 & 5,936 & 6,065 & 5,987 \\
\hline \multirow{5}{*}{3} & 3,938 & 3,542 & 3,403 & 5,813 & 6,146 & 5,875 \\
\hline & 4,000 & 3,639 & 3,471 & 5,948 & 5,743 & 5,921 \\
\hline & 3,983 & 3,500 & 3,385 & 5,716 & 5,657 & 5,949 \\
\hline & 3,969 & 3,581 & 3,450 & 5,795 & 5,908 & 5,930 \\
\hline & 3,975 & 3,538 & 3,386 & 5,853 & 5,786 & 5,900 \\
\hline $\mathbf{M}$ & 3,973 & 3,560 & 3,419 & 5,825 & 5,848 & 5,915 \\
\hline \multirow{5}{*}{4} & 3,956 & 4,030 & 3,776 & 6,033 & 5,984 & 6,037 \\
\hline & 4,044 & 3,718 & 3,681 & 6,030 & 6,133 & 6,147 \\
\hline & 3,944 & 3,907 & 3,749 & 6,052 & 6,134 & 6,152 \\
\hline & 3,997 & 3,898 & 3,699 & 6,041 & 6,093 & 6,097 \\
\hline & 3,964 & 3,872 & 3,770 & 6,034 & 6,071 & 6,127 \\
\hline $\mathbf{M}$ & 3,981 & 3,885 & 3,735 & 6,038 & 6,083 & 6,112 \\
\hline \multirow{5}{*}{5} & 3,935 & 3,863 & 3,563 & 5,723 & 5,846 & 5,777 \\
\hline & 3,907 & 3,695 & 3,555 & 5,645 & 5,768 & 5,867 \\
\hline & 3,888 & 3,656 & 3,613 & 5,678 & 5,800 & 5,987 \\
\hline & 3,926 & 3,741 & 3,584 & 5,691 & 5,873 & 5,889 \\
\hline & 3,894 & 3,735 & 3,570 & 5,673 & 5,733 & 5,865 \\
\hline $\mathbf{M}$ & 3,910 & 3,738 & 3,577 & 5,682 & 5,804 & 5,877 \\
\hline \multirow{5}{*}{6} & 3,985 & 3,967 & 3,761 & 5,899 & 6,033 & 6,127 \\
\hline & 3,968 & 4,029 & 3,783 & 6,114 & 6,215 & 6,350 \\
\hline & 4,031 & 3,944 & 3,784 & 6,059 & 5,964 & 6,214 \\
\hline & 3,990 & 3,976 & 3,778 & 5,946 & 6,108 & 6,196 \\
\hline & 3,996 & 3,984 & 3,774 & 6,102 & 6,030 & 6,263 \\
\hline $\mathbf{M}$ & 3,994 & 3,980 & 3,776 & 6,024 & 6,070 & 6,230 \\
\hline \multirow{5}{*}{7} & 4,422 & 5,253 & 4,046 & 6,225 & 6,186 & 6,302 \\
\hline & 4,463 & 4,182 & 4,016 & 6,339 & 6,263 & 6,509 \\
\hline & 4,467 & 4,285 & 4,216 & 6,403 & 6,405 & 6,237 \\
\hline & 4,448 & 4,876 & 4,118 & 6,287 & 6,306 & 6,412 \\
\hline & 4,450 & 4,269 & 4,064 & 6,356 & 6,260 & 6,285 \\
\hline $\mathbf{M}$ & 4,450 & 4,573 & 4,092 & 6,322 & 6,284 & 6,349 \\
\hline \multirow{5}{*}{8} & 3,703 & 3,613 & 3,427 & 5,406 & 5,335 & 5,314 \\
\hline & 3,741 & 3,581 & 3,283 & 5,449 & 5,199 & 5,583 \\
\hline & 3,750 & 3,500 & 3,307 & 5,433 & 5,250 & 5,540 \\
\hline & 3,738 & 3,553 & 3,357 & 5,427 & 5,308 & 5,461 \\
\hline & 3,723 & 3,573 & 3,321 & 5,430 & 5,213 & 5,497 \\
\hline $\mathbf{M}$ & 3,731 & 3,564 & 3,339 & 5,429 & 5,261 & 5,479 \\
\hline \multirow{5}{*}{9} & 4,223 & 3,770 & 3,756 & 5,928 & 5,839 & 5,992 \\
\hline & 3,831 & 3,892 & 3,776 & 5,860 & 5,803 & 6,067 \\
\hline & 3,944 & 3,923 & 3,777 & 5,947 & 5,845 & 5,980 \\
\hline & 4,170 & 3,901 & 3,766 & 5,892 & 5,827 & 6,035 \\
\hline & 3,827 & 3,819 & 3,770 & 5,928 & 5,831 & 5,991 \\
\hline $\mathbf{M}$ & 3,999 & 3,861 & 3,769 & 5,911 & 5,829 & 6,013 \\
\hline \multirow{5}{*}{10} & 3,925 & 3,542 & 3,145 & 5,854 & 6,222 & 5,840 \\
\hline & 3,583 & 3,565 & 3,194 & 5,885 & 6,003 & 5,867 \\
\hline & 3,839 & 3,554 & 3,136 & 5,907 & 6,161 & 6,026 \\
\hline & 3,723 & 3,549 & 3,162 & 5,890 & 6,093 & 5,920 \\
\hline & 3,840 & 3,555 & 3,153 & 5,874 & 6,161 & 5,902 \\
\hline
\end{tabular}




\begin{tabular}{|c|c|c|c|c|c|c|}
\hline $\mathbf{M}$ & 3,782 & 3,553 & 3,158 & 5,882 & 6,128 & 5,911 \\
\hline \multirow{5}{*}{11} & 3,958 & 3,591 & 3,579 & 6,473 & 6,283 & 6,408 \\
\hline & 3,959 & 3,506 & 3,632 & 6,553 & 6,522 & 6,311 \\
\hline & 3,964 & 3,451 & 3,514 & 6,480 & 6,436 & 6,470 \\
\hline & 3,963 & 3,487 & 3,603 & 6,495 & 6,355 & 6,376 \\
\hline & 3,956 & 3,545 & 3,547 & 6,509 & 6,469 & 6,415 \\
\hline $\mathbf{M}$ & 3,960 & 3,516 & 3,575 & 6,502 & 6,413 & 6,396 \\
\hline \multirow{5}{*}{12} & 4,279 & 4,069 & 3,234 & 6,577 & 6,592 & 6,808 \\
\hline & 4,154 & 4,130 & 3,720 & 6,765 & 6,696 & 6,486 \\
\hline & 4,266 & 4,093 & 3,793 & 6,657 & 6,726 & 6,630 \\
\hline & 4,195 & 4,104 & 3,652 & 6,710 & 6,702 & 6,599 \\
\hline & 4,271 & 4,089 & 3,511 & 6,621 & 6,639 & 6,682 \\
\hline $\mathbf{M}$ & 4,233 & 4,097 & 3,582 & 6,666 & 6,671 & 6,641 \\
\hline \multirow{5}{*}{13} & 3,966 & 3,438 & 3,336 & 6,144 & 5,638 & 5,956 \\
\hline & 3,844 & 3,537 & 3,261 & 5,931 & 6,004 & 5,995 \\
\hline & 3,922 & 3,641 & 3,292 & 5,972 & 6,090 & 6,036 \\
\hline & 3,875 & 3,497 & 3,321 & 5,988 & 5,879 & 5,966 \\
\hline & 3,943 & 3,577 & 3,270 & 6,040 & 5,939 & 6,022 \\
\hline $\mathbf{M}$ & 3,910 & 3,538 & 3,296 & 6,015 & 5,910 & 5,995 \\
\hline \multirow{5}{*}{14} & 4,191 & 4,013 & 3,625 & 6,153 & 6,258 & 6,204 \\
\hline & 4,106 & 4,022 & 3,610 & 6,184 & 6,110 & 6,265 \\
\hline & 4,156 & 3,972 & 3,643 & 6,245 & 6,304 & 6,182 \\
\hline & 4,163 & 3,989 & 3,637 & 6,210 & 6,195 & 6,223 \\
\hline & 4,139 & 4,014 & 3,615 & 6,178 & 6,253 & 6,211 \\
\hline M & 4,151 & 4,002 & 3,626 & 6,194 & 6,224 & 6,217 \\
\hline \multirow{5}{*}{15} & 4,254 & 3,983 & 3,826 & 6,599 & 6,525 & 6,628 \\
\hline & 4,320 & 4,083 & 3,805 & 6,772 & 6,580 & 6,564 \\
\hline & 4,189 & 4,001 & 3,760 & 6,625 & 6,554 & 6,258 \\
\hline & 4,307 & 4,035 & 3,810 & 6,731 & 6,548 & 6,397 \\
\hline & 4,200 & 4,008 & 3,784 & 6,598 & 6,558 & 6,568 \\
\hline $\mathbf{M}$ & 4,254 & 4,022 & 3,797 & 6,665 & 6,553 & 6,483 \\
\hline \multirow{5}{*}{16} & 4,230 & 4,156 & 3,674 & 6,706 & 6,634 & 6,800 \\
\hline & 4,286 & 3,821 & 3,877 & 6,857 & 6,771 & 6,847 \\
\hline & 4,152 & 3,930 & 3,733 & 6,882 & 6,736 & 6,735 \\
\hline & 4,177 & 4,004 & 3,814 & 6,795 & 6,698 & 6,809 \\
\hline & 4,265 & 3,934 & 3,707 & 6,835 & 6,726 & 6,779 \\
\hline $\mathbf{M}$ & 4,222 & 3,969 & 3,761 & 6,815 & 6,713 & 6,794 \\
\hline \multirow{5}{*}{17} & 3,836 & 3,440 & 3,301 & 5,711 & 6,044 & 5,773 \\
\hline & 3,898 & 3,537 & 3,369 & 5,846 & 5,641 & 5,819 \\
\hline & 3,881 & 3,398 & 3,283 & 5,614 & 5,555 & 5,847 \\
\hline & 3,867 & 3,479 & 3,348 & 5,693 & 5,806 & 5,828 \\
\hline & 3,873 & 3,436 & 3,284 & 5,751 & 5,684 & 5,798 \\
\hline $\mathbf{M}$ & 3,871 & 3,458 & 3,317 & 5,723 & 5,746 & 5,813 \\
\hline \multirow{5}{*}{18} & 3,716 & 3,626 & 3,440 & 5,419 & 5,348 & 5,327 \\
\hline & 3,754 & 3,594 & 3,296 & 5,462 & 5,212 & 5,596 \\
\hline & 3,763 & 3,513 & 3,320 & 5,446 & 5,263 & 5,553 \\
\hline & 3,751 & 3,566 & 3,370 & 5,440 & 5,321 & 5,474 \\
\hline & 3,736 & 3,586 & 3,334 & 5,443 & 5,226 & 5,510 \\
\hline $\mathbf{M}$ & 3,744 & 3,577 & 3,352 & 5,442 & 5,274 & 5,492 \\
\hline \multirow{5}{*}{19} & 4,014 & 3,647 & 3,635 & 6,529 & 6,339 & 6,464 \\
\hline & 4,015 & 3,562 & 3,688 & 6,609 & 6,578 & 6,367 \\
\hline & 4,020 & 3,507 & 3,570 & 6,536 & 6,492 & 6,526 \\
\hline & 4,019 & 3,543 & 3,659 & 6,551 & 6,411 & 6,432 \\
\hline & 4,012 & 3,601 & 3,603 & 6,565 & 6,525 & 6,471 \\
\hline $\mathbf{M}$ & 4,016 & 3,572 & 3,631 & 6,558 & 6,469 & 6,452 \\
\hline \multirow{5}{*}{20} & 4,285 & 4,014 & 3,857 & 6,630 & 6,556 & 6,659 \\
\hline & 4,351 & 4,114 & 3,836 & 6,803 & 6,611 & 6,595 \\
\hline & 4,220 & 4,032 & 3,791 & 6,656 & 6,585 & 6,289 \\
\hline & 4,338 & 4,066 & 3,841 & 6,762 & 6,579 & 6,428 \\
\hline & 4,231 & 4,039 & 3,815 & 6,629 & 6,589 & 6,599 \\
\hline $\mathbf{M}$ & 4,285 & 4,053 & 3,828 & 6,696 & 6,584 & 6,514 \\
\hline
\end{tabular}

